\title{
Examining the Impact of Body Worn Cameras on Police Officer Memory Following a Critical Incident
}

\author{
by
}

\author{
Brittany Blaskovits
}

A thesis submitted to the Faculty of Graduate and Postdoctoral Affairs in partial fulfillment of the requirements for the degree of

Doctor of Philosophy

in

Psychology

Carleton University

Ottawa, Ontario

(C)2020 


\begin{abstract}
Numerous high-profile events have contributed to an increase in public scrutiny of police performance; this has resulted in many agencies considering the use of body worn cameras (BWCs). However, some research suggests that having access to saved information can have a negative effect on memory, particularly when an individual experiences stress during the recorded event. Therefore, the aim of the current research was to: (1) examine how BWCs impact the quality of an officer's encoding and retrieval of event details, (2) determine the benefits and challenges associated with officers viewing BWC footage when writing their reports, and (3) attain a better understanding of the efficacy of cognitive interviewing (CI) as a means to enhance memory retrieval of use-of-force events.

More specifically, Study 1 examined the recall of officers who were aware that they could "offload" memory encoding tasks to their BWC. Interestingly, regardless of whether officers believed they could rely on a camera, or not, a similar amount of information was recalled. In Study 2, differences between officers who provided a statement before watching their BWC footage were compared to officers shown their footage first. The findings indicated that officers allowed to preview their footage before reporting included more details about the subject in their statement. Moreover, higher levels of stress were associated with an increase in the amount of moderate and major errors made by officers who were barred from seeing their footage. Lastly, the goal of Study 3 was to investigate the efficacy of the CI as a means to improve recall. The comparison found that officers recalled more information and confabulated less information if they completed a CI.
\end{abstract}

Broadly speaking, the current research answers important questions about the impact of BWCs on officer's ability to recall use-of-force events; thereby adding to the cognitive 
psychological literature, as well as the legal field. The research may also have an applied impact namely by: (1) assisting police agencies in developing more informed policies around BWCs, and (2) by educating police officers and juries about the impact of BWCs on memory to ensure the critical appraisal of this controversial technology.

Keywords: Body worn cameras, police, memory, stress 


\section{Acknowledgements}

First and foremost, I would like to thank my supervisor, Dr. Craig Bennell, for his support, understanding, humour, and patience over the years. You challenged me to accomplish more, think independently, and strive toward a future I never thought possible. Thank you for every opportunity you have given me and for being the role model I needed.

I would like to thank my committee members, Dr. Shelley Brown, Dr. Joanna Pozzulo, Dr. William Lewinski, and Dr. Gregory Brown. You committed to making this unorthodox project the best it could be, and I can't thank you enough for your advice, consideration, and receptivity to the process. I would like to thank Dr. Brent Snook and his laboratory at Memorial University for the time spent training me and their research insights. I would also like to thank Etelle and the Psychology Department for their help over the years. You truly go above and beyond for the students of the department and it is more appreciated than you know.

I would like to send a special thank you to the police agency that allowed me to conduct this research, and those who facilitated it, including the police trainers, the safety instructors, and all those who saw the importance in it and volunteered their time, day-after-day, to making sure it happened. Importantly, thank you to the officers who participated and all those in uniform. You serve as reminders of the generosity and strength of the human spirit.

I would like to thank the members of the Police Research Laboratory, both past and present. Each of you has made my degree more than just a degree. You are a family that has been there through good times and bad, and it's hard to imagine finding a group that would fight harder for each other. To my friends outside the lab: Thank you for the coffee we drank, the champagne we popped, the weekend brunches, and long walks and talks. I am a better person because of you. 
Lastly, thank you to my parents and brother, Cole. The way you believed in me made me believe too. 


\section{Dedication}

To my nephew Brantley - For teaching me what's important. 


\section{Table of Contents}

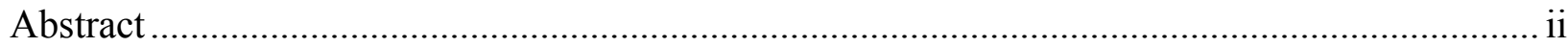

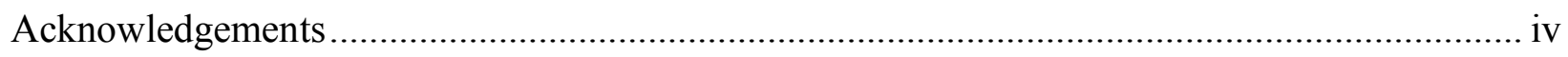

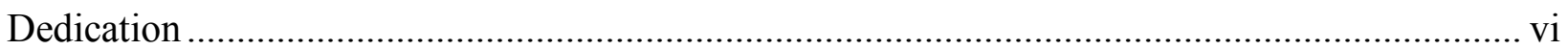

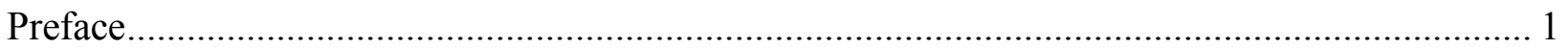

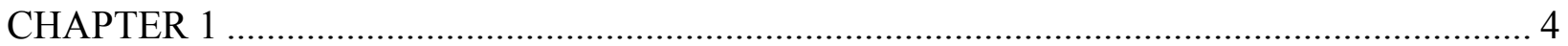

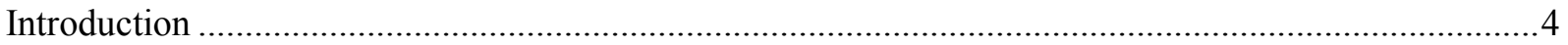

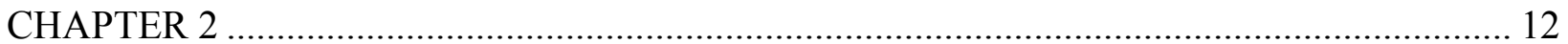

Exploring the Potential Impact of Body Worn Cameras on Memory in Officer-Involved Critical

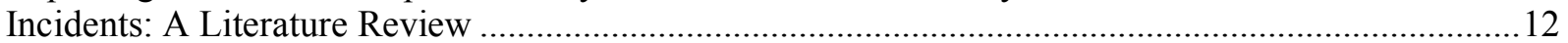

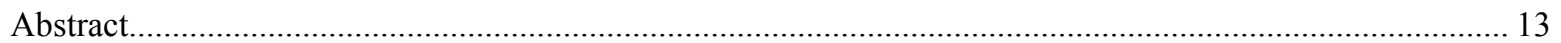

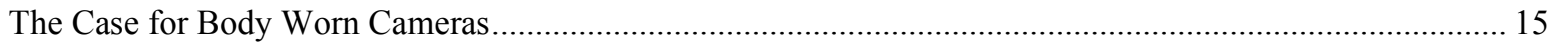

Potential Benefits of Body Worn Cameras for Memory ……....................................................................... 18

Potential Negative Consequences of Body Worn Cameras for Memory ........................................................ 24

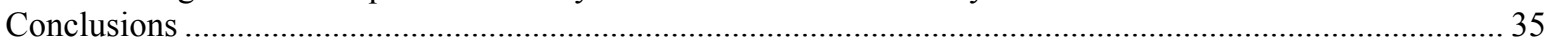

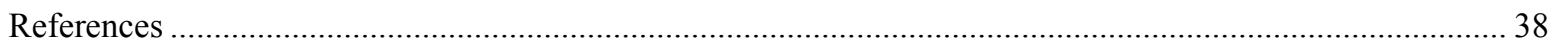

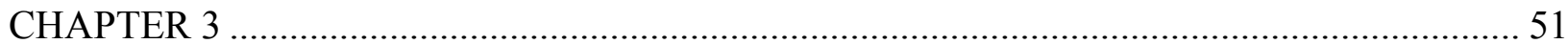

Misplacing Memory: Examining the Phenomenon of Cognitive Offloading During an Officer-Involved

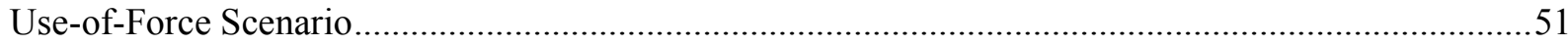

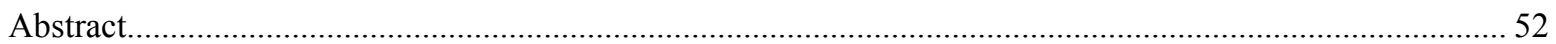

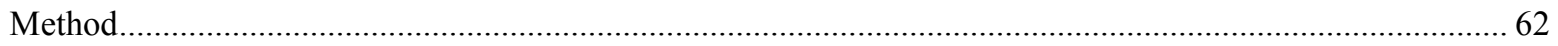

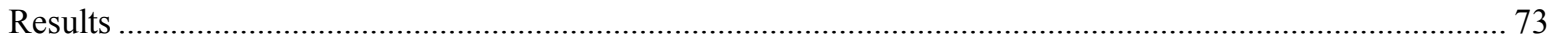

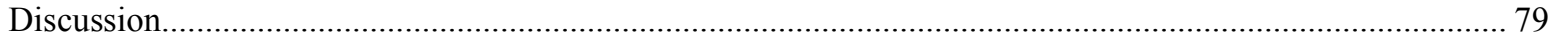

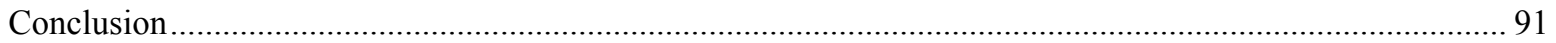

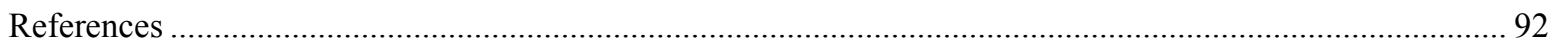

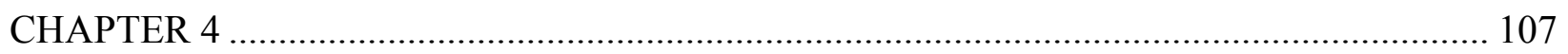

Triggering Memory: Examining How the Viewing of Body Worn Camera Footage Impacts Police

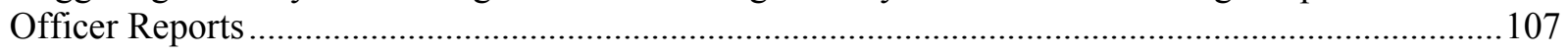

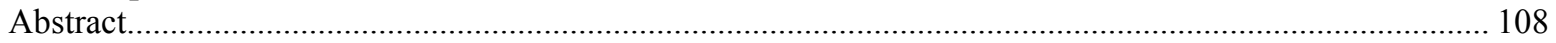

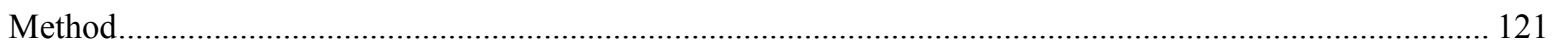

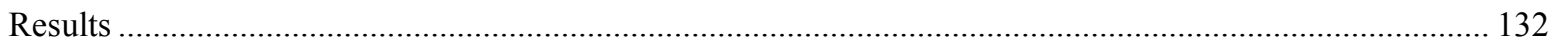

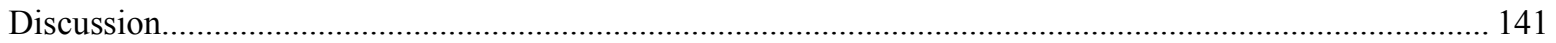

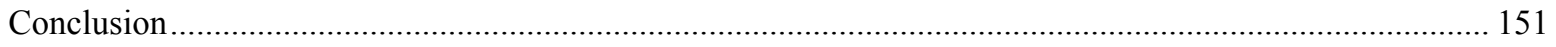

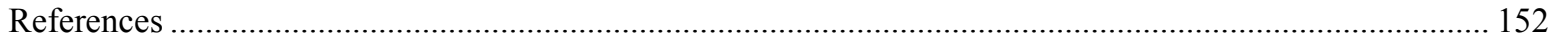

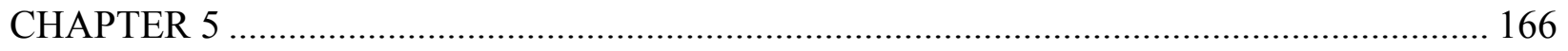

Evaluating the Utility of the Cognitive Interview for Enhancing the Memory of Police Officers

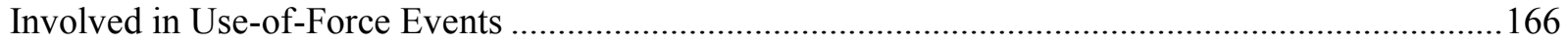

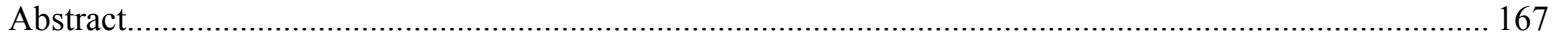

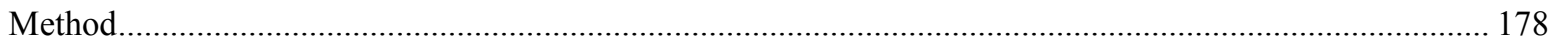

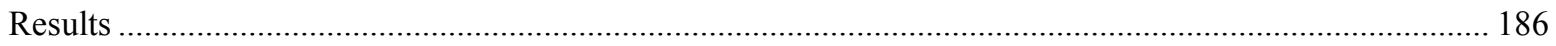

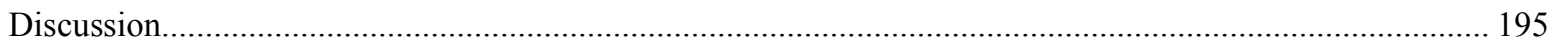

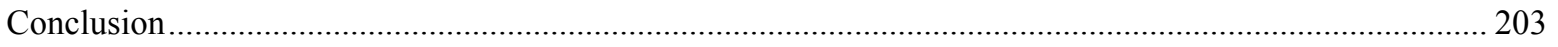

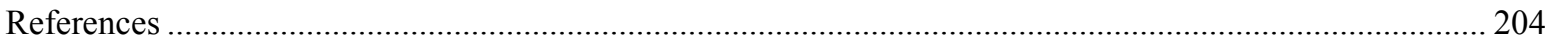

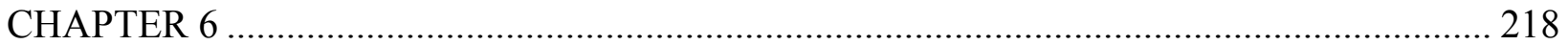




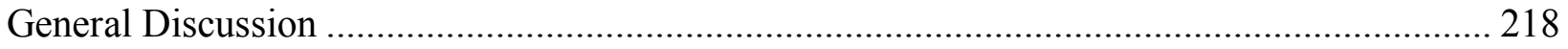

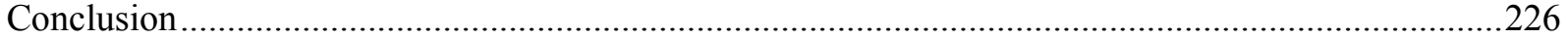

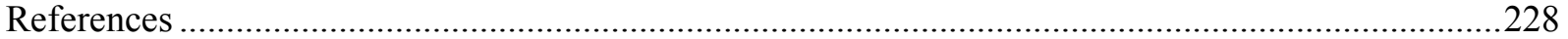

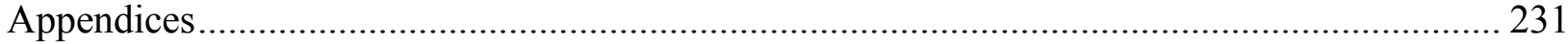

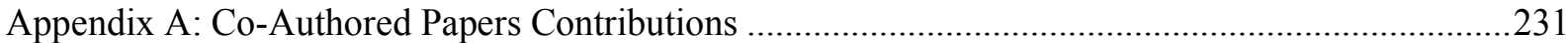

Appendix B: Screenshot of Published Literature Review from Chapter 2 .......................................233

Appendix C: Examination of Within-Group Differences Across Studies ...........................................234 


\section{List of Tables}

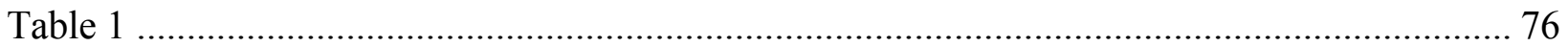

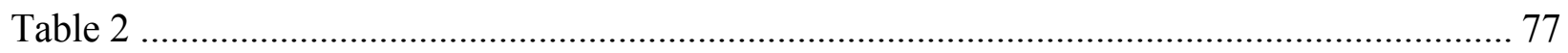

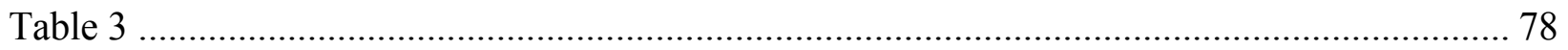

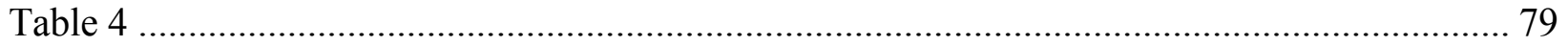

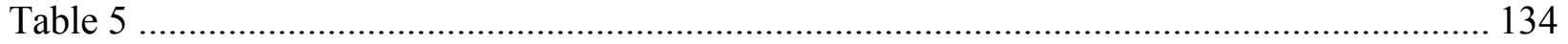

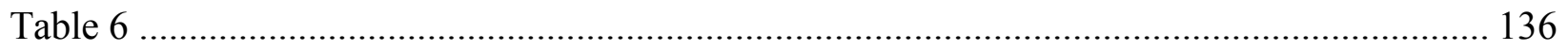

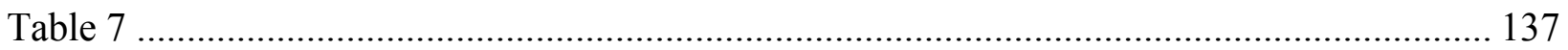

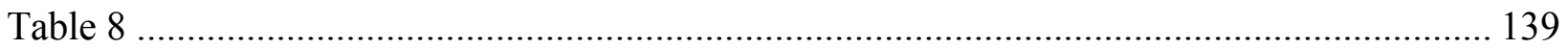

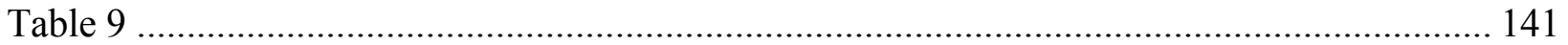

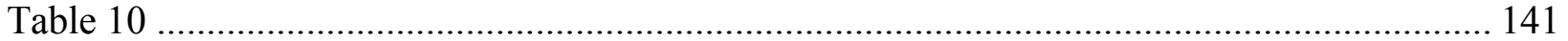




\section{List of Figures}

Figure 1. Photographs taken from various mounted cameras that recorded the scenario........... 127

Figure 2. Grading Guidelines (adapted from Dawes et al. 2015) ........................................... 131 


\section{Preface}

The present dissertation was completed via Carleton University's Integrated Thesis Policy for Psychology. Therefore, the dissertation is structured as a series of manuscripts, all reproduced in full from the journal in which they are published. The first paper, "Exploring the Potential Impact of Body Worn Cameras on Memory in Officer-Involved Critical Incidents: A Literature Review" was researched and written by myself, and edited and reviewed by Dr. Craig Bennell, whom co-authored the paper. The remaining three papers involved rigorous methodological planning, the procurement of ethics from Carleton University and the Human Resources Review Board from the police agency that facilitated the studies, the completion of a pilot study conducted in Ontario, travel to and subsequent data collection for a month in British Columbia, the training of multiple coders, analyses, preparation and revision of the manuscripts, and submission for approval for publication. I affirm that I was fully involved in leading all aspects of the research for my dissertation.

Several other co-authors are listed on each paper as a team was required to facilitate the research. Most notably, Bryce Jenkins performed as an actor in the scenario that each officer experienced and coded the subsequent use-of-force reports at my direction. Similarly, Andrew Brown equipped participants with the necessary devices prior to entering the scenario and acted as the second coder for the use-of-force reports. Simon Baldwin was involved in recruiting participants, liaising with internal stakeholders (e.g., police trainers, safety instructors, commanding officers), arranging travel and acquiring the necessary equipment, and also performed as the perpetrator in the scenario. Heather McGale was trained (by me) in cognitive interviewing and was thus able to act as the second cognitive interviewer. She was later involved in coding the interviews to acquire interrater reliability. While I analyzed the data, wrote each of 
the articles, and submitted them for publication, all of the co-authors contributed substantially to their revisions. In accordance with the Integrated Thesis Policy, Appendix A lists each coauthors contribution, of which they have signed, confirming their agreement with the statement. Dr. Craig Bennell's signed statement, in support of the preface, can also be found in Appendix A. 


\section{CHAPTER 1}

\section{Introduction}

In a cognitive interview conducted on June 12, 2018, a police officer recounted their memory of an incident: "I'm kind of engaging him saying 'Look, Jeff, you're in breach of your probation, come with me and we'll get this sorted out...' Meanwhile John is...jabbering off to the right-hand side...I say 'Look, let me do my thing, just stay out of this...' They say my backup is 20 minutes away. The table has kind of got a few articles on it. And to tell you the truth I don't know if that firearm was sitting on the table all along... There's a couple of bottles. I think there's a bottle on the table of liquor. If I could've turned the music off, that probably would've helped a little bit. The next thing I know, I look back, Jeff has a blue handgun...And he points it at me. And I shoot him. You know, I don't remember if I fired first or he fired first...I can't... That part doesn't..."

The incident that the officer is referring to is simulated - a mock scenario designed to assess officer recall for a lethal force event. However, the public has seen similar narratives in the testimonies of accused officers across the globe; and while the police are sanctioned to use force when necessary (Criminal Code, 1985; International Association of Chiefs of Police, 2001), public scrutiny of such events has mounted in recent years (e.g., Bialik, 2017; Patil, 2019). In large part, this increased criticism has paralleled the rise of various recording devices including camera-phones, dash cameras, and closed-circuit television, so much so, that some scholars argue we are experiencing 'de-policing' whereby officers are reluctant to proactively engage in their communities out of fear of reprisal (e.g., Brown, 2019).

Many police agencies have considered the use of body worn cameras (BWCs) to improve police-public encounters, with the goal to generate a sense of trust and promote confidence in 
policing (Jennings, Fridell, \& Lynch, 2014). Importantly, BWCs provide an alternate viewpoint from which all parties involved can better understand an incident. However, BWCs also offer officers a secondary mechanism (over and above their own memory) that could help them recall what occurred in an incident. Indeed, following a lethal force event, officers will be inevitably asked to report what occurred (Emberlin, 2017; Grady et al., 2016; Long Beach Police Department, n.d.). Should they have difficulty remembering the incident or end up "caught" in a situation where their recall is different from a recorded version of the event, their credibility could be seriously undermined. BWCs could, potentially, "take some of the pressure off" trying to encode everything during an encounter and improve recall later on.

Yet, the impact of BWCs on officer recall for critical incidents has received surprisingly little attention. Thus, the objective of my dissertation research was to answer three questions related to the impact of BWCs on officer recall for a use of force event. First, I was interested in the extent to which simply believing that one had access to their BWC footage following an event impacted memory of an encounter. Second, I examined the impact of viewing BWC footage on note writing following a critical incident. Lastly, I sought a better understanding of whether there was improvement in recall when utilizing a cognitive interview (CI) to facilitate recall for use of force events as opposed to extracting that information through a standard use of force report. These questions were addressed across three studies.

More specifically, Study 1 aimed to investigate the extent to which BWCs impacted encoding and retrieval of information related to a simulated use-of-force scenario. Prior to the scenario, one group of officers were deceived into believing that their BWC video footage would be accessible to them before they completed a statement about the event. Another group was not provided BWCs and were aware they had no footage to rely on. Recall accuracy was quantified 
for both groups to determine how one's expectation of having access to BWC footage impacts memory recall. Given that internal resources may be taxed during use-of-force encounters, officers who think that they can "offload" memory encoding tasks to their BWC may experience poorer recall of the encounter, relative to those who know the event information is not being saved (or that they will not have access to the saved information when having to recall the event).

In Study 2, differences between officers who prepared their report before watching their BWC footage were compared to officers who prepared their report after watching their video footage. Questions have been raised about the ideal timing for when officers should view BWC footage relative to writing their report about an event. Viewing footage prior to writing a report might, for instance, prompt retrieval, resulting in more complete reports. Alternatively, the initial viewing of one's BWC footage could contaminate officers' true memory of an event. By carefully tracking differences in the officers' statements, it was possible to better understand the discrepancies that might occur in naturalistic settings if officers are permitted to view BWC footage while preparing their reports.

Lastly, given that officers will not always be able to rely on BWC footage to (potentially) “jog" their memory about an event (e.g., if the footage is unavailable due to technical issues), the goal of Study 3 was to investigate the efficacy of cognitive interviewing to improve recall of useof-force encounters. The CI is often used to enhance victim and witness recall and is based on principles of memory and communication theory (Geiselman \& Fisher, 2014). While it has been found to produce significantly more accurate information than other interview formats, it has not been used to improve the recall accuracy of the police when they are tasked with remembering critical incidents. Therefore, in Study 3, officers were assigned to participate in a CI about the 
scenario they were involved in, or to complete a standard use of force report. The comparison of these two conditions provides a better understanding of what improvements to memory are achieved by utilizing a CI in these instances.

The research contributes to the psychological literature and has implications for the policing and legal field. Importantly, the studies provide a better understanding of how our memory systems utilize and adapt to new technology, particularly under conditions of stress. The research also helps inform police agencies, particularly in relation to their policies around BWCs. It provides agencies new, evidence-based options that may enhance the memory of their officers, post use-of-force events. For the legal field, the results of these studies aim to improve awareness of officers' limitations under conditions of stress, which has consequences for how use-of-force decisions (particularly the articulation of these decisions by the officer who employed force) are considered in court.

The dissertation was completed via Carleton University's Integrated Thesis option, which allows one to complete a series of interrelated, publishable papers as opposed to the traditional monograph thesis. All rules governing the Integrated Thesis Policy were followed, as detailed in the preface to this dissertation. This option was chosen for two main reasons. First, the specialized sample necessary to complete the research (i.e., police officers) is challenging to recruit, and the methodology employed allowed me to maximise the research conducted with this group. Essentially, one large pool of participants all completed the same scenario but were divided into various groups; each group experienced a different manipulation. This united the studies into a coherent research project while ensuring that each study was distinct from one another - a requirement of the Integrated policy. Secondly, the Integrated option allowed me to expedite the publishing process that is often delayed following monograph theses. My ultimate 
goal in conducting this research has been to advance the limited evidence-base on this topic and provide agencies a foundation to help inform future decisions. The peer-review process for each manuscript also contributed to the development of a considerably stronger dissertation.

The dissertation is structured as follows. In Chapter 2, a literature review published in the Journal of Police and Criminal Psychology is reproduced in full (i.e., the pre-print is provided, see Appendix B). This review examines existing literature that speaks to the impact that BWCs may have on memory. It encapsulates research from the policing area specifically, but also highlights what is known from studies of camera technology more broadly. While some of the issues referred to in Chapter 2 are slightly outside of the scope of the current dissertation research, they were important to include in order to provide a comprehensive review of the field at present.

After contextualizing the research to be conducted, Chapter 3 presents a manuscript currently under consideration by the Journal of Police and Criminal Psychology. This manuscript presents the methodology and findings of Study 1, which examined the possibility that officers might offload their memory of a critical incident to their BWC. Next, Chapter 4 presents a manuscript that is currently under review by Police Quarterly. Recall that this study examined differences between officers who saw their BWC footage before completing a statement about the event, relative to those who did not have an opportunity to see their footage.

The final manuscript, which presents Study 3, is provided in Chapter 5. This manuscript is under review by the police agency that the research was completed in collaboration with and is awaiting submission to the Journal of Applied Cognitive Psychology. Recall that Study 3 aimed to determine the efficacy of a CI for enhancing the recall of officers, as opposed to a standard written report. Chapter 6 summarizes the findings from all three studies and reflects on their 
theoretical and practical implications. That chapter also qualifies the results, outlining overarching limitations of the research, and provides some directions for future research. 


\section{References}

Bialik, C. (2017, January 11). Police officers say scrutiny of police killings has made their job tougher. FiveThirtyEight. Retrieved from https:/fivethirtyeight.com/features/policeofficers-say-scrutiny-of-police-killings-has-made-their-job-tougher/

Brown, G. R. (2019). To Swerve and Neglect: De-Policing Throughout Today's Front-Line Police Work (Doctoral dissertation, Carleton University, Ottawa, Ontario, Canada). Retrieved from https://curve.carleton.ca/system/files/etd/5ff0e0ff-65c8-42ae-a10ac4f63246d159/etd_pdf/f680d2aceb5e8ac84ec2fbcfed49ea4c/browntoswerveandneglectdepolicingthroughouttodays.pdf

Criminal Code, RSC 1985, c. C - 46. Protection of persons acting under authority, RSC 1985, s. 25. Retrieved from https://laws-lois.justice.gc.ca/eng/acts/c-46/section-25.html

Emberlin, R. (2017, December 20). What happens after a police officer uses deadly force? Police One. Retrieved from https://www.policeone.com/health-fitness/articles/what-happensafter-a-police-officer-uses-deadly-force-Pko1xmTB2dbHXDOu/

Geiselman, R. E., \& Fisher, R. P. (2014). Interviewing witnesses and victims. In M. St. Yves (Ed.), Investigative interviewing: Handbook of best practices (pp. 1-21). Thomson Reuters Publishers.

Grady, R. H., Butler, B. J., \& Loftus, E. F. (2016). What should happen after an officer-involved shooting? Memory concerns in police reporting procedures. Journal of Applied Research in Memory and Cognition, 5(3), 246-251.

International Association of Chiefs of Police. (2001). Police use offorce in America. Retrieved from https://www.theiacp.org/sites/default/files/2018-08/2001useofforce.pdf

Jennings, W. G., Fridell, L. A., \& Lynch, M. D. (2014). Cops and cameras: Officer perceptions 
of the use of body-worn cameras in law enforcement. Journal of Criminal Justice, 42(6), $549-556$.

Long Beach Police Department. (n.d.). Officer involved shooting investigation process.

Retrieved from http://www.longbeach.gov/police/about-the-lbpd/bureaus/investigationsbureau/officer-involved-shooting-investigation-process/

Patil, S. (2019, August 7). Relentless, unchecked scrutiny of police hurts us all. The Hill.

Retrieved from https://thehill.com/opinion/criminal-justice/460381-relentless-uncheckedscrutiny-of-police-hurts-us-all 


\section{CHAPTER 2}

Exploring the Potential Impact of Body Worn Cameras on Memory in Officer-Involved Critical Incidents: A Literature Review

Brittany Blaskovits* \& Craig Bennell Department of Psychology, Carleton University, Ottawa, Ontario, Canada

* Address for correspondence: Brittany Blaskovits, Department of Psychology, Carleton University, 1125 Colonel By Drive, Ottawa, Ontario, Canada, K1S 5B6. Email: brittanyblaskovits@cmail.carleton.ca

\section{Ethical Statement:}

Funding: This research was funded by a Social Sciences and Humanities Research Council Insight Grant that was awarded to the second author (SSHRC\# 435-2017-1354).

Conflict of Interest: None to declare.

Ethical Approval: Not applicable (review article - no participants).

Informed Consent: Not applicable (review article - no participants)

Published in the Journal of Police and Criminal Psychology 


\begin{abstract}
The current paper reviews existing literature that relates to how body worn cameras might influence an officer's memory of their interactions with the public, namely those that involve the use of force. Notably, most of this research does not come from the policing field but focuses on the impact of camera technology in other settings. Much of the available research supports the commonly held view that body worn cameras could be used to enhance memory for these interactions, particularly interactions that are complex or stressful. However, contrary to what people might expect, research also exists that suggests body worn cameras may actually have a detrimental effect on officer memory. Three major potential detriments: cognitive offloading, retrieval-induced forgetting, and misinformation-type effects are highlighted. Future studies examining the impact of body worn cameras on officers' memory are necessary. Ways forward are discussed.
\end{abstract}

Keywords: police; body worn cameras; memory; offloading; misinformation; use of force 


\section{Exploring the Potential Impact of Body Worn Cameras on Memory in Officer-Involved Critical Incidents: A Literature Review}

On June 25th, 2016 two members of the Fresno Police Department shot and killed 19year-old Dylan Noble (Hamilton \& Winton, 2016). Noble was suspected of carrying a rifle, and did not comply with police instructions; unfortunately, it was not until after the police opened fire that it became apparent that Noble was unarmed. The Fresno shooting is only one case in a succession of controversial use-of-force $(\mathrm{UoF})$ incidents that have occurred in recent years, such as the 2013 fatal shootings of Sammy Yatim in Toronto, Ontario (Loriggio, 2016) and that of Michael Brown in Ferguson, Missouri in 2014 (British Broadcasting Corporation, 2015). Consequently, there has been growing, widespread public criticism of police decision-making and performance (Hansford, 2019; Kleinig, 2016), culminating in protests (Hamilton \& Winton, 2016), allegations of police brutality (Hamilton \& Winton, 2017; Smith, 2018), and even deadly attacks, including the sniper attack in Dallas, Texas in 2016 (Karimi, Shoichet, \& Ellis, 2016).

Many police agencies are now using body worn cameras (BWCs) as a way to improve police-public encounters, and subsequently instill confidence and trust in policing (Jennings, Fridell, \& Lynch, 2014). Not only might BWCs positively influence how the police and the public act, by potentially encouraging more respectful interactions (Ariel, Farrar, \& Sutherland, 2015), this technology might also allow the police and the public to more fully understand what transpired during police-public encounters. One mechanism by which BWCs might do this is by facilitating an officer's ability to recall details of their encounters, such as what transpired during the incident, including aspects of their risk assessment, which speak to why they made the decisions they did (Dawes, Heegaard, Brave, Paetow, Weston, \& Ho, 2015). If viewing BWC footage can enhance an officer's memory for a UoF encounter, this may assist the officer in a 
variety of contexts (e.g., preparing their report about the encounter, when being questioned during internal investigations, or when testifying about the incident in court).

The current paper reviews the literature to date, which speaks to how BWCs might influence an officer's memory of their interactions with the public. Notably, most of this research does not come from the policing field but focuses on the impact of camera technology in other settings. Much of the available research supports the commonly held view that BWCs could be used to enhance memory for these interactions, particularly interactions that are complex or stressful. However, contrary to expectations, research also exists that suggests BWCs may actually have a detrimental effect on officer memory. Both types of potential memory effects (i.e., positive and negative) will be reviewed in this paper. For the most part, we will focus our discussions on interactions with the public that involve UoF by the police. While these are not the only type of incidents where BWCs may have value, the discussion of BWCs often takes place within the context of such cases (Ariel, Farrar, \& Sutherland, 2015; Farrar \& Ariel, 2013; Sullivan \& Marrero, 2016).

\section{The Case for Body Worn Cameras}

BWCs are small audio/video recording devices that can be mounted on an individual's clothing as "wearable" cameras (Jennings et al., 2014), or attached to eyewear, collars, an epaulette, ball caps, or helmets (TASER International Inc., 2015). The recordings are temporarily stored on the device before being transferred to a storage system (Freund, 2015). Some of the more sophisticated BWC models are weatherproof, can store up to 70 hours of footage, and are encrypted to prevent privacy leaks (TASER International Inc., 2015). Typically, officers are responsible for turning the $\mathrm{BWC}$ on prior to interacting with a citizen, and then off again afterwards to preserve battery life and recording space (Freund, 2015). However, some recent 
models (e.g., Axon Flex 2) have been redesigned with the capacity to detect changes in the environment, such as the opening of car doors, which automatically initiates recording (TASER International Inc., 2015).

The earliest reported use of BWCs in a police force was in 2005 by the Cornwall Police Department in the United Kingdom (U.K.; Findlay, 2017). Their primary goal in using BWCs was to improve the collection of evidence in domestic violence cases. By 2016, nearly half (47\%) of all police departments in the United States (U.S.) had acquired BWCs, and many other police services were evaluating their possible use (Freund, 2015; Hyland, 2018). The majority of agencies who acquired BWCs have fully deployed them and developed formal BWC policy (Hyland, 2018). In the U.K., more than 70\% of police forces have BWCs, with the rest to follow suit in 2019 (College of Policing, 2017; Coudert, Butin, \& Metayer, 2015; Privacy International, 2019; The Economist, 2018). Currently in Canada, many agencies (e.g., Toronto, Thunder Bay, Durham) continue to pilot BWCs, but relatively few have fully implemented them (Findlay, 2017; Ling, 2019; Rosen, 2019). Increasingly, conversations are turning to the need for costbenefit analyses, in order for police services to decide whether or not to roll out BWCs, especially in Canada (Bud, 2016; Saulnier, 2019).1

In a large agency, front-end costs to purchase BWCs to equip all officers can be substantial (Police Executive Research Forum [PERF], 2018). Then, there are ongoing costs to store and manage the videos following the initial expenditure (Thunder Bay Police Service, 2019; Toronto Police Service, 2016). Cloud-based technology is currently being considered by

\footnotetext{
1 Given the first use of BWCs in the U.K. and their current popularity in North America, we felt it pertinent to contextualize our review within the broader international community. However, we acknowledge that each country (and the various factions of law enforcement within each country) have different sets of policies and procedures dictating BWC use. While some portions of our review may not be applicable for all agencies given these differences, many of the cognitive concerns discussed are general enough to be widely relevant.
} 
some agencies as a means to alleviate costs of storage and data management. However, there may also be hidden cost-savings to BWCs. Dawes and colleagues (2015) note that BWCs help provide compelling evidence which may promote earlier guilty pleas. For example, BWC footage can make it difficult for civilians to argue that they were not driving under the influence if the interaction is caught on tape. Less time spent by prosecutors and officers on cases like these may result in notable cost-savings. In fact, a pilot study by Goodall (2007) saw a time savings of 20 minutes per officer per nine-hour shift with the introduction of BWCs. This increased efficiency is likely to have some positive financial implications over the long-term.

The fiscal consequences associated with BWCs must be considered alongside others, such as their effect on community relations. Indeed, as highlighted above, it has been argued that the presence of BWCs will reduce the opacity surrounding policing and subsequently improve officer accountability (Jennings et al., 2014). Some advocate, for instance, that BWCs will reduce police misconduct and ensure interactions between officers and citizens are fair. Several studies have corroborated such arguments, finding that officers who wear BWCs are involved in significantly fewer UoF incidents (Ariel et al., 2015; Farrar \& Ariel, 2013; Jennings et al., 2014; Mesa Police Department, 2013; Sullivan \& Marrero, 2016). Notably however, others have failed to find support for this effect (Ariel, et al., 2016a; Edmonton Police Service, 2015; Grossmith, Owens, \& Finn, 2015; Hedberg, Katz, \& Choate, 2016; White, 2014; Yokum, Ravishankar, \& Coppock, 2017).

It has been further argued that BWCs may reduce false claims of police misconduct and allegations of excessive UoF (Ariel et al., 2015; Ariel et al., 2016; Freund, 2015), as well as provide an additional perspective of events, beyond that captured by bystanders via cameraphones. For example, while the aforementioned Fresno shooting was originally caught on tape 
by a bystander, the officer's BWC also recorded the event (Hamilton \& Winton, 2016). When the bystander's video was shared publicly, the officers received extensive backlash as many citizens viewed the event as a gross misuse of force (Almasy \& Moshtaghian, 2016; Hamilton \& Winton, 2016). However, the police agency later released the officer's footage; providing the public with a different perspective, and perhaps for some, a different interpretation of the event.

\section{Potential Benefits of Body Worn Cameras for Memory}

Of particular value for police departments is the use of BWCs as a potential memory aide. Whenever an officer uses force, they are required to articulate their reason for doing so. Although there is no standardized reporting procedure in Canada (Laming, 2017) or the U.S. (National Institute of Justice, 2016), most agencies require officers to explain what happened via some type of report. The Royal Canadian Mounted Police (RCMP), for instance, asks all officers to complete an electronic Subject Behaviour/Officer Response (SB/OR) report after each UoF incident (RCMP, 2014). The information may be scrutinized by oversight bodies including command staff, the courts, and the media if obtained via an Access to Information and Privacy request. It is thus pertinent that officers provide the most complete and accurate report possible of what transpired. It has been argued that allowing officers to watch their BWC footage before writing their statement could enhance recall in such statements (PERF, 2014).

There is, for instance, a long tradition of research showing that that visual imagery (static and dynamic) can enhance memory (Ally \& Budson, 2006; Aschermann, Dannenberg, \& Schulz, 1998; Houts, Bachrach, Witmer, Tringali, Bucher, \& Localio, 1998; Ishai, Haxby, \& Ungerleider, 2002; Jack, Martyn, \& Zajac, 2015). Pictures are often shown to eyewitnesses to cue recognition memory (e.g., is what you are currently seeing the same as a previously witnessed person of interest?; Jack et al., 2015), props or scale models may be provided in court 
to elicit recall (Gordon, Ornstein, Nida, Follmer, Crenshaw, \& Albert, 1993; Salmon, Bidrose, \& Pipe, 1995), and visual retrieval aids during interviews (e.g., like the cognitive interview; Geiselman, Fisher, Mackinnon, \& Holland, 1985) can be used to remember more than one otherwise would (Aschermann et al., 1998; Matsuo \& Miura, 2017; Vrij et al., 2018). In fact, according to Tulving's (1983) 'encoding specificity principle,' memory retrieval is enhanced when the retrieval environment is similar to the environment in which the encoding took place. In other words, visual cues that overlap with the features of a to-be-remembered event are advantageous for memory.

\section{Research From Outside Policing}

There is a growing body of literature outside of the policing context that is finding significant improvements in memory with the use of BWC technology, mainly for autobiographical events. For example, Hodges, Berry, and Wood (2011) investigated the effects of SenseCam, a wearable camera, on memory of daily events. SenseCam is one of a growing list of devices colloquially referred to as a 'lifelogging technology' (Kalnikaite, Sellen, Whittaker, \& Kirk, 2010). Lifelogging is the phenomena of capturing daily life, to have a record of the places and people visited. SenseCam works much like a disjointed BWC. It is worn around one's neck, hanging at mid-chest level, and does not require user-intervention once turned on. However, instead of a continual video recording, the SenseCam produces a 'flipbook' of photographs. Every 30 seconds, the SenseCam automatically snaps a picture and it snaps additional pictures when it 'senses' a change in the environment. Its microprocessor is designed to detect various changes in the environment, similar to some of the more advanced BWCs. Moving from a light to dark room, or a person moving in-front of the camera, are incidents that might trigger the 
SenseCam to take an additional photograph. Depending on how long the device is worn, thousands of images may be taken.

The original inspiration for SenseCam was for it to be a "human black box recorder" (Hodges et al., 2011, p. 3). However, its utility for individuals with severe memory impairment was quickly recognized. Clinical trials demonstrated that after reviewing images produced by SenseCam, amnesic patients could describe thoughts, feelings, and happenings associated with the images, but not depicted in the images per se (Berry et al., 2007; Hodges et al., 2006; Hodges, Berry, \& Wood, 2011). Follow-up tests with specific patients revealed that even when the images had not been reviewed for months at a time, the events associated with them could still be recalled (Berry et al., 2007; Hodges et al., 2006).

Anecdotally, healthy individuals have also reported that reviewing images produced by SenseCam enhances memory for incidents they otherwise forgot (Silva, Pinho, Macedo, \& Moulin, 2013). Interestingly, when functional magnetic resonance imaging (fMRI) was employed with both amnesic and healthy individuals to examine the potential neurological changes occurring when one reviewed the images, regions of the brain involved in autobiographical memory were activated (Berry et al., 2007, 2009, Loveday \& Conway, 2011). Advocates of SenseCam argue that the device acts as a powerful cue, reinforcing “...consolidation of the episode into a retrievable long-term memory store" (Hodges et al., 2011, p. 695).

It is unclear why SenseCam appears to improve memory, at least in the limited studies that have investigated it (Berry et al., 2007, 2009; Browne et al., 2011; Hodges et al., 2006, 2011; Kalnikaite et al., 2010; Silva et al., 2013). However, because the camera produces such a detailed inventory of events, at least one of the images of a to-be-remembered event was likely 
captured during a moment of encoding. Hodges et al. (2011) argue that subsequent review of that event may then trigger recall. On the other hand, the very nature of the footage may imitate autobiographical memory. SenseCam images are short slices of experience, temporally ordered, and produced outside of one's awareness. Some research suggests that memory is mediated by visual images (Brewer \& Sampaio, 2006; Conway, 2009), and recall, being a reconstructive process, relies heavily on visual cues, like those produced by the SenseCam (Kalnikaite et al., 2010).

Another possible explanation for the memory-enhancing effect of this wearable technology could relate to the way in which some lifelogging technologies cluster the hundreds of images produced into meaningful categories (Kalnikaite et al., 2010). This technique may aid the memory archiving process by expanding one's network of understanding about a particular topic (Anderson, 1983, Collins \& Quillian, 1969). Some scholars argue that knowledge structures within one's memory can be understood as configurations of nodes that are linked together by associations, broadly referred to as 'associative network models' (Anderson, 1983; Collins \& Quillian, 1969). Information about a particular topic is held at one node, and as related information is acquired, associative pathways are created, giving way to a cognitive representation of a person, event, or situation. A picture produced by the SenseCam may thus cue an initial memory, and the hundreds of related pictures provide additional cues which one can use to associate and build other memories from. Alternatively, because the SenseCam is triggered by changes in the environment, the photos taken following a change in the environment may correspond to goal sequences that the brain encodes as an episodic memory: "That is, episodic memories may be formed at goal junctions... [and] the detection of changes in the 
wearer's activity and in their environment through onboard sensors could cause the SenseCam to trigger at junctions of goal processing” (Hodges et al., 2011, p. 11).

BWCs are, in themselves, a type of lifelogging technology. The only substantial difference is that rather than producing a store of photographs, BWCs result in a videoed record of the event. Since they too capture experiences in the temporal order that they occurred, potentially outside one's awareness, that can be observed later, it may be argued that BWCs also act like an artificial extension of autobiographical memory; or at the very least, a depository of rich visual images that can cue memory. In contexts outside of policing where BWCs have been used, research suggests that BWCs are useful for enhancing episodic memory. Hoisko (2003), for example, explored the use of cameras as a "memory prosthesis," and found that image and audio data helped individuals recall additional facts about a recorded incident (p. 210). Similarly, Silva and colleagues' (2018) systematic review found that wearable cameras appear to be a beneficial memory rehabilitation technique, particularly if they evoke "more than a mere familiarity with previous stimuli... [but also] reinstate previous thoughts, feelings, and sensory information..." (p. 117).

\section{Research Related to Policing}

While this research suggests that there may be some value in BWCs in terms of memory enhancement potential, unfortunately, very little attention has been paid to the memory enhancing potential of BWCs in the police setting. Indeed, as far as we are aware, Dawes et al.'s (2015) study is the only empirical study to date that has examined this issue. They equipped 11 law enforcement officers in the U.S. with a BWC and had them take part in three simulated UoF training scenarios. After the scenarios, the officers completed a UoF report on one of the scenarios. Once the report was complete, officers had an opportunity to view their BWC footage 
and were told they could revise their report as appropriate. Details in each report were counted and compared to a "gold standard," which was defined as the details known to be true about the scenario from developing it and from observing footage of it from an independent moderator's video. Dawes and his colleagues quantified the number of errors between initial reports, preBWC observation, and revised reports, post-BWC observation. They also categorized these errors according to their operational relevancy as "minor," "moderate," or "major" errors.

Findings from Dawes et al.'s (2015) study revealed that, following observation of BWC footage, reports became more accurate. Reviewing footage from the BWCs allowed officers to correct, on average, 2.63 minor errors, 5.4 moderate errors, and 0.9 major errors, including 21 errors related to miscounting, mis-sequencing, or omitting force, warnings, or compliance descriptors. Assuming that any revisions made to the reports were because the BWC footage truly elicited that memory from an officer's memory store, rather than providing 'new' information that had not been encoded by the officer, the results are consistent with research examining other wearable technologies (Hodges et al., 2011; Loveday \& Conway, 2011; Silva et al., 2015); that is, observation of the BWC footage enhanced officers' memory of the event. Dawes and his colleagues contend that many of the errors that were corrected via observation of the BWC footage could have led to “... challenges of the officers' credibility, successful pursuit of an excessive force complaint, or dismissal of charges" (p. 15).

Interestingly, certain details in the BWC footage examined by Dawes et al. (2015) that should have cued proper recall were still inaccurate in the revised report. For instance, even after viewing the BWC footage, more than half of the sample failed to notice a third person in the room and instances of UoF occurred that were still not reported in revised reports. These types of errors would likely increase in naturalistic settings where the difficulties associated with memory 
retrieval would likely be more severe. Indeed, while Dawes et al. (2015) note that their sample consisted of rested officers, who were experiencing minimal stress and distractions, this is far from the reality faced by most officers in the field (Andersen \& Gustafsberg, 2016).

In summary, while BWCs cannot replace officer reports, 2 just as a camera cannot replace the human experience of an event, they may help mitigate some memory issues occurring during officer-involved UoF events or any other police-public encounter. Video footage might cue recall for certain aspects of an event, ensuring more complete and accurate accounts. Apart from the few studies reviewed above though, very little research has examined how BWCs impact memory processes, and more research is urgently needed to explore these issues.

\section{Potential Negative Consequences of Body Worn Cameras for Memory}

While research suggests that BWCs may have real value for police services (Ariel et al., 2015; Bureau of Justice Assistance, 2016; Jennings, Lynch, \& Fridell, 2015, PERF, 2014; White, 2014; White, Gaub, \& Todak, 2017), some researchers have raised concerns with the idea of them being omniscient. For example, The Force Science Institute has highlighted several operational limitations of BWCs, such as the fact that they are unable to capture depth and peripheral information (Force Science Institute, 2014). While an officer might notice threats to the side of them, for instance, BWCs positioned on the officer's chest will probably not capture these threats. Even BWC models that attempt to increase the field of view by utilizing fish-eye lenses are limited by the distortion these lenses can cause. Danger cues that an officer observes could also easily be missed by a camera if the officer unintentionally obstructs the camera's view, by raising their gun in front of the camera for example (Boivin, Gendron, Faubert, \& 
Poulin, 2017). Furthermore, very subtle tactile cues that may be felt by officers, like a subject's body tensing, and factored into their risk assessment, are unlikely to be captured by a BWC.

It has also been argued that BWCs may not provide sufficient context to allow policepublic encounters to be fully understood (Dawes et al. 2015). Rarely, for instance, does BWC footage include the events leading up to an interaction since most cameras are not set to record continuously (e.g., due to privacy issues; Miller, 2016). Moreover, BWCs are only able to capture interactions from one particular perspective or angle, and this can impact how viewers of the footage perceive the interaction; much like how camera angle impacts understanding in other contexts, such as videotaped interrogations (Lassiter, Geers, Handley, Weiland, \& Munhall, 2002). For example, Boivin et al. (2017) provided participants with two perspectives of the same incident, which involved an officer using lethal force on an assailant who was threatening police with a baseball bat. One perspective was from a BWC; another was from a surveillance camera placed in a corner of the room. The results indicated that participants who viewed the BWC footage perceived the assailant to be further away from the officer compared to individuals who viewed the surveillance footage. Those who watched the BWC footage also believed that the officer fired their weapon earlier than necessary.

\section{Misinformation-Type Effects}

The physical restrictions of BWCs cited above limit, to some extent, what they can tell officers (as well as the courts and the public) about what happened in any given instance. There are, however, also cognitive consequences to having officers view their footage before preparing a statement about an event. Viewing one's footage prior to preparing a statement may promote deceit for instance; an officer could, theoretically, lie about what they observed during an encounter based on what the footage revealed. An officer could claim, for example, that a gun 
observed at the scene, which was visible in the BWC footage but not originally encoded by the officer, was the basis for their lethal force decision. Moreover, allowing officers to view their footage before preparing their statement could also result in misinformation-type effects, whereby details from the video are unintentionally incorporated into an officer's "memory" of the event, even if those details were not originally encoded (Loftus, 2005).

In contrast to typical misinformation studies, where the post-event information that is presented to research participants is often factually incorrect information (Loftus, Donders, Hoffman, \& Schooler, 1989), the information that may be incorporated into one's memory from BWC footage might not be "incorrect," but simply not originally encoded by the responding officer. Grady et al. (2016) argue that while BWC footage provides true information, it may be different from what an officer actually noticed and could inadvertently bias their memory accordingly: "Even though their report may seem more accurate since it confirms to the objective reality of the situation, it is actually less accurate about the officer's perception of the event, which may be far more relevant when it comes to figuring out what led to the use of force" (p. 247).

The misinformation effect has been well-studied in laboratory settings, and the effect has been shown to exist for misinformation that ranges from minor details to very significant life events such as being lost as a child or the victim of an accident (Loftus, 1993; Porter, Yuille, \& Lehman, 1999). Researchers who study these issues have also identified a range of factors that influence the likelihood of internalizing misinformation, and these factors are now reasonably understood (Loftus, 2005). Much of this research leads us to believe that misinformation-type effects are distinctly possible in the police setting where BWCs are involved. Not only does it seem possible that officers could misremember important details of their encounters with the 
public, but the environment within which they will be encoding aspects of these encounters are particularly conducive to misremembering.

For example, Loftus (2005) suggests that misinformation is more likely to be internalized when memories for the event in question are weak. This may accurately characterize many police-public encounters, especially those that involve the use of force, because these encounters often unfold rapidly in less-than-ideal environmental conditions (e.g., low light). Such encounters are also frequently complex in nature and they generally induce stress. All of these things can negatively impact cognitive functioning and can result in weak memory traces of an event (Artwohl, 2002; Klinger, 2004; Sharps, 2010). Under these circumstances, it might be quite easy for an officer to misattribute the source of some detail contained in BWC footage of an event; they may genuinely think that the detail was observed while at the scene, when in fact they did not attend to the detail until they were exposed to it while watching the BWC footage. Indeed, even in situations that are far less stressful than police-public encounters, individuals frequently exhibit such source misattribution errors. In fact, misattributing the source of a memory is considered to be one of the "seven sins of memory" given how frequently it can occur (Grady et al. 2016; Schacter \& Dodson, 2001).

The only study we are aware of that has examined the impact of BWC viewing on report writing is the previously discussed study by Dawes et al. (2015). As indicated above, Dawes and his colleagues found that viewing BWC footage influenced the information contained in postevent statements. Unfortunately, it is not clear from the results reported by Dawes et al. (2015) whether viewing BWC footage of an event led the participating officers in that study to present originally unobserved, yet important, information in their reports to justify their actions in the encounter. Future research is needed to examine this concern. By carefully tracking differences 
between the reports of officers who either view their footage prior to or after completing their statement, we might obtain a better understanding of this issue. We believe that mobile eyetracking technology will also play a valuable role in such research. Data from eye-trackers may allow researchers to determine more precisely what an officer attended to during a simulated event. This should assist with the task of distinguishing between details including in postviewing statements that were legitimately forgotten, but cued by BWC footage, and details that were not originally encoded, but visible within the BWC footage.

\section{Retrieval-Induced Forgetting}

Another memory-related concern associated with BWCs, especially in cases where officers are permitted to view their BWC footage before providing a statement about an incident, is that they may foster retrieval-induced forgetting (RIF). Retrieval-induced forgetting refers to the phenomena whereby the act of remembering part of an event prompts other aspects of the event to be forgotten (Grady et al., 2016). Retrieval-induced forgetting has been consistently demonstrated via the retrieval-practice paradigm (Anderson, Bjork, \& Bjork, 1994; Camp, Wesstein, \& De Bruin, 2012; Murayama, Miyatsu, Buchli, \& Storm, 2014). In the retrievalpractice paradigm individuals learn a list of word-pairs (e.g., fruits-banana, drinks-coffee), and practice retrieval on half of them (e.g., drinks-coffee). They then receive a test where they are asked to recall all word pairs. Not surprisingly, retrieval practice tends to improve recall of the practiced material (drinks-coffee). However, the retrieval practice also appears to “... [impair] recall of the unpracticed material (fruits-banana), relative to a control condition in which no retrieval practice occurs at all” (Johannson, Aslan, Bauml, Gabel, \& Mecklinger, 2007, p. 1335). Hundreds of studies have been conducted investigating the effect of RIF, with several literature 
reviews and meta-analyses finding that remembering certain things does in fact lead to memory loss for other things (Murayama et al., 2014; Storm \& Levy, 2012; Verde, 2012).

Some scholars have theorized that RIF occurs as a result of an inhibitory mechanism (Anderson, 2003; Levy \& Anderson, 2002; Storm \& Levy, 2012). According to this view, when an individual attempts to retrieve a certain item, multiple, related items are activated. This creates competition such that an individual must inhibit the related items in order to selectively retrieve the to-be-remembered item from their memory bank. Consequently, the inhibited items are less accessible. In other words, inhibition reduces interference from competing memories, resulting in enhanced recall of practiced items, but a loss of unpracticed items. Others have argued that RIF is better explained by strength-based competition or blocking (Jonker, Seli, \& MacLeod, 2013; Raaijmakers \& Jakab, 2013). Proponents of this view argue that retrieval strengthens certain items, consequently causing them to interfere with non-strengthened (i.e., unpracticed) items. The interference prevents the unpracticed items from being retrieved. Essentially, when one attempts to retrieve an unpracticed item, it is blocked by the practiced item. Murayama and colleagues (2014) conducted a meta-analysis to better understand whether RIF occurs as a result of an inhibitory mechanism or if it is better explained by a strength-based competition or blocking mechanism. They examined 512 samples utilizing 759 effect size estimates and found that the results supported an inhibition mechanism, although some evidence relevant to strength-based or blocking existed as well.

In either case, RIF may occur in contexts where BWC technology is used. When officers watch their BWC footage they are essentially re-exposed to a to-be-remembered event. The act of watching one's BWC footage may thus be comparable to someone receiving additional retrieval practice on certain word-pairs. However, as argued previously, BWCs do not 
necessarily capture details of an entire incident, including details that an officer may have attended to. An officer who sees their BWC footage before providing their statement about the event may be able to document what is in the footage, but could experience worsened recall for anything not captured by the BWC; that is, information outside the camera's view, their internal perceptions, or obstructed items (Grady et al., 2016). Future research that utilizes the retrievalpractice paradigm in a policing context, may thus hold value. If, for instance, police who review their footage accurately report aspects of the incident captured in the recording, but fail to report other, not captured, non-reviewed portions of the event, then policy may need to be adopted related to when footage can be seen in relation to report writing.

\section{Cognitive Offloading}

Lastly, beyond these concerns related to the appropriate timing of when to view BWC footage, research suggests that BWCs may be associated with other, yet to be explored, negative consequences related to officer memory. Indeed, research from non-police settings suggests that the presence of a camera itself could change the way that officers encode information during their encounters with the public (Gilbert, 2015; Henkel, 2014; Marsh \& Rajaram, 2019; Risko \& Dunn, 2015; Risko \& Gilbert, 2016; Soares \& Storm, 2018; Sparrow, Liu, \& Wegner, 2011). In fact, recent research is finding that, when possible, individuals may attempt to reserve limited cognitive resources by engaging in a process commonly referred to as cognitive offloading (Risko \& Gilbert, 2016).

According to Risko and Gilbert (2016), one may offload cognitive demands "onto-thebody" or "into-the-world." When one physically moves their body to facilitate understanding and reduce demand, they are attempting to offload cognitions "onto-the-body;" this is referred to as “external normalization.” Risko and Gilbert give the example of tilting one's head to the side 
when trying to interpret a rotated object. The head tilt normalizes the object's orientation so that it is more consistent with a representation of that object that is stored in memory. Alternatively, offloading cognitions "into-the-world" is called "intention offloading." This form of offloading is generally used to enhance prospective memory. The use of reminders, lists, and alarms are all ways one might reallocate mental tasks to technological prostheses in order to remember something later. Using a BWC to "remember" an event is a form of intention offloading that BWC-equipped police officers might practice.

Research suggests that individuals are more apt to rely on intention offloading when it is difficult to recall to-be-remembered things; namely when there is a lot of information to retain, or if there are interruptions or other difficulties experienced during the encoding process (Gilbert, 2015; Risko \& Gilbert, 2016). An individual who is experiencing stress or exposed to a complex situation in which there are multiple tasks required of them are thus likely to offload. This, of course, is the exact situation that police officer often find themselves in - potentially dangerous situations are frequently encountered, where multi-tasking is common and consequential decisions must typically be made, sometimes very quickly, on the basis of a risk assessment that takes into account a variety of interacting risk factors (e.g., subject behaviours, environmental variables, tactical considerations; Sharps, 2010).

In many respects, using physical devices such as BWCs as an extension of memory is beneficial. As Risko and Gilbert (2016) argue, “Offloading cognition helps us to overcome...capacity limitations, minimize computational effort, and achieve cognitive feats that would not otherwise be possible" (p. 676). In other words, relying on a device like a BWC to store something that would have otherwise been the job of an officer's working memory (WM) system increases the chance that details are accurately retained, and frees up space for other 
cognitive (e.g., communication, problem-solving, or decision-making) and motor tasks (e.g., unholstering, aiming, or deploying a UoF intervention option). However, intention offloading, which has peaked with the advent of the internet, has also raised concerns among academics and the public (Risko \& Gilbert, 2016; Sparrow et al., 2011). Indeed, even the media has questioned whether technology is being abused (Carr, 2008). It appears that the ease with which we can acquire, store, and retrieve information almost instantaneously from technology has resulted in the offloading of simple, easily remembered information (Gilbert, 2015; Risko \& Gilbert, 2016).

A seminal study by Sparrow et al. (2011) investigated the cognitive consequences of having constant, easy access to information. Across four studies, Sparrow and colleagues (2011) found that: (1) people are primed to think about computers when presented with a question, as opposed to searching their own memory for answers to the question at hand, even when the answer to the question is known; the effect is particularly acute though, when the question is hard; (2) people who believe that they will be able to access information later are less likely to encode that information, and thus appear to have more difficulty recalling it; (3) people have difficulty recalling where they accessed online information from; and (4) people are significantly better at recalling where information is kept (e.g., a particular website), than the actual saved information itself.

Although not confirmed yet in the police setting, such findings have clear implications for officers wearing BWCs who are involved in challenging interactions with the public, if such results are shown to generalize to this setting. Given research showing that stress can result in gaps in knowledge (Shields, Sazma, McCullough, \& Yonelinas, 2017), Sparrow et al.'s (2011) findings suggest that officers may be particularly prone to offloading. Moreover, if officers believe they will be able to access information about an event later via their BWC footage, 
Sparrow et al.'s study suggests they will be less apt to encode information about the event, which is likely to hinder recall. This could prove especially problematic when BWC footage ends up being unavailable after the event, either because the camera was not recording due to human error or technological issues, the footage is of low quality, or the officer is not allowed to view the video.

Several other studies have also demonstrated a "save-and-forget-it" type effect, whereby knowledge that information is being saved in another form impairs encoding of that information at the point of contact (Henkel, 2014; Risko \& Gilbert, 2016; Soares \& Storm, 2018). For example, Henkel (2014) investigated memory for observed versus photographed objects in two experiments. In the first experiment, she led $(N=27)$ participants on an art museum tour. Participants were directed to 30 different artefacts on the tour. They were told to only observe half of the objects, whereas they were told to photograph the other half. In all cases, they were asked to pay attention to the objects and were informed that they would later be asked about the objects. Following the tour, Henkel had participants recall the objects and object details. She tested the participants' memory of the objects with free recall, and then via an activity that asked them to name the objects, recognize them visually using a photograph, and report details about them using multiple choice questions. The results demonstrated a "photo-taking impairment effect" - if participants had taken a photograph of the object, they were less likely to remember it and reported fewer details about it.

In her second experiment, Henkel (2014) hypothesized that the act of taking the photograph may have interrupted the amount of time that participants had spent examining, and therefore encoding, the object. It was further posited that narrowing in on the object may draw attention to the object in a way that photographing it in its entirety does not. As such, participants 
were given additional time to view the objects when they took photographs of them. In addition, for some of the objects, participants were asked to zoom in on a part of the object before taking the photograph. According to Henkel, "Despite the added time or attention required to angle the camera and adjust the lens so as to capture the best shot of the object in its entirety, the act of photographing the object appears to enable people to dismiss the object from memory, thereby relying on the external devise of the camera to 'remember' for them" (p. 401). Assuming that Henkel's participants were not experiencing any exceptional stress on the museum tour, it appears that the presence of a camera might alter recall even under innocuous, low-threat circumstances.

It is important to emphasize that, while the non-policing research cited above suggests that cognitive offloading may occur if officers encounter challenging situations and think that they will have access to BWC footage available to them, post-event, it may be that contextual factors in the police setting prevent this from occurring. For example, it is possible that the training police officers receive prevents offloading from occurring; this is obviously training that typical research participants who exhibit offloading do not receive. Additionally, an officer's awareness that they may have to articulate what occurred during an encounter, due to organizational policies or legal requirements, could prevent offloading from occurring; again, this is clearly something that would not concern the sort of individuals participating in the previously discussed studies. Thus, future research is needed to confirm whether being equipped with a BWC may negatively impact memory for encounters with the public through cognitive offloading. This could easily be done by conducting experiments with officers who are made to believe (or not) that they will have access to their BWC footage while they prepare their post- 
event report. If both groups of officers are not provided access to their BWC footage, and differences emerge in recall accuracy, cognitive offloading may be to blame. 3

\section{Conclusions}

Body worn cameras are now being used by officers in many police services. However, it appears that the popularity of BWCs has outpaced research on this technology. Much of the research that does exist suggests that the use of BWCs is associated with valuable outcomes, such as decreased UoF on the part of police officers and fewer complaints made about the police by members of the public. To the extent that such results replicate and generalize to other settings, this is obviously good news. However, concerns have also been raised about this technology. Many of these concerns relate to technological and practical limitations associated with BWCs. There is clearly a need for people to be aware of these limitations and to take them into account when viewing BWC footage and deciding how much weight to put on these videos. In the current paper, we conducted a literature review that focused on another aspect of BWCs that has received less attention - how BWCs might impact memories for police-public encounters, especially those encounters that involve UoF.

Unfortunately, we could find few studies that have examined this issue within a police setting, so we were forced to look further afield to find research that speaks to this topic. Much of the research we located suggests that BWCs may have a positive impact on an officer's memory for previously experienced encounters. For example, a reasonable amount of research supports the view that visual imagery can be used to facilitate recall. Indeed, regardless of whether one examines a static photograph, a series of static images (e.g., SenseCam), or a

3 We are currently in the process of completing such a study. One group of officers in our study were led to believe that they would have access to their BWC footage, post-event, which might encourage cognitive offloading. After the event, we feigned that their BWCs had malfunctioned and thus they had to prepare their statement without the aid of their BWC footage. 
dynamic video recording, it appears that these sources of information can be used to facilitate recall by cueing forgotten memories. This research raises the real possibility that BWCs will play a similar memory-enhancing role in the policing field, by providing a useful aid to police officers who must frequently have to recall details of encounters that may have been complex or stressful.

However, existing research also raises another, less appealing possibility; that in some cases at least, BWCs may have a negative effect on an officer's memory. Indeed, research conducted outside of a police setting highlights three specific issues that we need to be concerned about - misinformation-type effects, RIF, and cognitive offloading. We have to be particularly concerned about these issues because the characteristics of many police-public encounters are consistent with the sorts of conditions that result in these effects. For example, cognitive offloading is more likely to be observed under conditions where the encoder is overloaded in some way (e.g., due to stress or scene complexity), which is likely a common occurrence for many police officers.

To be clear, there is, as of yet, no strong evidence to suggest that these negative effects are associated with BWCs. In fact, there are good reasons to think that they may not actually be a problem in the police setting. Indeed, unlike typical research participants, police officers receive training, and are governed by policies and laws, that may enhance their encoding abilities or, at the very least, encourage careful observation. However, given the consequences of the sorts of effects described above, we need to be concerned with the possibility that they might occur. In addition to studying the positive outcomes associated with BWCs, researchers should turn some of their attention to these other issues. By conducting such research, it will be possible to 
determine the degree to which these potential problems exist, under what conditions they emerge, and what might be done to minimize their impact.

Only once such research has been conducted can we fully understand how we might combat the potential negative effects associated with the use of BWCs. But, one can imagine what sorts of implications might arise from such research. Training may need to be revised to stress to officers the importance of memory encoding during police-public interactions. For example, officers cannot assume that BWC footage of the event will be available, post-event. There may also be policy recommendations that emerge from such research, such as where BWCs should be placed on the officer to maximize video quality or when BWC footage should be viewed in relation to note-taking and providing a statement. Undoubtedly, there will be things that even BWC manufacturers can learn from such studies as well, such as features of cameras that could be particularly beneficial if cognitive offloading appears to be a problematic issue. 


\section{References}

Ally, B. A., \& Budson, A. E. (2006). The worth of pictures: Using high density event-related potentials to understand the memorial power of pictures and the dynamics of recognition memory. NeuroImage, 35, 378-395.

Almasy, S., \& Moshtaghian, A. (2016). Fresno police video shows shooting of unarmed suspect. Cable News Network. Retrieved from https://www.cnn.com/2016/07/14/us/fresno-dylannoble-shooting-video/index.html

Anderson, M. C., Bjork, R. A., \& Bjork, E. L. (1994). Remembering can cause forgetting: Retrieval dynamics in long-term memory. Journal of Experimental Psychology: Learning, Memory, and Cognition, 20, 1063-1087.

Andersen, J. P., \& Gustafsberg, H. (2016). A training method to improve police use of force decision making: a randomized controlled trial. SAGE Open, 6(2), 2158244016638708.

Anderson, J. R. (1983). A spreading activation theory of memory. Journal of Verbal Learning and Verbal Behavior, 22(3), 261-295.

Anderson, M. C. (2003). Rethinking interference theory: Executive control and the mechanisms of forgetting. Journal of Memory and Language, 49, 415-445.

Ariel, B., Farrar, W. A., \& Sutherland, A. (2015). The effect of police body-worn cameras on use of force and citizens' complaints against the police: A randomized controlled trial. Journal of Quantitative Criminology, 31(3), 509-535.

Ariel, B., Sutherland, A., Henstock, D., Young, J., Drover, P., Sykes, J... \& Henderson, R. (2016a). Wearing body cameras increases assaults against officers and does not reduce police use of force: Results from a global multi-site experiment. European Journal of Criminology, 13(6), 744-755. 
Ariel, B., Sutherland, A., Henstock, D., Young, J., Drover, P., Sykes, J., ... \& Henderson, R. (2016b). "Contagious accountability" a global multisite randomized controlled trial on the effect of police body-worn cameras on citizens' complaints against the police. Criminal Justice and Behavior, 44(2), 293-316.

Artwohl, A. (2002). Perceptual and Memory Distortion During Officer-Involved Shootings. FBI Law Enforcement Bulletin, 71(10), 18-24.

Aschermann, E., Dannenberg, U., \& Schulz, A. P. (1998). Photographs as retrieval cues for children. Applied Cognitive Psychology: The Official Journal of the Society for Applied Research in Memory and Cognition, 12(1), 55-66.

Boivin, R., Gendron, A., Faubert, C., \& Poulin, B. (2017). The body-worn camera perspective bias. Journal of Experimental Criminology, 13(1), 125-142.

Berry, E., Hampshire, A., Rowe, J., Hodges, S., Kapur, N., Watson, P., ... \& Owen, A. M. (2009). The neural basis of effective memory therapy in a patient with limbic encephalitis. Journal of Neurology, Neurosurgery \& Psychiatry, 80(11), 1202-1205.

Berry, E., Kapur, N., Williams, L., Hodges, S., Watson, P., Smyth, G., ...\& Wood, K. (2007).

The use of a wearable camera, SenseCam, as a pictorial diary to improve autobiographical memory in a patient with limbic encephalitis: A preliminary report. Neuropsychological Rehabilitation, 17(4-5), 582-601.

Brewer, W. F., \& Sampaio, C. (2006). Processes leading to confidence and accuracy in sentence recognition: A metamemory approach. Memory, 14(5), 540-552.

British Broadcasting Corporation. (2015, August 10). Ferguson unrest: From shooting to nationwide protests. Retrieved from http:/www.bbc.com/news/world-us-canada30193354 
Browne, G., Berry, E., Kapur, N., Hodges, S., Smyth, G., Watson, P., \& Wood, K. (2011). SenseCam improves memory for recent events and quality of life in a patient with memory retrieval difficulties. Memory, 19(7), 713-722.

Bud, T. K. (2016). The rise and risks of police body-worn cameras in Canada. Surveillance \& Society, 14(1), 117-121.

Bureau of Justice Assistance. (2016). Body-worn camera toolkit. Retrieved from https://www.bja.gov/bwc/

Camp, G., Wesstein, H., \& Bruin, A. B. (2012). Can questioning induce forgetting? Retrievalinduced forgetting of eyewitness information. Applied Cognitive Psychology, 26, 431435.

Carr, N. (2008, July/August). Is Google making us stupid? What the internet is doing to our brains. The Atlantic. Retrieved from https://www.theatlantic.com/magazine/archive/2008/07/is-google-makingusstupid/306868/

College of Policing. (2017). Mayor on track to roll-out police body cameras across the Met. Retrieved from https://www.college.police.uk/News/archive/November_2015/Pages/Mayor_toroll_out_police_body_cameras.aspx

Collins, A. M., \& Quillian, M. R. (1969). Retrieval time from semantic memory. Journal of Verbal Learning and Verbal Behavior, 8, 240-248.

Conway, M. A. (2009). Episodic memories. Neuropsychologia, 47(11), 2305-2313.

Crick, F., \& Koch, C. (2003). A framework for consciousness. Nature Neuroscience, 6(2), 119126. 
Coudert, F., Butin, D., \& Le Metayer, D. (2015). Body-worn cameras for police accountability: Opportunities and risks. Computer Law and Security Review, 31, 749-762.

Dawes, D., Heegaard, W., Brave, M., Paetow, G., Weston, B., \& Ho, J. (2015). Body-worn cameras improve law enforcement officer report writing accuracy. The Journal of Law Enforcement, 4(6), 1-21.

Edmonton Police Service. (2015). Body worn video: Considering the evidence (Final report of the Edmonton Police Service Body Worn Video Pilot Project). Edmonton Police Service, Edmonton, AB.

Farrar, W., \& Ariel, B. (2013). Self-awareness to being watched and socially desirable behavior: A field experiment on the effect of body-worn cameras on police use-of force. Washington, DC: Police Foundation.

Findlay, V. (2017). Body-worn cameras: Not seeing the forest for the technology? Retrieved from https://www.researchgate.net/publication/312234531_Body Worn_Cameras_Not_Seeing_the_Forest_for_the_Technology

Force Science Institute. (2014, September 23). 10 limitations of body cams you need to know for your protection. Police One. Retrieved from https://www.policeone.com/policeproducts/body-cameras/articles/7580663-10-limitations-of-body-cams-you-need-toknow-for-your-protection/

Freund, K. (2015). When cameras are rolling: Privacy implications of body-mounted cameras on police. Columbia Journal of Law and Social Problems, 49, 91-133.

Geiselman, R. E., Fisher, R. P., MacKinnon, D. P., \& Holland, H. L. (1985). Eyewitness memory enhancement in the police interview: Cognitive retrieval mnemonics versus hypnosis. Journal of Applied Psychology, 70(2), 401-412. 
Gilbert, S. J. (2015). Strategic use of reminders: Influence of both domain-general and taskspecific metacognitive confidence, independent of objective memory ability. Consciousness and Cognition, 33, 245-260.

Goodall, M. (2007). Guidance for the police use of body-worn video devices, Police and Crime Standards Directorate. Home Office. Retrieved from http://library.college.police.uk/docs/homeoffice/guidance-body-worn-devices.pdf

Gordon, B. N., Ornstein, P. A., Nida, R. E., Follmer, A., Crenshaw, M. C., \& Albert, G. (1993). Does the use of dolls facilitate children's memory of visits to the doctor? Applied Cognitive Psychology, 7(6), 459-474.

Grady, R. H., Butler, B. J., \& Logtus, E. F. (2016). What should happen after an officer-involved shooting? Memory concerns in police reporting procedures. Journal of Applied Research in Memory and Cognition, 5, 246-251.

Grossmith, L., Owens, C., Finn, W., Mann, D., Davies, T., \& Baika, L. (2015). Police, camera, evidence: London's cluster randomized controlled trial of body worn video. College of Policing and Mayor's Office for Policing and Crime, London, UK.

Hartman, M., O’Neill, D., O’Neill, J., \& Lewinski, W. (2017). Law enforcement memory of stress events: Recall accuracy as a function of detail type. Law Enforcement Executive Forum, 17(3), 22-41.

Hamilton, M., \& Winton, R. (2016, July 14). Fresno police release dramatic body-camera footage of fatal shooting of unarmed 19-year-old. Los Angeles Times. Retrieved from http://www.latimes.com/local/lanow/la-me-ln-fresno-police-shooting-video-20160713snap-story.html 
Hamilton, M., \& Winton, R. (2017, January 19). Video shows police cornering mentally ill man and fatally shooting him: 'This was an execution.' Los Angeles Times. Retrieved from https://www.latimes.com/local/lanow/la-me-ln-fontana-police-video-20170118story.html

Hansford, J. (2019, August 9). 5 years after Ferguson, we're losing the fight against police violence. The New York Times. Retrieved from https://www.nytimes.com/2019/08/09/opinion/ferguson-anniversary-policerace.html?rref=collection $\% 2$ Ftimestopic\%2FPolice $\% 20$ Brutality $\% 20$ and $\% 20$ Misconduct \&action $=$ click\&contentCollection $=$ timestopics\&region=stream\&module $=$ stream_unit\&v ersion=latest\&contentPlacement $=17 \&$ pgtype $=$ collection

Hedberg, E. D., Katz, C. M., \& Choate, D. E. (2016). Body-worn cameras and citizen interactions with police officers: Estimating plausible effects given varying compliance levels. Justice Quarterly, 1-25.

Henkel, L. A. (2014). Point-and-shoot memories: The influence of taking photos on memory for a museum tour. Psychological Science, 25(2), 396-402.

Hodges, S., Berry, E., \& Wood, K. (2011). SenseCam: A wearable camera that stimulates and rehabilitates autobiographical memory. Memory, 19(7), 685-696.

Hodges, S., Williams, L., Berry, E., Izadi, S., Srinivasan, J., Butler, A., ... \& Wood, K. (2006, September). SenseCam: A retrospective memory aid. In International Conference on Ubiquitous Computing (pp. 177-193). Berlin, Heidelberg: Springer.

Hoisko, J. (2003). Early experiences of visual memory prosthesis for supporting episodic memory. International Journal of Human-Computer Interaction, 15(2), 209-230.

Houts, P. S., Bachrach, R., Witmer, J. T., Tringali, C. A., Bucher, J. A., \& Localio, R. A. (1998). 
Using pictographs to enhance recall of spoken medical instructions. Patient Education and Counseling, 35(2), 83-88.

Hyland, S. S. (2018). Body-worn cameras in law enforcement agencies, 2016. U.S. Department of Justice, Office of Justice Programs, Bureau of Justice Statistics. Retrieved from https://www.bjs.gov/content/pub/pdf/bwclea16.pdf

Ishai, A., Haxby, J. V., \& Ungerleider, L. G. (2002). Visual imagery of famous faces: Effects of memory and attention revealed by fMRI. Neuroimage, 17(4), 1729-1741.

Jack, F., Martyn, E., \& Zajac, R. (2015). Getting the picture: Effects of sketch plans and photographs on children's, adolescents' and adults' eyewitness recall. Applied Cognitive Psychology, 29(5), 723-734.

Jennings, W. G., Fridell, L. A., \& Lynch, M. D. (2014). Cops and cameras: Officer perceptions of the use of body-worn cameras in law enforcement. Journal of Criminal Justice, 42, $549-556$.

Jennings, W. G., Lynch, M. D., \& Fridell, L. A. (2015). Evaluating the impact of police officer body-worn cameras (BWCs) on response-to-resistance and serious external complaints: Evidence from the Orlando police department (OPD) experience utilizing a randomized controlled experiment. Journal of Criminal Justice, 43(6), 480-486.

Johansson, M., Aslan, A., Bäuml, K. H., Gäbel, A., \& Mecklinger, A. (2006). When remembering causes forgetting: Electrophysiological correlates of retrieval-induced forgetting. Cerebral Cortex, 17(6), 1335-1341.

Jonker, T. R., Seli, P., \& MacLeod, C. M. (2013). Putting retrieval-induced forgetting in context: An inhibition-free, context-based account. Psychological Review, 120, 852-872. 
Kalnikaite, V., Sellen, A., Whittaker, S., \& Kirk, D. (2010, April). Now let me see where I was: Understanding how lifelogs mediate memory. Proceedings of the SIGCHI Conference on Human Factors in Computing Systems, 2045-2054.

Karimi, F., Shoichet, C. E., \& Ellis, R. (2016, July 9). Dallas sniper attack: Five officers killed, suspect identified. Canadian News Network. Retrieved from http://www.cnn.com/2016/07/08/us/philando-castile-alton-sterling-protests/index.html89

Kleinig, J. (2016, May 24). To protect and serve: What is wrong with the policing of minorities in the U.S.? The Critique. Retrieved from http://www.thecritique.com/articles/toprotectserve- what-is-wrong-with-the-policing-of-minorities-in-the-u-s/

Klinger, D. (2004). Into the kill zone: A cop's eye view of deadly force. San Francisco, CA: Jossey-Bass.

Lassiter, G. D., Geers, A. L., Handley, I. M., Weiland, P. E., \& Munhall, P. J. (2002). Videotaped interrogations and confessions: A simple change in camera perspective alters verdicts in simulated trials. Journal of Applied Psychology, 87(5), 867-874.

Laming, E. (2017, July 18). Canada needs a national database to track deadly force by police. HuffPost. Retrieved from https://www.huffingtonpost.ca/erick-laming/deadly-force-bypolice_a_23034831/

Levy, B. J. \& Anderson, M. C. (2002). Repression can (and should) be studied empirically. Trends in Cognitive Sciences, 6, 502-503.

Ling, J. (2019, July 15). As use of bodycams becomes common in U.S., most Canadian police forces - including RCMP - resistant. National Post. Retrieved from https:/nationalpost.com/news/as-use-of-bodycams-becomes-common-in-u-s-mostcanadian-police-forces-including-rcmp-resistant 
Loftus, E. F. (1993). The reality of repressed memories. American Psychologist, 48(5), 518-537.

Loftus, E. F. (2005). Planting misinformation in the human mind: A 30-year investigation of the malleability of memory. Learning \& Memory, 12(4), 361-366.

Loftus, E. F., Donders, K., Hoffman, H. G., \& Schooler, J. W. (1989). Creating new memories that are quickly accessed and confidently held. Memory and Cognition, 17(5), 607-616.

Loriggio, P. (2016, July 28). Const. James Forcillo sentenced to 6 years in prison for shooting death of Sammy Yatim. Global News. Retrieved from https://globalnews.ca/news/2852879/const-james-forcillo-to-be-sentenced-inshootingdeath-of-sammy-yatim/

Loveday, C., \& Conway, M. A. (2011). Using SenseCam with an amnesic patient: Accessing inaccessible everyday memories. Memory, 19(7), 697-704.

Marsh, E. J., \& Rajaram, S. (2019). The digital expansion of the mind: Implications of internet usage for memory and cognition. Journal of Applied Research in Memory and Cognition, $8(1), 1-14$.

Matsuo, K., \& Miura, H. (2017). Effectiveness of the Self-Administered Interview and Drawing Pictures for Eliciting Eyewitness Memories. Psychiatry, Psychology and Law, 24(5), 643-654.

Mesa Police Department. (2013). On officer body camera system: Program evaluation and recommendations. Mesa, Arizona: Mesa Police Department.

Miller, K. (2016). Watching the watchers: Theorizing cops, cameras, and police legitimacy in the 21st century. The Politics of Policing: Between Force and Legitimacy (pp. 257-276). Emerald Group Publishing Limited.

Murayama, K., Miyatsu, T., Buchli, D., \& Storm, B. C. (2014). Forgetting as a consequence of 
retrieval: A meta-analytic review of retrieval-induced forgetting. Psychological Bulletin, 140, 1383-1409.

National Institute of Justice. (2016). Police use of force. Retrieved from https://www.nij.gov/topics/law-enforcement/officer-safety/useofforce/pages/welcome.aspx

Police Executive Research Forum. (2014). Implementing a body-worn camera program:

Recommendations and lessons learned. Office of Community Oriented Policing Services. Retrieved from https://www.policeforum.org/assets/docs/Free_Online_Documents/Technology/impleme nting $\% 20 \mathrm{a} \% 20$ body-worn $\% 20$ camera $\% 20$ program.pdf

Porter, S., Yuille, J. C., \& Lehman, D. R. (1999). The nature of real, implanted, and fabricated memories for emotional childhood events: Implications for the recovered memory debate. Law and Human Behavior, 23(5), 517-537.

Police Executive Research Forum. (2018). Cost and benefits of body-worn camera deployments: Final report. Retrieved from https://www.policeforum.org/assets/BWCCostBenefit.pdf

Privacy International. (2019, March 3). Neighbourhood watched: How policing surveillance technology impacts your rights. Retrieved from https://privacyinternational.org/long$\mathrm{read} / 2724 /$ every-police-force-uk-will-soon-use-body-worn-video-cameras-record-uspublic

Raaijmakers, J. G. W., \& Jakab, E. (2013). Rethinking inhibition theory: On the problematic status of the inhibition theory for forgetting. Journal of Memory and Language, 68, 98122.

Risko, E. F., \& Dunn, T. L. (2015). Storing information in-the-world: Metacognition and 
cognitive offloading in a short-term memory task. Consciousness and Cognition, 36, 6174.

Risko, E. F., \& Gilbert, S. J. (2016). Cognitive offloading. Trends in Cognitive Sciences, 20(9), 676-688.

Rosen, B. (2019, June 26). Durham police begin evaluating the permanent use of body cameras. Global News. Retrieved from https://globalnews.ca/news/5430598/durham-policeevaluating-body-cameras/

Royal Canadian Mounted Police. (2014). Subject Behaviour/Officer Response Database (SBOR) - Addendum. Retrieved from http://www.rcmp-grc.gc.ca/en/privacy-impactassessmentaddendum-subject-behaviour-officer-response-database-sbor95

Salmon, K., Bidrose, S., \& Pipe, M. E. (1995). Providing props to facilitate children's event reports: A comparison of toys and real items. Journal of Experimental Child Psychology, $60(1), 174-194$.

Saulnier, A. (2019, April 22). The effect of body-worn cameras on public perceptions of police: A Canadian study. Blue Line. Retrieved from https://www.blueline.ca/the-effect-of-bodyworn-cameras-on-public-perceptions-of-police-a-canadian-study-6341/

Schacter, D. L., \& Dodson, C. S. (2001). Misattribution, false recognition and the sins of memory. Philosophical Transactions of the Royal Society of London B: Biological Sciences, 356, 1385-1393.

Sharps, M. J. (2010). Processing under pressure: Stress, memory, and decision-making in law enforcement. Flushing, NY: Looseleaf Law Publications.

Shields, G. S., Sazma, M. A., McCullough, A. M., \& Yonelineas, A. P. (2017). The effects of acute stress on episodic memory: A meta-analysis and integrative review. Psychological 
Bulletin, 143(6), 636-675.

Silva, A. R., Pinho, M. S., Macedo, L., \& Moulin, C. J. A. (2018). A critical review of the effects of wearable cameras on memory. Neuropsychological Rehabilitation, 28(1), 117-141.

Smith, D. (2018, October 10). Where does police brutality fit in America's first law enforcement museum? The Guardian. Retrieved from https://www.theguardian.com/usnews/2018/oct/10/national-law-enforcement-museum-police-brutality

Soares, J. S., \& Storm, B. C. (2018). Forget in a flash: A further investigation of the photo-taking impairment effect. Journal of Applied Research in Memory and Cognition, 7(1), 154-160.

Sparrow, B., Liu, J., \& Wegner, D. M. (2011). Google effects on memory: Cognitive consequences of having information at our fingertips. Science, 333(6043), 776-778.

Storm, B. C., \& Levy, B. J. (2012). A progress report on the inhibitory account of retrievalinduced forgetting. Memory \& Cognition, 40, 827-843.

Sullivan, D., \& Marrero, T. (2016, August 24). USF study suggests Tampa police with body cameras less likely to use force. Retrieved from http://www.tampabay.com/news/publicsafety/usfstudy-suggests-tampa-police-with-bodycameras-lesslikely-to-use-force/2290851

Taser International Inc. (2015). About Axon body worn cameras by TASER International. Retrieved from http://www.lumbertonpolice.com

The Economist. (2018, July 28). Body-worn cameras are spreading beyond the police. Retrieved from https:/www.economist.com/britain/2018/07/28/body-worn-cameras-are-spreadingbeyond-the-police

Thunder Bay Police Service. (2019). Body worn camera viability review. Retrieved from https://www.thunderbaypolice.ca/sites/default/files/pdfs/tbps_bwc_report.pdf 
Toronto Police Service. (2016). Body-worn cameras: A report on the findings of the pilot project to test the value and feasibility of body-worn cameras for police officers in Toronto.

Toronto Police Service Strategy Management, Strategic Planning Section. Retrieved from https://www.torontopolice.on.ca/media/text/20160915-body_worn_cameras_report.pdf

Tulving, E. (1983). Elements of episodic memory. New York, NY: Oxford University Press.

Verde, M. F. (2012). Retrieval-induced forgetting and inhibition: A critical review. The psychology of learning and motivation (pp. 47-80). San Diego, CA: Elsevier Academic Press.

Vrij, A., Leal, S., Fisher, R. P., Mann, S., Dalton, G., Jo, E., ... \& Houston, K. (2018). Sketching as a technique to eliciting information and cues to deceit in interpreter-based interviews. Journal of Applied Research in Memory and Cognition, 7(2), 303-313.

White, M. (2014). Police officer body-worn cameras: Assessing the evidence. Office of Community Oriented Police Services. Retrieved from https://www.publicsafety.gc.ca/lbrr/archives/cnmes-pleng/cn31934-eng.pdf

White, M., Gaub, J., \& Todak, N. (2017). Exploring the potential for body-worn cameras to reduce violence in police-citizen encounters. Policing: A Journal of Policy and Practice, $12(1), 66-76$.

Yokum, D., Ravishankar, A., \& Coppock, A. (2017). Evaluating the effects of police body-worn cameras: A randomized controlled trial. Retrieved from https://bwc.thelab.dc.gov/TheLabDC_MPD_BWC_Working_Paper_10.20.17.pdf 


\section{CHAPTER 3}

\section{Misplacing Memory: Examining the Phenomenon of Cognitive Offloading During an}

\section{Officer-Involved Use-of-Force Scenario}

Brittany Blaskovits*, Bryce Jenkins, Andrew Brown, Simon Baldwin, \& Craig Bennell

Department of Psychology, Carleton University, Ottawa, Ontario, Canada

* Address for correspondence: Brittany Blaskovits, Department of Psychology, Carleton University, 1125 Colonel by Drive, Ottawa, Ontario, Canada, K1S 5B6. Email:

brittanyblaskovits@cmail.carleton.ca

Under review by the Journal of Police and Criminal Psychology 


\begin{abstract}
People are known to offload memory processing tasks to devices, such as cameras. Why remember things, when we can rely on these devices? We examined whether body worn cameras (BWCs) are used in this way by police officers. Fifty officers responded to a simulated domestic dispute that resulted in lethal force. Half the sample was provided a BWC and told their footage would be available to assist with post-event recall, but it was later feigned that there was a technological issue. The remaining officers were not equipped with a BWC and thus were aware they would not have any footage to rely on. The amount, accuracy, and type of details reported by officers were coded and subjected to analysis. The results revealed that wearing a camera did not promote cognitive offloading in officers, suggesting that the training officers receive, or other factors that might be unique to policing, may mitigate an effect that has been observed in other contexts.
\end{abstract}

Keywords: cognitive offloading, police, body worn cameras, use-of-force 


\section{Misplacing Memory: Examining the Phenomenon of Cognitive Offloading During an Officer-Involved Use-of-Force Scenario}

In a high stress situation, like an officer-involved use-of-force event, an officer's memory can be negatively affected such that they fail to properly attend to and encode important details of the event (Bremner, 1999; Fortin, Agster, \& Eichenbaum, 2002). In extreme cases, officers may experience tunnel vision and/or auditory exclusion whereby perceptual narrowing occurs to such a degree that numerous (potentially important) cues are ignored (e.g., weapons, bystanders; Artwohl, 2002; Grossman \& Christensen, 2007). This restriction in one's field of view leaves them vulnerable to memory errors and/or gaps in their recall (Grossman \& Christensen, 2007; van der Kolk \& Fisler, 1995). However, even moderately stressful tasks appear to impact memory processes, interfering with one's ability to both encode and retrieve information (see Shields, Sazma, McCullough, \& Yonelinas, 2017).

To compensate for the potential memory deficits resultant from stress, body worn cameras (BWCs) have been revered as a tool to enhance officers' ability to recall details about their encounters with members of the public (Jennings, Fridell, \& Lynch, 2014). When an officer re-watches their BWC footage, certain details might prompt them to better remember what transpired during the encounter, as well as aspects of their risk assessment (i.e., why they made the decisions they did during the encounter; Dawes et al., 2015). From a policing perspective, the hope is that by enhancing officers' recall, citizens will better understand police-public interactions, and that perceptions (or accusations) that officers are being intentionally deceptive following an incident (should their recall be discrepant), will be mitigated.

Interestingly however, new research has found that having access to saved information about an event (e.g., via photographs or video) may actually have a negative effect on memory 
for that same event (Henkel, 2014; Risko \& Gilbert, 2016; Sparrow, Liu, \& Wegner, 2011); and that this "photo-taking impairment effect" could be due cognitive offloading (Henkel, 2014; Soares \& Storm, 2018). When we engage with recording devices in the physical environment (e.g., a camera, phone, or notepad) in an effort to change the processing requirements of a task (i.e., recording information to act as a cue for later recall), we are said to be "offloading" information to a prosthetic "memory" bank (Risko \& Gilbert, 2016; Soares \& Storm, 2018). Doing so can reduce cognitive demand in the encoding environment and theoretically "frees up resources" for other tasks (e.g., better communication, problem-solving, decision-making, and motor tasks). Yet, it could also leave us reliant on the source of the saved information (e.g., the camera) - Why remember, when we can later rely on a recording device?

Moreover, the literature suggests that individuals are more apt to relinquish their cognitions to a tool when it is difficult to recall to-be-remembered things, such as when they are stressed, experiencing interruptions during encoding, and/or being exposed to an overwhelming amount of information (Gilbert, 2015; Risko \& Gilbert, 2016). The police are, of course, a population that is exposed to complex, often stressful events that require them to multi-task (e.g., communicate with subjects, make tactical decisions, utilize intervention options); leaving them particularly vulnerable to engage in offloading (e.g., to their BWCs). Unfortunately, officers do not always have access to their recorded footage. There may be human or technological errors made that prevent recording, the footage may not always be useable (e.g., if it is of poor quality), or the footage could be used as hold-back evidence against officers involved in critical incidents (Office of the Privacy Commissioner of Canada, 2015; Reporters Committee, 2019). If officers offload encoding responsibilities to their BWC only to find that the source of the saved information is unavailable, their recall could be compromised. Therefore, determining the degree 
to which officers in high-stress use-of-force encounters offload encoding responsibilities to their BWC is important.

\section{The Potential Impact of Stress on Police Officer Memory}

Officer involved use-of-force events are rare. For example, in Canada, 99.9\% of all police-public interactions are resolved without lethal intervention (Baldwin et al., 2018; Butler \& Hall, 2008; Hall, Votova, \& Wood, 2013); and in the United States it is estimated that less than $2 \%$ of interactions involve use-of-force by the police (MacDonald, Kaminski, \& Smith, 2009). Nevertheless, the unpredictable nature of policing, and the potential for injuries or death undoubtedly contributes to stress in officers (Andersen, Pitel, Weerasinghe, \& Papazoglou, 2016; Anderson, Litzenberger, \& Plecas, 2002). While the stress response has implications for one's overall body functioning and health (e.g., Anderson et al., 2002), it also appears to impact psychological processes including memory and learning.

It has been argued that a certain amount of stress can improve subsequent recall, since the perceptual narrowing that occurs under stress allows individuals to ignore irrelevant information and attend to that which is most pertinent (Lewinski, 2008). This is consistent with the "weapon focus effect," whereby individuals tend to remember weapons better than other, less salient details (Steblay, 1992). Alternatively, some research has found that stress, particularly high and/or chronic stress, can restrict one's attention to such an extent that important information fails to be properly encoded, consequently impairing recall (consistent with Easterbrook's classic [1959] cue-utilization hypothesis; e.g., Artwohl, 2002; Grossman \& Christensen, 2007). A recent meta-analysis comprised of 113 studies aimed at clarifying the effect of stress on memory, found that while stress can enhance certain memory processes, it also appears to disrupt others 
depending on whether it occurred prior to encoding, during encoding, post-encoding, or at retrieval (Shields et al., 2017).

The debilitating effect of stress on encoding and retrieval are supported by the "executive control account" of memory (Shields et al., 2017; Schwabe, Wolf, \& Oitzl, 2010). This theory assumes that stress targets "executive functions" (i.e., those that support effective encoding and retrieval; Blumenfeld \& Ranganath, 2007; Gagnon \& Wagner, 2016; Levy \& Anderson, 2002), consequently impairing “...working memory, selective attention, and cognitive flexibility” (Shields et al., 2017, p. 639). The impairment of these functions is particularly concerning for officers involved in high-risk incidents in which they are forced to make sound judgements under high levels of stress. Working memory, for example, temporarily stores information so that cognitive tasks such as problem-solving can be accomplished (Baddeley, 1983). In other words, it allows one to remember something (e.g., such as where to go to respond to a call for service), while also engaging in something else (e.g., communicating with dispatch). Should one's WM become overwhelmed or otherwise short-circuited, breakdowns in short- and long-term memory may occur (Taverniers, Smeets, Van Ruysseveldt, Syroit, \& von Grumbkow, 2011; Taverniers, Van Ruysseveldt, Smeets, \& von Grumbkow, 2010; Wine, 1971).

The impact of stress on memory is not necessarily surprising considering that one of the areas of the brain most affected by the stress response is the hippocampus, a structure that plays a major role in the encoding and retrieval of autobiographical event details (Bremner, 1999; Dusek \& Eichenbaum, 1997; Fortin et al., 2002). Under a "typical" level of stress, the hippocampus works to encode important information about a stressor and may even improve threat detection by facilitating the comparison of a current dangerous situation to prior dangerous situations (Bremner, 1999). However, exposure to extreme or prolonged stress has the potential to 
overwhelm the hippocampus, and even damage it (Arbel, Kadar, Silbermann, \& Levy, 1994;

Bachevalier \& Meunier, 1996; Fortin et al., 2002). It has been suggested that hippocampal dysfunction may represent, “...the anatomic basis for alterations in memory, such as fragmented or delayed recall of traumatic memories...” (Bremner, 1999, p. 798).

\section{Body Worn Cameras as Tools for Intention Offloading}

Following an officer-involved use-of-force event, most agencies ask their officers to explain what happened in a report (Alpert \& Smith, 1999; Garner, Hickman, Malega, \& Maxwell, 2018; Laming, 2019). Yet, tense interactions with members of the public, particularly those that involve the application of force, clearly represent situations where an officer would be stressed and thus vulnerable to certain memory issues. It has been argued that BWCs may be able to enhance officers' ability to recall details about their encounters with the public, better ensuring reports are completed as fully and accurately as possible (Dawes et al., 2015; Jennings et al., 2014), similar to a "walk-through" of a crime scene (Geiselman, 2010; Honig \& Lewinski, 2008). Because BWCs have the potential to record full events, they should, theoretically, capture idiosyncrasies of use-of-force events that might otherwise be forgotten or distorted. More specifically, if officers have the opportunity to refer to their BWC footage while writing their reports, any loss of information resultant from stress, should be allayed.

Similar to the use of reminders, alarms, and notes, using a BWC to assist in "remembering" an event is arguably a form of intention offloading. When one offloads, they are effectually relinquishing their cognitions "into the world" in order to enhance their prospective memory (i.e., trigger a later intention; Risko \& Gilbert, 2016). Interestingly, research suggests that we offload often and may even attempt to do so more than is necessary (Risko \& Dunn, 2015; Risko \& Gilbert, 2016). For example, in a study conducted by Risko and Dunn (2015), 
participants chose to offload (i.e., write down the to-be-remembered items), even when the memory load was so minimal that performance did not improve with offloading. "This tendency to engage in offloading despite it not benefiting performance may result from (i) an undetected performance benefit, (ii) a bias against cognitive effort... and/or (iii) an erroneous metacognitive belief that the offloading will in fact benefit performance" (Risko \& Gilbert, 2016, p. 681). However, offloading is even more likely to occur when our mental capacities are exhausted (e.g., because we are stressed and/or the information is complex or overwhelming) - a state typical of officers who find themselves in a precarious interaction with an assailant.

Successful offloading allows us to reallocate our mental resources elsewhere (Risko \& Gilbert, 2016; Storm \& Stone, 2015). Should an officer rely on a BWC, for instance, to store information that would otherwise have been the job of their working memory, space is theoretically "freed up" for other cognitive (e.g., communication, problem-solving, decisionmaking) and motor tasks (e.g., unholstering, aiming, and deploying an intervention option). It is argued that offloading is underpinned by one's own metacognitive awareness of their limitations (Redshaw, Vandersee, Bulley, \& Gilbert, 2018; Risko \& Gilbert, 2016). The notion is similar to transactive memory, a theory that describes how individuals in close partnerships develop mnemonic systems whereby one person can rely on the other (and vice versa) to recall shared information (e.g., Wegner, Erber, \& Raymond, 1991). Knowing that we might have difficulty remembering later on, we surrender certain information to external support systems (e.g., Gilbert, 2015; Redshaw et al., 2018).

Clearly, though, offloading comes at a price. When one redistributes their cognitions to a device, like a camera, less effort is put forth to encode and retain that information (i.e., the tradeoff for increased mental capacity is some loss of information; e.g., Henkel, 2014; Marsh \& 
Rejaram, 2019; Risko \& Gilbert, 2016). In other words, knowing that the instance is being saved in some other form appears to give us permission to forget it. Indeed, recent research has revealed that having constant, easy access to saved information (often in the form of photos and/or video) negatively affects memory (Henkel, 2014; Risko \& Gilbert, 2016; Sparrow et al., 2011). Sparrow and colleagues (2011) for instance, conducted a series of four studies showing that when people expect to have future access to information (like via the internet), they tend to have lower rates of recall. In one study, participants were asked to type various statements and told that half the statements they wrote would be deleted and the other half would be saved. In a subsequent recall test, participants were significantly more likely to remember those they believed had been erased. This suggests that we may be less motivated to encode and retain information that will be saved in another form. Relatedly, Henkel (2014) found that when individuals take photos of objects, they are less likely to remember those objects and recall fewer details about them, compared to if they had only observed them; a phenomenon referred to as the photo-taking impairment effect. In fact, even when participants were provided additional time to view the objects prior to taking a photo they displayed impaired recall.

It is unclear if the impaired recall for saved information is a direct by-product of cognitive offloading, although it seems likely. Marsh and Rejaram (2019), for example, argue that it makes sense to rely on external sources (like the internet) as memory stores - “...it is unlimited in its capacity, almost always available, fast, and relatively unlimited in scope. There is no point memorizing an address when one can look it up quickly, from anywhere” (p. 6). Henkel (2014), however, notes that cameras may act as a cue to "dismiss and forget," similar to what seems to occur in studies examining directed-forgetting (e.g., Bjork \& Woodward, 1973; Golding \& MacLeod, 1998). In such studies, individuals have tended to dismiss information they 
are explicitly told to forget (and better recall that which they are told to remember). Likewise, a camera may signal that the information being captured is either unimportant and can be disregarded, or that it is being stored elsewhere.

Finally, Soares and Storm (2018) argue that other processes, specifically attentional disengagement, may better explain the problematic recall for photographed objects. They conducted a within-subjects study wherein participants took photos of a group of paintings with the messaging application Snapchat.4 They also took photos of paintings that would not be deleted (i.e., with a regular camera); and finally, participants simply viewed a group of paintings. The findings revealed a photo-taking impairment effect for the paintings that were photographed (whether they were saved in a permanent form or not [i.e., via Snapchat]). The findings were replicated in another study where participants were aware that they would have to physically delete the photos they took of the paintings. Given that offloading depends on one's ability to rely on an external source to "remember for them," Soares and Storm note that it may not fully explain the impairment in recall observed. In any case, we appear to dismiss information when a camera is present. While this effect is concerning in a general sense (see Carr's [2008] article "Is Google making us stupid?"), it would be even more alarming if it were to occur amongst police officers tasked with accurately recalling life or death events.

\section{Purpose}

If officers can rely on BWCs to "hold" a memory for them, offloading may be beneficial (given its ability to overcome capacity limitations and minimize computational effort; Risko \& Gilbert, 2016). However, officers do not always have access to their footage. There may be problems with the recording if, for example, they forget to turn on the camera prior to an event or 
the camera malfunctions. Alternatively, the footage itself may be of poor quality (if the image is obstructed, freezes, or if the camera is damaged during an altercation), or officers may simply not be allowed to view it if it is being used as hold-back evidence. Consider an officer who offloads to a BWC, and as a result does not adequately encode important information during an encounter (consistent with Henkel's [2014] photo-taking impairment effect). If they then turn to the source of the "saved information" only to find that it is unavailable, their ability to recall and articulate their actions could be compromised.

In a courtroom trial about a use-of-force event, discrepancies and/or memory failures may be perceived negatively, as if an officer is withholding evidence, or acting deceptively. Given that memory deficits are already likely to occur under stress (Shields et al., 2017), and that various problems with BWC footage appear quite likely (Blaskovits, McGale, \& Bennell, 2017; Remsberg, 2016), determining the degree to which officers in use-of-force encounters offload encoding responsibilities to BWCs (potentially exacerbating memory deficits) is important. Therefore, the aim of the current research was to examine how BWCs impact the amount, accuracy, and type of details reported by officers during a simulated use-of-force event.

\section{Hypotheses}

Hypothesis 1A. Consistent with research in other domains (e.g., Henkel, 2014; Sparrow et al., 2011), it is expected that officers who are led to believe that they will be able to view their BWC footage following their involvement in a simulated use-of-event, but later are prevented from doing so due to a feigned technological issue (i.e., the primed group), will report significantly fewer details about the event when prompted to do so, relative to officers who are not wearing a camera (and aware that they will not have the opportunity to view any footage prior to completing their statement about the event; i.e., the control group). 
Hypothesis 1B. Consistent with prior research that found associations between high levels of stress and deleterious effects on memory (Dawes et al., 2015), it is further hypothesized that stress may act as a covariate, such that officers will provide fewer details about the use-offorce event they were involved in if they were primed to believe that they could rely on the footage from their BWC, particularly if they were highly stressed.

Hypothesis 2A. Given natural biases to fill in gaps in memory with what we believe to have happened (e.g., based on prior experience; Dawes et al., 2015; Lacy \& Stark, 2013), it is expected that the statements provided by the primed group of officers will be significantly less accurate compared to the control group.

Hypothesis 2B. Moreover, much of the literature suggests that, as stress increases, memory impairments become more pronounced (e.g., Dawes et al., 2014; Dawes et al., 2015; Morgan, Doran, Steffian, Hazlett, \& Southwick, 2006). Therefore, it is further hypothesized that stress may act as a covariate such that statements provided by those in the primed condition will be less accurate, particularly for those experiencing higher stress.

Research Question. Lastly, the current study aimed to explore the type of details recalled by officers. Specifically, it investigated the extent to which officers include more details related to certain aspects of the event, like the perpetrator, relative to others. Given that few studies have examined the type of details recalled in statements made by police officers, no hypotheses regarding this were made $a$ priori.

\section{Method}

\section{Participants}


A total of 50 operational police officers were recruited from a training center in Canada.5 Approximately $88 \%(n=44)$ of the sample was male, and $12 \%(n=6)$ were female, relatively consistent with the dispersion of most police organizations in North America (Conor, 2018; Data USA, 2019). Participants were $37.10(S D=8.21)$ years of age, on average, and had $10.66(S D=$ 6.66) years of overall police service, $10.22(S D=6.17)$ of which were operational. Independent samples $t$-tests indicated that female participants had significantly more years of overall service $(M=16.88, S D=7.45)$ relative to males $(M=9.81, S D=6.16), t(48)=2.57, p=.013$. They also had significantly more years of operational service $(M=16.42, S D=7.53)$ compared to males $(M=9.38, S D=5.54), t(48)=2.80, p=.007$. More than half the sample reported that they were married $(52 \%, n=26)$, and the same amount reported that they had children. Approximately $30 \%(n=15)$ of participants had a college diploma or certificate and $28 \%(n=$ 14) had a bachelor's degree. The majority of the sample were Constables $(74 \%, n=37)$ or Corporals $(12 \%, n=6)$, and did not have use-of-force instructor training6 $(71.4 \%, n=35)$. Most had never been involved in a lethal force encounter $(86 \%, n=43)$, although $10 \%(n=5)$ had been witness to one, and $4 \%(n=2)$ had been involved as a subject officer.

Given that the current study was not clinical in nature, participants were not medically examined prior to participating. However, in order to participate, all officers needed to be considered "fit for duty" by their police agency and currently on active duty. Moreover, they were asked to report if they had cardiovascular disease and whether or not they were taking any medications that could affect their heart rate (HR). None of the participants reported that they

5 The current sample of participants is a subset of a larger pool of 123 participants that was collected for other research purposes.

${ }_{6}$ "Use-of-force instructor training" was a dichotomous yes/no item. If participants had instructor level training, then they could expand on the type of training they had in an open-text box if they chose to. Types of training that participants reported delivering included: firearms, emergency response team, use-of-force, active threat, and conducted energy weapon, among others. 
had cardiovascular disease and only $6 \%(n=3)$ indicated that they took medication affecting their HR.

Across participants, the average maximum heart rate (HR) during the scenario (i.e., calculated from the time at which participants received the simulated dispatch call until the time they were de-equipped) was 149.46 beats per minute (bpm; $S D=21.82)$, which is consistent with the literature suggesting that participants experienced a stress response (Baldwin, Bennell, Andersen, Semple, \& Jenkins, 2019; Johnson, 2008; Woody \& Szechtman, 2011). Participants’ average resting rate was $70.03 \mathrm{bpm}(S D=9.68)$, which is similar to the baseline reported by Andersen and Gustafsberg (2016) and consistent with the normal resting HR for adults (Laskowski, 2018). The average bpm above-resting was also calculated to better account for individual differences in HR variability. This ensured that if multiple officers displayed a maximum HR of $145 \mathrm{bpm}$ for example, those with a lower resting rate would show a larger relative increase (Anderson et al., 2002). Consistent with Anderson et al. (2002), Andersen et al. (2016), Baldwin et al. (2019), and Andersen and Gustafsberg (2016), bpm above-resting was calculated by subtracting participants' maximum HR from their average resting rate. 7 The average bpm above-resting across participants was $80.72(S D=17.92)$. This rate is notably higher than that reported by Anderson et al. (2002) whom recorded officers' HR while on shift where they engaged in various activities including fighting, handcuffing, and pursuing subjects. It is consistent with that reported by Andersen et al. (2016) and Andersen and Gustafsberg (2016).

\footnotetext{
7 Participants' resting HR was calculated by acquiring one-minute of their lowest bpm. This approach aimed to avoid using potential artifacts (i.e., excessive and/or irregular low beats) as the resting rate. Although we acknowledge that a more accurate measure of resting HR might be acquired from officers immediately upon waking (Plowman \& Smith, 2013), similar approaches to ours has been used in prior research (e.g., Anderson et al., 2002; Andersen \& Gustafsberg, 2016; Baldwin et al., 2019). The average of the lowest one-minute observed was used in the calculation for participants' bpm above-resting.
} 
Independent samples $t$-tests and chi-square tests indicated that there were no significant differences between males and females on any of these items (i.e., marital status, presence of children, level of education, rank, training, involvement in a lethal force encounter, maximum HR, or bpm above-resting).

\section{Measures}

Demographics. Each participant completed a demographic questionnaire comprised of 16 questions that asked them their age, rank, and years of service, among other qualities.

Heart Rate. Salivary cortisol, heart rate variability (HRV), and heart rate (HR) have all been used to measure stress reactivity in police officers (Anderson et al., 2002; Burke, Waters, \& Ussery, 2007; McCraty \& Atkinson, 2012). However, readings of salivary cortisol may be confounded by the time of day that they are taken and HRV is argued to be inconsistent and susceptible to error when collected whilst participants are moving (Dickerson \& Kemeny, 2004; Heathers \& Goodwin, 2017). Alternatively, HR, averaged over time, is a robust, ecologically valid measure that is likely to be more appropriate for the continuous monitoring of officer stress during an active duty shift, such as that simulated in the current study (Andersen \& Gustafsberg, 2016; Arble, Daugherty, \& Arnetz, 2019; Vrijkotte, Van Doornen, \& De Geus, 2000). Increases in sympathetic activity caused by real or perceived threats is associated with HR increases; whereas relative increases in parasympathetic activity, causing one to become calmer and more relaxed, are associated with HR decreases (Thayer, Ahs, Fredrikson, Sollers, \& Wager, 2012). Therefore, given the dynamic nature of the scenario participants were exposed to, HR was used as a proxy for stress.

Standard Use-of-Force Report. Following an application of force, most police organizations require that their officers complete a statement about the encounter (Alpert \& 
Smith, 1999; Garner et al., 2018; Laming, 2019). To assess recall, the standard use-of-force report from the organization from which the sample of officers were recruited was used in the current study. This particular report is completed online and contains 25 drop-down questions that request information about the subject's behaviour at the time of the event and various situational factors (e.g., weather conditions, time of day, intervention method[s] used [e.g., pistol, Taser, Oleoresin Capsicum spray]). There are two open text boxes where officers are asked to elaborate on the subject's known history and behaviour, and a final incident summary where officers describe in full what occurred. Such reports are generally completed as an articulation and oversight tool, ensuring an officer's actions are lawful and have been appropriately articulated should they ever be questioned. However, these reports may also be used as a method for analysts to infer trends that could inform policy, training, and the procurement of equipment.

Other research (e.g., Soares \& Storm, 2018; Sparrow et al., 2011) has asked participants a pre-determined set of questions to assess their recall, which may not capture the full extent of their memory about an object or situation. Thus, while the current study used a standard use-offorce report that cued participants by asking some close-ended questions similar to prior research, they were also asked to freely recall what they could about the event. Free recall appears to enhance episodic memory and may provide a better indication of individuals' complete memory for an event (see research related to the cognitive interview; e.g., Aschermann, Mantwill, \& Kohnken, 1991; Fisher, Geiselman, \& Amador, 1989; Memon \& Bull, 1991).

\section{Equipment}

Heart Rate. In order to measure the extent to which the scenario elicited stress in officers, all participants were equipped with a Polar H7 Chest Strap Heart Rate Monitor ${ }^{\circledR}$ and 
two Polar V800 Heart Rate Monitor Watches ${ }^{\circledR}$. In combination, the devices can be used to obtain a live, accurate reading of HR and corresponding R-R intervals8 (Giles, Draper, \& Neil, 2015). Previous research has validated the use of this technology (e.g., Barton, Vrij, \& Bull, 2000; Hope et al., 2016; Kayihan, Ersoz, Ozkan, \& Koz, 2013), and has shown that it may be a useful alternative to other technologies (e.g., electrocardiograms; ECG) for obtaining measures of HR during periods of activity, such as when officers are participating in high fidelity training scenarios (Baldwin et al., 2019; Giles et al., 2015; Hope et al., 2016). Moreover, similar to other research, participants were also equipped with FirstBeat Bodyguard 2 Heart Rate Monitors $(\mathrm{C}$ to reduce the likelihood of lost or corrupted HR data, and to ensure a secondary source from which to verify the accuracy of the data collected (Parak \& Korhonen, 2013; Ramey et al., 2016).

StressVestrm. Since it is not feasible to systematically assess the impact of stress on memory during actual use-of-force events due to the irregularity and low base rate of these incidents, ethical standards, and the lack of control required to adequately measure the variables of interest consistently across officers, specialized training technology was incorporated into the design of the study. One type of technology utilized was the StressVestrm system. The actors in the scenario, and every participant, wore a StressVestTm, along with a StressXTM PRO belt. They were also provided a standard issue pistol that was equipped with SecuriBlank Loud 9mm simmunition and had been converted with laser barrels which emitted infrared light when discharged. When a participant is "shot" while wearing the Stress VestTm system, the wearer receives a localized shock to the abdomen through the belt (Setcan Corporation, 2019). The shock (and/or potential for a shock) is argued to induce stress similar to that which an officer 
would experience in a genuine use-of-force encounter (Staller, Cole, Zaiser, \& Korner, 2017). The system provides the added benefits of safety (e.g., non-projectile based weapons are used) and other forms of fidelity (e.g., participants can communicate with each other freely since they are not wearing safety gear such as face masks).

Body Worn Cameras. Half of the sample was equipped with an Axon Body 2 BWC. It was attached to the front of the officers' uniform as per the manufacturer's instruction and turned on prior to the start of the scenario.

Surrounding Cameras. In addition to the BWCs, participants also wore an (CApplied Science Laboratories (ASL) Mobile Eye-5 Glasses (i.e., eyetracker) and (CGoPRO HERO4 Silver cameras were mounted in central locations around the facility where the scenario took place. Given potential issues with BWCs (e.g., limited field of view), these additional cameras were installed to record the officers' activities from other angles. The videos were also reviewed to verify statements made by the officers in their reports about what occurred.

\section{Procedure}

Police officers were recruited from a large Canadian police organization either via email or by signing up for the study in-person during in-service training at a training facility. Upon arrival, participants were provided a consent form and were cleansed of their live intervention options. All participants were then equipped with a Polar H7 Chest Strap Heart Rate Monitor® and two Polar V800 Heart Rate Monitor Watches ${ }^{\circledR}$. The FirstBeat Bodyguard 2 Heart Rate Monitors $\subset$ were also applied. They completed a demographic form and a series of questionnaires not relevant to the current study. Upon completing the questionnaires, participants were equipped with a StressVestTM. 
Approximately half the sample $(52 \%, n=26)$ was selected to wear a BWC.9 An explicit statement was made to this group informing them that they would have the opportunity to view their BWC footage prior to completing their statement about the event. This primed group of participants, who were under the impression that they could rely on their footage, was expected to offload elements of their cognition (i.e., certain encoding tasks) to their cameras. The remaining half of the participants $(48 \%, n=24)$ were not assigned to wear a BWC and were thus aware that they would not have any footage to rely on. Since they would not have the opportunity to look back on any footage, this control group was expected to put in significantly more effort to attend, encode, and ultimately retain event details. All participants were then exposed to a realistic domestic disturbance call.

The scenario was developed in collaboration with several use-of-force subject matter experts and instructors. It was piloted with 12 officers, after which, modifications were made to enhance the scenario's realism and ensure that it remained standardized regardless of the various ways a participant could react. It aimed to include stressors known to overload arousal including time pressure, task load, threat, ambiguity, novelty, noise, and performance pressure (Driskell \& Salas, 1996; Wollert, Driskell, \& Quail, 2011). In brief, the scenario required that participants respond to a call in an upstairs apartment where a male subject was reported to be in breach of his probation conditions. The apartment had a combined living and dining area, as well as a separate bedroom, adorned with a couch, coffee table, television, dining room table, and bed. There were also numerous items (e.g., clothing, sheets, magazines, posters, candles, coffee cups),

9 Note that while every effort was made to ensure the random assignment of participants to the primed versus control conditions, the groups were counterbalanced to ensure each group had a relatively equal number of participants in them. Some participants were also assigned to a certain condition as the result of limited time, equipment, and/or availability. Therefore, while the study cannot be said to have true random assignment, the lack of demographic differences between the groups suggest that it is unlikely any pre-existing differences contributed to the results. 
including weapons (e.g., sledgehammer, knives) placed around the residence to add to the complexity of the scenario. Empty bottles of alcohol were displayed around the room, a radio was blaring loud music, and a scent training system (AirAware $\left.{ }^{\circledR}\right)$ released the smell of marijuana.

The scenario was designed such that while initially the subject simply refuses to leave the residence on account of his breach, it quickly evolves into a mental health related call (i.e., the subject threatens suicide by holding a knife to his throat). Depending on a participant's response, the scenario may progress from there into a physical altercation between the subject and another male witness who was also in the residence. Eventually, the subject grabs a gun and begins shooting at the participant while the witness grabs a cellphone to record the incident. The scenario concludes when participants return fire on the subject, make an arrest, and/or apply first aid while waiting for back-up and emergency response. 10

Post-scenario, participants were de-equipped and asked to complete a second series of questionnaires unrelated to the current study.11 Participants then completed a standard use-offorce report about the event. None of the participants were allowed to see their BWC footage before writing their statement. Those who had been assigned to wear a camera were told that there was an error with their footage and that they would need to complete the statement without any aid. When they finished their statement, they were debriefed by the researchers as well as by a use-of-force instructor and given the opportunity to withdraw their data. None of the

10 Note that the same actors played in every scenario. They followed a standard script that was flexible enough to ensure they could adapt to whatever decisions a participant made. The scenario room was re-adjusted after every participant so that it appeared the same for each participant.

11 These questionnaires namely asked participants about the stress they experienced as a result of the scenario, and whether or not they experienced any cognitive distortions (e.g., tunnel vision, auditory exclusion). Importantly for the current study, the questionnaires provided a brief time interval before participants were asked to recall what occurred, more closely resembling the time gap likely to occur after a real-life critical incident (i.e., before an officer would have the opportunity to complete their notes). 
participants chose to withdraw. The entire study took approximately one hour and fifteen minutes to complete, and each officer received a $\$ 50$ gift card as compensation for their time. The study was approved by the XXXX University Ethics Committee for Psychological Research (CUREB-B Clearance \# 108733) as well as the Human Resources Research Review Board (2018-04) from the agency in which the officers were recruited.

\section{Analytical Approach}

Qualitative Coding. All 50 use-of-force reports were coded into their smallest component parts. If, for instance, an officer wrote "When I knocked, there was a blonde male," the sentence was broken down to acquire three details pertaining to: (1) a behaviour enacted by the officer (i.e., them knocking), (2) the hair colour of the witness (i.e., blonde), and (3) the sex of the witness (i.e., male). The details were counted to obtain the total number of details recalled by each participant. The majority of the details came from the free recall portion of the report, although there were approximately 25 drop-down questions that could be counted toward the total (depending on what information a participant provided and/or what they chose to answer). A trained research assistant independently coded a random subset $(25 \%)$ of the reports. The intraclass correlation (ICC) for the total number of details reported was .84 , which is considered a 'good' degree of agreement (e.g., Hallgren, 2012; Koo \& Li, 2016; McHugh, 2012).

Each detail was then compared to ground truth 12 to determine accuracy (i.e., if the participant reported that the witness was blonde, is he, in fact, blonde?). The ICC for the determination of accuracy was .85 , indicating 'good' reliability across raters. The reports were then subjected to deductive content analysis. The deductive method is driven by prior knowledge or models; categories and subcategories are created a priori and then the data is coded according 
to them (Elo \& Kyngas, 2008). Given that use-of-force reports are a standard tool in the agency from which the officers were recruited, making them familiar to most officers, there is a general understanding about the type of information that needs to be included. As such, the reports tend to be similar (i.e., officers typically provide a description of the call, subject[s], weapons, their response, and the outcome). Pre-determined categories based on this general model of what a typical use-of-force report includes, were thus created.

Details were categorized as those which related to the: (1) context, (2) subject, or (3) officer. Statements about the lighting conditions or descriptions of the witness, for example, were classified into the category related to context; whereas statements about the subject's appearance were slotted into the subject category. Any statements about the participant's response to the scenario, including behaviour and/or statements they made, were coded into the officer-related category. While an unconstrained matrix was adopted, which allowed for the addition of extra categories should new themes emerge that were not anticipated a priori, none were established. The ICC's for classification into the above categories were predominately above .65 , which is considered 'moderate' agreement (Bobak, Barr, \& O’Malley, 2018; Koo \& Li, 2016).

Assumptions. The coded data was subjected to an Analysis of Covariance (ANCOVA). Assumptions relevant for ANCOVA were conducted prior to analyses. Four cases had standardized residuals that exceeded \pm 3 standard deviations, suggesting they were outliers. Further exploration determined they were legitimate responses and that winsorizing them did not alter the results. To reduce the potential for bias introduced by winsorizing, they were left as is (Aguinis, Cascio, \& Ramani, 2017; Ghosh \& Vogt, 2012; Liao, Li, \& Brooks, 2016). Linear relations were observed between participants' bpm above-resting and each of the dependent variables (total number of details, accurate details, inaccurate details, confabulated details, 
number of subject-related details, accuracy of subject-related details, number of context-related details, accuracy of context-related details, number of officer-related details, accuracy of officerrelated details) for both conditions, as assessed by visual inspection of scatterplots. There was homogeneity of the regression slopes as all interaction terms were $p>.05$. Standardized residuals for the experimental condition were nearly all normally distributed at $p>.05$, as assessed by Shapiro-Wilk's test. However, Shapiro-Wilk's test was violated in several instances in the control condition. Therefore, histograms and Q-Q plots were examined, and skew and kurtosis values were calculated. The visual tests appeared relatively normal and skew and kurtosis was within an acceptable range (Field, 2009; George \& Mallery, 2010; Kline, 1998, 2005). Since ANCOVA is robust to violations of normality and there were an approximately equal number of cases in both groups, the data were left untransformed. Homoscedasticity was evident as assessed by inspecting the standardized residuals plotted against the predicted values for each dependent variable. The assumption of homogeneity of variances, as assessed by Levene's test, was met on all except one analysis. 13 That result of that analysis did not change when the data was transformed. For ease of interpretation, the untransformed result is reported.

\section{Results}

\section{Demographic Differences}

Independent samples $t$-tests were conducted to determine whether there were any preexisting mean differences between the primed and control group on the continuous demographic variables age, years of service, and operational years of service, as well as average maximum HR during the scenario and bpm above-resting. None of the tests were significant, suggesting that the groups were relatively equally distributed on these items. Chi-square analyses were conducted to 
examine differences between the primed and control group on the categorical items gender, education level, rank, prior involvement in a lethal force encounter, prior use-of-force instructor training, presence of dependents, and marital status. Once again, no differences were observed, reducing the likelihood that any differences between the groups were the result of demographic characteristics.

\section{Heart Rate}

Data from the Polar H7 Chest Strap Heart Rate Monitor ${ }^{\circledR}$ and two Polar V800 Heart Rate Monitor Watches ${ }^{\circledR}$ were transferred onto the $@$ Kubios software where it was cleaned and spliced into phases, providing a measure of each participant's average maximum HR during the scenario (i.e., cut to start when participants received the simulated dispatch call until the time they were de-equipped). A paired samples $t$-test was conducted to examine whether there was a significant difference in participants' average resting rate relative to the maximum rate elicited during the scenario. There was a significant difference between the two phases, $t(46)=26.52, p$ $<.001$, indicating that, on average, participants experienced significantly more stress during the scenario $(M=149.46, S D=21.82)$, compared to at rest $(M=69.97, S D=9.89)$. Participants' bpm above-resting was used as a covariate in every analysis to control for the effect of stress on recall.

\section{Analyses Examining Overall Recall}

The results indicated that, on average, participants recalled over 89 individual details about the interaction, which lasted, on average 9.74 minutes $(S D=2.52)$. Those wearing a BWC (and who were expected to be offloading their cognitions) actually recalled slightly more details93 details on average. However, an ANCOVA indicated that there was no significant difference in the amount recalled between those wearing a BWC and those without one. The majority of 
details that the participants reported were accurate. On average, participants wearing a BWC reported approximately 82 accurate details, whereas those without one recalled 77 accurate details. There was no significant difference in accuracy between the two conditions (see Table $1)$.

In order to ensure that those participants who reported very few details were not artificially inflating the accuracy count, a percentage was calculated by dividing the total number of each officers' details by the amount that they reported accurately; this number was then multiplied by 100 . For those who were wearing a BWC, approximately $88.42 \%(S D=3.73)$ of all the details participants reported were accurate. Similarly, $87.79 \%(S D=4.85)$ of the details reported by participants who were not wearing a BWC were accurate. Not surprisingly, an ANCOVA indicated that there was no difference in the percentage of details recalled accurately by those who wore a BWC and those who did not, $F(1,43)=.208, p=.651, \mathrm{n}_{\mathrm{p} 2}=.005$.

To better understand participants' recall, the inaccuracies participants reported were also examined. Inaccuracies were those details that a participant reported incorrectly when compared against ground truth (e.g., the participant reported that the subject wore a black hoodie, when it is, in fact, white). On average, across both conditions, participants recalled approximately six inaccurate details. There was no significant difference between participants who wore a BWC and those without one on the number of inaccuracies recalled (see Table 1). The percentages indicated that, on average, $6.53 \%(S D=2.40)$ of the details reported by participants wearing BWCs were inaccurate, whereas approximately $7.37 \%(S D=3.71)$ of the details reported by participants without a BWC were inaccurate. There was no significant difference in the percentage of inaccurate details recalled by those who wore a BWC and those without one, $F(1$, $43)=.844, p=.363, \mathrm{n}_{\mathrm{p} 2}=.019$. 
A distinction was made between details that were inaccurate, and those that were confabulated. Confabulated details were those that participants fabricated (i.e., they reported something that never actually occurred; consistent with French, Garry, and Loftus [2009] and Schacter, Norman, \& Koutstaal [1998]). For example, if a participant reported that the subject was holding scissors when there is, in actuality, no scissors present, it counted as a confabulated detail. Inaccurate details, on the other hand, were those that were present/truly occurred in the scenario but were recalled in a manner that was factually incorrect (i.e., noting that the radio was playing a country song, when it was actually playing a rap song). On average, across both conditions, participants confabulated approximately 4-5 details. There was no significant difference between the two conditions on the extent to which they confabulated (see Table 1). The percentages indicated that, on average, $5.09 \%(S D=3.47)$ of the details reported by participants wearing BWCs were confabulated. Alternatively, 4.84\% $(S D=3.33)$ of the details reported by participants without BWCs were confabulated. Once again, there was no significant difference between the conditions in regard to the percentage of confabulations made by participants, $F(1,43)=.089, p=.767, \mathrm{n}_{\mathrm{p} 2}=.002$.

Table 1

ANCOVA Examining Differences in the Total Amount of Details Recalled by Officers and the Accuracy of Those Details

\begin{tabular}{llllllr}
\hline & \multicolumn{2}{c}{ Primed Groupa } & \multicolumn{2}{c}{ Control Groupa } & \\
& $M$ & $S D$ & $M$ & $S D$ & $p$ & $\mathrm{n}_{\mathrm{p} 2}$ \\
\hline Number of Details & 93.48 & 32.29 & 89.17 & 31.18 & .700 & .003 \\
Accurate Details & 81.78 & 29.13 & 77.22 & 27.14 & .637 & .005 \\
Inaccurate Details & 6.13 & 3.43 & 6.30 & 3.32 & .812 & .001 \\
Confabulated Details & 4.52 & 3.04 & 4.61 & 3.94 & .949 & .000 \\
\hline
\end{tabular}

Note. Technological errors with the heart rate (HR) monitors resulted in the loss of three participants' data, and one participant's recall was irretrievable when the online use-of-force reporting program closed unexpectedly. Analyses were thus conducted on a total of 46 participants. Above-resting bpm was used as a covariate in every analysis. Reported are the estimated marginal means while controlling for the covariate. a $N=23$. 
Participants' bpm above-resting was used as a covariate in every analysis to control for the effect of stress on recall. As outlined in Table 2, a series of ANCOVAs indicated that participants' bpm above-resting was not a significant covariate in any of the analyses that examined the total amount of details recalled and the accuracy of those details.

Table 2

ANCOVA Examining the Effect of HR on the Total Amount of Details Recalled by Officers and the Accuracy of Those Details

\begin{tabular}{lccccc}
\hline & Mean Square & $d f$ & $F$ & $p$ & $\mathrm{n}_{\mathrm{p} 2}$ \\
\hline Number of Details & 677.85 & 1 & .67 & .418 & .015 \\
Accurate Details & 583.06 & 1 & .73 & .397 & .017 \\
Inaccurate Details & 7.24 & 1 & .63 & .432 & .014 \\
Confabulated Details & .597 & 1 & .05 & .829 & .001 \\
\hline
\end{tabular}

Note. Technological errors with the HR monitors resulted in the loss of three participants' data, and one participant's recall was irretrievable when the online use-of-force reporting program closed unexpectedly. Analyses were thus conducted on a total of 46 participants.

\section{Analyses Examining the Type of Details Recalled}

Recall that details were coded according to whether they related to the context, the subject, or the officer. A series of ANCOVAs were conducted to explore whether officers with BWCs recalled more about certain aspects of the event, and if said recall was more (or less) accurate, compared to those without BWCs. The results revealed that officers recalled the most about the context - the mean number of context-related details was approximately 45 for those wearing a BWC, and 44 for those without a camera. As outlined in Table 3, there was no significant difference between the two conditions on the number of context-related details recalled. The majority of those contextual details were also accurate. Again, there was no significant difference between the accuracy of the details recalled for those with BWCs relative to those without. More specifically, the percentages indicated that approximately $91.05 \%(S D=$ 5.92) of the context-related details recalled by those wearing a BWC were accurate, whereas 
$91.33 \%(S D=5.78)$ were accurate for those without a BWC, $F(1,43)=.010, p=.922, \mathrm{n}_{\mathrm{p} 2}=$ .000 .

In regard to the amount and accuracy of details recalled that were related to the subject, the results showed that, on average, officers recalled over 20 details, and that the majority of those details were accurate. There appeared to be no significant difference in terms of the number of subject-related details recalled between the two conditions, nor on the accuracy of those details. The percentages indicated that $88.56 \%(S D=4.92)$ of the subject-related details recalled by those wearing BWCs were accurate, whereas $84.23 \%(S D=9.93)$ of the details recalled by those without BWCs were accurate, $F(1,43)=3.13, p=.084, \mathrm{n}_{\mathrm{p} 2}=.068 .14$

Lastly, the amount and accuracy of details recalled that were related to the officer were calculated. The results revealed that, on average, participants recalled approximately 25 officerrelated details. There was no significant difference in the amount recalled between those wearing BWCs compared to those without cameras. Of those details, most were accurate, and there was no significant difference in accuracy between the two conditions. For those wearing BWCs, on average, $84.99 \%(S D=8.77)$ of the officer-related details recalled were accurate, while for those without cameras $81.27 \%(S D=13.05)$ of the details noted were accurate, $F(1,43)=1.10, p=$ $.299, \mathrm{n}_{\mathrm{p} 2}=.025$.

Table 3

ANCOVA Examining the Type of Details Recalled by Officers and the Accuracy of Those Details

\begin{tabular}{lcccccc}
\hline & Primed Group & \multicolumn{2}{c}{ Control Group } & & \\
& $M$ & $S D$ & $M$ & $S D$ & $p$ & $\mathrm{n}_{\mathrm{p} 2}$ \\
\hline Number of Context-Related Details & 45.09 & 18.59 & 43.91 & 17.52 & .870 & .001 \\
Accurate Context-Related Details & 39.78 & 16.62 & 39.04 & 15.55 & .910 & .000 \\
Number of Subject-Related Details & 23.17 & 5.01 & 21.70 & 6.48 & .443 & .014 \\
Accurate Subject-Related Details & 20.61 & 4.99 & 18.30 & 5.76 & .186 & .040
\end{tabular}

14 This analysis violated Levene's test of homogeneity of variances. The finding should thus be interpreted with caution. 


\begin{tabular}{lllllll} 
Number of Officer-Related Details & 25.22 & 11.98 & 24.57 & 11.11 & .888 & .000 \\
Accurate Officer-Related Details & 21.43 & 10.28 & 19.87 & 9.64 & .649 & .005 \\
\hline
\end{tabular}

Note. Technological errors with the heart rate (HR) monitors resulted in the loss of three participants' data, and one participant's recall was irretrievable when the online use-of-force reporting program closed unexpectedly. Analyses were thus conducted on a total of 46 participants. Above-resting bpm was used as a covariate in every analysis. Reported are the estimated marginal means while controlling for the covariate.

a $N=23$.

As outlined in Table 4, a series of ANCOVAs demonstrated that participants' bpm above-resting was not a significant covariate in any of the analyses that examined the type of details recalled, nor the accuracy of those details.

Table 4

ANCOVA Examining the Effect of HR on the Type of Details Recalled by Officers and the Accuracy of Those Details

\begin{tabular}{lccccc}
\hline & Mean Square & $d f$ & $F$ & $p$ & $\mathrm{n}_{\mathrm{p} 2}$ \\
\hline Number of Context-Related Details & 135.09 & 1 & .41 & .526 & .009 \\
Accurate Context-Related Details & 62.62 & 1 & .24 & .628 & .005 \\
Number of Subject-Related Details & 38.40 & 1 & 1.15 & .290 & .026 \\
Accurate Subject-Related Details & 58.65 & 1 & 2.07 & .157 & .046 \\
Number of Officer-Related Details & 44.82 & 1 & .33 & .568 & .008 \\
Accurate Officer-Related Details & 71.76 & 1 & .72 & .401 & .016 \\
\hline
\end{tabular}

Note. Technological errors with the HR monitors resulted in the loss of three participants' data, and one participant's recall was irretrievable when the online use-of-force reporting program closed unexpectedly. Analyses were thus conducted on a total of 46 participants.

\section{Discussion}

As far as we are aware, the current study was the first to examine the phenomena of cognitive offloading in a policing context. The findings suggest that unlike other contexts (e.g., Henkel, 2014; Soares \& Storm, 2018), officers do not appear to relinquish their cognitions to a camera. It was hypothesized that officers who were led to believe that they would have the opportunity to view their BWC footage following their involvement in the simulated use-ofevent would report significantly fewer details about the event, and that those details would be less accurate, compared to those not wearing a camera (and aware that they would not have the opportunity to view any footage prior to completing a statement about the event). However, the 
results revealed no significant differences between the two groups. Moreover, the majority of the details $(\approx 80 \%)$ were accurate, regardless of what condition participants were assigned.

Most of the details that participants recalled were in relation to the context in which the event took place (e.g., items they noticed in the residence, the layout of the building, and statements the witness made). Participants recalled a lesser amount of details about the subject (i.e., the main perpetrator's appearance, behaviour, and statements he made) and about their own behaviour. Although they were most accurate about the context, the majority of the details recalled about the subject and themselves were also accurate. The null findings seemed to hold even after controlling for the effect of stress on recall. Consistent with the few experimental studies that have examined memory in a use-of-force context (e.g., Hope, Lewinski, Dixon, Blocksidge, \& Gabbert, 2012; Hope et al., 2016; Morgan et al., 2006) it had been hypothesized that stress elicited during the scenario would impair recall. While we were able to elicit a significant amount of stress in participants (averaging a maximum HR of $149 \mathrm{bpm}$ ), stress (as measured via HR) was not a significant covariate in any of the analyses.

\section{Failure to Offload}

The findings in the current study support recent work conducted by Marsh and Rajaram (2019), although they are at odds with much of the research to date (e.g., Henkel, 2014; Risko \& Gilbert, 2016; Sparrow et al., 2011). Marsh and Rajaram's (2019) online study did not find a significant difference in recall for statements participants were told would either be saved or deleted on their computers. They suggested that their differential findings could be the result of a pervasive belief that “...things cannot ever be completely purged from the internet” (Marsh \& Rajaram, 2019, p. 6). This may have made the "delete" manipulation implausible. Likewise, the priming in the current experiment may not have been entirely believable. BWCs remain a 
relatively new form of technology that officers might still distrust. There are various well-known issues related to quality for example, that can make the footage unusable (if, for example, something is blocking the lens and/or the camera angle fails to catch peripheral details; Blaskovits et al., 2017; Remsberg, 2016). If participants assumed the BWC would be unreliable, then it would make sense that they would refuse to offload to it.

Indeed, some research indicates that officers may be cynical toward BWC technology (e.g., Gaub, Choate, Todak, Katz, \& White, 2016; Huff, Katz, \& Webb, 2018; Tankebe \& Ariel, 2016). For example, officers appear to be aware that BWCs are likely to have perceptual issues that fail to provide a complete understanding of an event (Pelfrey \& Keener, 2016). They have also voiced concerns about various logistical problems with BWCs, such as knowing when they are turned on and what to do should they have connection issues. It is thus possible that officers may defer to their own memory bank, rather than rely on a potentially fickle camera. Officers' beliefs about the utility of the BWC footage in relation to their own meta-cognitive abilities may therefore be necessary in future research.

Relatedly, the organization that the current sample of officers were recruited from are not issued BWCs for operational use. Therefore, they had little-to-no personal experience in regard to the camera's efficacy and never actually turned it on themselves during the study (i.e., the researcher attached each camera and turned it on). The limited deployment in their own agency may thus have led participants to be cautious about the reliability of the technology. Moreover, the lack of familiarity with BWCs may have made it difficult for officers to offload to them. This is a particularly likely explanation if offloading is not an automatic, but rather a learned process. Officers who are unaccustomed to BWCs may simply forget they have it on initially; they would thus not be habitually inclined to offload onto them. Samples of officers who regularly use 
BWCs should therefore be examined, as BWC-related impairment associated with offloading may be more likely with these individuals.

Alternatively, the lack of an offloading effect may be explained, in large part, by the sample examined. Police officers are trained in ways that distinguish them from the wider population that have been participants in previous offloading research. For example, most officers are required to provide detailed notes after use-of-force incidents with the public that may serve as an "aide memoire" for court purposes. Their familiarity with legally articulating their actions could result in an increase in the amount of information reported, compared to others without similar experience. Moreover, many agencies train their officers on indicators of risk and/or potential signs of danger (e.g., Kahn, McMahon, \& Stewart, 2018). Kahn and colleagues (2018) note that such training ensures officers are sensitive to gestures, language, and attire that could indicate a situation might become threatening. It is possible that this type of training may mitigate cognitive offloading to some extent, since it encourages officers to attend to and encode a variety of cues in an environment. Officers, unlike most members of the public, are taught to be highly vigilant, consolidate the information they observe in a scene, and act accordingly (regardless of camera presence); in fact, they are required to, given their position in society (as members of authority that can enforce the law) and the critical lens used to examine their decisions. Future research utilizing civilian populations could provide insight into the extent to which officers are resilient to this type of potential impairment.

However, it is also possible that the use-of-force report itself is not an ideal means of capturing offloading in officers. The report might capture those details that officers are trained to encode and recall, rather than those that might be offloaded. That is, if officers are accustomed to encoding information relevant to what they will be required to report on and tend to offload 
extraneous information (i.e., that which is not necessary to be reported on), then it is possible that the lack of cognitive offloading was actually a product of selective reporting. For example, during a stressful encounter, an officer may offload the pictures/posters that they notice on the wall of a potential assailant's home to their BWC. However, these types of details tend not to be reported in use-of-force reports, as they often do not impact an officer's risk assessment process. Therefore, while this detail might be offloaded, examining the use-of-force report would not provide any indication of this effect. Alternative methods of accessing officers' memories for police-public interactions is necessary.

Relatedly, the participants in the current study were exposed to very different type of information than what has been examined in other relevant research to date (which is typically quite trivial information). Prior studies have looked at recall for objects in a museum (Henkel, 2014), pictures in a studio (Soares \& Storm, 2018), and arbitrary information online (Sparrow et al., 2011). Risko and Dunn (2015), for instance, found that individuals offload the rotation of words and array frames if given the opportunity, even when there is no real performance benefit from doing so. Considering individuals' preference to offload even simple information, it has been argued that they will be even more likely to offload when their mental capacities are strained (i.e., when there is a lot of information to retain and/or there are interruptions during encoding; Gilbert, 2015; Risko \& Gilbert, 2016). However, previous findings do not account for information that might have personal implications for the participant. Offloading photographs, especially those exchanged via social media platforms like Snapchat are so transient, that they are arguably inconsequential (recall Soares and Storm's [2018] research). Whereas offloading vital information, on the other hand, may be a risky cognitive short-cut. The current findings ask 
us to consider the type of information we offload and whether the effect could be assuaged for that which is personally relevant and/or of significant value.

Indeed, the current findings suggest that information which is salient to personal and public safety for example, may be prioritized (despite having a camera capturing it). While the scenario participants experienced was obviously fabricated, it closely mimics the type of stress officers can expect to experience in the field (Andersen et al., 2016). In fact, scenario-based training has been revered as the gold standard in policing because it can be so realistic (e.g., Andersen et al., 2016; Fletcher, 2009; Oudejans, 2008). When exposed to high fidelity scenarios, officers are motivated to perform as they would in real life and seriously consider the decisions they make in the scenario as they could resemble those made in similar circumstances on-the-job (Staller \& Zaiser, 2015).

Interestingly, while the current findings are contrary to those reported by Soares and Storm (2018), they may lend credence to their argument that attentional disengagement might better explain the photo-taking impairment effect. Recall in their study, that memory was impaired when participants took a picture, regardless of whether that photo was saved or deleted. Because offloading depends on one being able to rely on an external source to "remember for them," Soares and Storm suggested that individuals may not be offloading when they use cameras. Rather, their attention might be compromised during the act of photo-taking itself, resulting in disrupted encoding and a loss of information. Unlike in Soares and Storms' study, officers did not need to manipulate the BWC in any way during the current study. In fact, the camera was turned on for them and left to record throughout the entire experiment. Therefore, there was arguably less chance that participants would experience attentional disengagement, and 
as such, no impairment was observed. Camera and/or video manipulation may thus play a role in the photo-taking impairment effect and in intention offloading more broadly.

Lastly, it is interesting to note that while not significant, the results suggested that the officers wearing cameras actually recalled slightly more than those without a camera (i.e., the findings trended in the opposite direction than what was hypothesized). It is thus possible that the cameras actually acted as a cue to motivate participants, subconsciously or not, to ensure their recall was exceptional so as to avoid any potential issues that could arise if their recall was inconsistent with the cameras. Video and/or photographic evidence in particular, tends to be heavily relied on in court (Dawes et al, 2015; Mezey, 2013; Mnookin, 1998); often, it is considered to portray the objective truth of an event, despite its numerous issues (e.g., perspective, frame rate, and the quality of footage can all impact how an event is portrayed on screen; Boivin, Gendron, Faubert, \& Poulin, 2017; Dawes et al., 2015). Therefore, it is important to consider the contextual factors (e.g., personal and/or political pressure) at play in this research and that conducted prospectively, and their potential impact on offloading.

\section{The Effect of Stress on Recall}

The scenario, combined with the technological additions (e.g., the StressVestTM, inert intervention options, and scent training system), appeared to elicit an appreciable amount of stress in the current sample of participants. Their maximum HR during the scenario averaged 149 bpm, which is comparable to that elicited in other police research (e.g., Andersen \& Gustafsberg, 2016; Andersen et al., 2016; Federal Law Enforcement Training Center [FLETC], 2004). For example, in FLETC's (2004) study examining the effect of stress on cognition and performance during a shoot-out exercise, officers' average maximum HR reached nearly 140 bpm. Likewise, participants in Hope and colleagues' (2012) study displayed HRs averaging 
between 159-163 bpm. Moreover, participants' average increase from their resting rate was nearly 81 bpm - well above that reported in studies like Anderson and colleagues' (2002) and Baldwin et al.'s (2019), which captured officers' HR while on duty.

However, contrary to other studies examining the effect of stress on recall (e.g., Hope et al., 2012; Hope et al., 2016; Morgan et al., 2006), the variability in stress (i.e., bpm aboveresting) did not affect recall. Research like Hope and colleagues' (2016) study found that stress mediated the effect of an officer's role (either as an active participant or as a witness) on recall. Those who were actively engaged in the scenario reported significantly fewer details about the scenario compared to witnesses, and this was explained, in part, by their higher levels of stress.

While it is unclear why the current findings did not replicate prior research, it could be that seemingly small differences in the amount of stress elicited (measured via HR increases) result in differential outcomes. Maladaptive stress arousal has been shown to disrupt cognitive functions (e.g., attention, perception; Driskell \& Salas, 1996; Vickers, 2007), contributing to inattentional blindness (Eysenck, Derakshan, Santos, \& Calvo, 2007; Nieuwenhuys \& Oudejans, 2011) and perceptual narrowing (Honig \& Lewinski, 2008; Vickers, 2007). Said deficits may result in individuals missing important details and being unable to recall various aspects of an event (Easterbrook, 1959; Yuille, Davies, Gibling, Marxsen, \& Porter, 1994; Hope et al., 2016). However, not all stress is maladaptive - indeed, the stress response is designed to improve many functions, thereby ensuring survival (Fenici, Brisinda, \& Sorbo, 2011; Tsigos \& Chrousos, 2002).

Under high levels of stress one can experience improved sensory awareness (Siddle, 1995), performance (e.g., see Andersen \& Gustafsberg, 2016; Andersen et al., 2016), and memory consolidation (e.g., McGaugh, 2000, 2013; Payne, Jackson, Ryan, Hoscheidt, Jacobs, \& 
Nadel, 2006; Hope, 2016). It is not until stress becomes chronic or maladaptive that hippocampus function is disrupted, and cognitive impairments appear (e.g., Davis \& Loftus, 2009; Hope, 2016; Shackman et al., 2006). Thus, while there was a significant increase in HR during the scenario (relative to officers' resting rate), the surge may actually have put participants in the optimal range; allowing them to narrow their attention on important threatrelated stimuli, ensuring encoding (and ultimately retrieval) remained unaffected. Moreover, recent research also suggests that stress may have less of an effect on cognition and movement that is rehearsed and/or automated (Arble, Daugherty, \& Arnetz, 2019; Renden, Savelsbergh, \& Oudejans, 2017; Vickers \& Lewinski, 2012). Given that officers are repeatedly exposed to certain skill sets (e.g., drawing a firearm) in training and on-the-job, they may recover quickly from stress. This could help them maintain a high level of cognitive functioning and performance in the midst of a critical incident.

Alternatively, it is possible that differences in coding (i.e., into context, subject, and officer-related themes) may distinguish the findings from prior research. For example, others that have educed similar levels of stress in their participants, but observed impairments in recall (e.g., Hope et al., 2016; Morgan et al., 2006), did not categorize officers' statements in the same way we did. Moreover, due to the complexity of the scenario, it was impossible to code for omissions in the current study (i.e., everything an officer could have seen but failed to recall in their statement). As was apparent from Shields and colleagues (2017) meta-analysis, slight changes in methodology can reveal differences in episodic memory. Additional, fine-grained analyses of the type of details officers recalled (e.g., divided into information relevant to verbal dialogue versus critical details [e.g., hidden hands, number of shots fired]; similar to Hartman, O’Neill, O’Neill, and Lewinski [2017]) may provide greater insight into the findings. Nevertheless, the current 
results suggest that individual variability in stress, as measured by HR, may not affect recall; but rather that officer memory may remain relatively well preserved despite the impact of stress, at least for those details that are recalled.

\section{Limitations and Future Directions}

Although the average maximum HR and average bpm above-resting during the scenario were comparable to other relevant research (e.g., Andersen \& Gustafsberg, 2016; FLETC, 2004; Hope et al., 2012, 2016), it is difficult to mimic the sort of stress officers experience when exposed to a true life or death event. Mason (1968) argues that conditions which involve: (1) novelty, (2) unpredictability, (3) loss of control, and (4) threat to one's ego, tend to induce a stress response. The scenario in the current study was designed to incorporate these aspects in various ways and fully immerse participants in the event (i.e., they were not passively viewing objects and/or photos; Henkel, 2014; Soares \& Storm, 2018). The inclusion of multiple actors and the presence of weapons were included to enhance realism; indeed, the scenario was designed to mimic the sorts of conditions that might overload arousal in a naturalistic setting and included time pressure, task load, threat, novelty, coordination demands, performance pressure, and noise; Driskell \& Salas, 1996; Wollert et al., 2011). It also ensured that there was enough happening in the scenario that officer recall could be tested. The methodological differences between offloading studies make comparisons with other research challenging and does not guarantee that the scenario elicited stress that would promote maladaptive functioning. 15 However, it adds to the literature by providing a more applied examination of offloading than has

15 While we acknowledge that there is a necessary difference between a simulated scenario and a true life-or-death event, many of the subject matter experts and use-of-force trainers involved in the current scenario reported that it was one of the most realistic and stressful scenarios they had ever encountered. Indeed, high-fidelity scenario-based training appears able to replicate various physiological aspects (e.g., HR) observed in real-life, high-stress encounters (e.g., Armstrong, Clare, \& Plecas, 2014). The HR acquired in the current study is, in fact, comparable to those recorded in actual police encounters (Andersen et al., 2016, Anderson et al., 2002). 
been conducted to date. Should future research utilize more observational methodology (e.g., onshift HR tracking), greater external validity may be achieved, thereby corroborating relations between stress and recall.

HR was used in the current study as a proxy measure for stress and has been used in prior studies examining the effect of stress on police officers (e.g., Andersen \& Gustafsberg, 2016; Andersen et al., 2016; Arble et al., 2019). While HR is argued to be a robust, ecologically valid, objective measure of stress reactivity (Vrijkotte et al., 2000), it is not an absolute measure of an individual's stress (Arble et al., 2019; Brisinda, Fioravanti, Sorbo, Venuti, \& Fenici, 2015). The collection of additional biomarkers of stress, such as cortisol, were not feasible in the current study (given how the officers were responding to the scenario). However, they would provide additional evidence for the impact of stress on episodic memory processes, and are encouraged in future studies with police officers. Likewise, the equipment that was used to measure HR, while allowing for movement, are not as accurate as hospital-grade ECG testing. The findings must thus be interpreted in light of these limitations.

There are also some drawbacks related to when officers were asked to complete the useof-force report. Similar to other memory-related research, all participants in the current study were asked to complete a filler task (a series of questionnaires) prior to providing their statement. While this sort of methodology whereby participants are exposed to some distraction task prior to retrieval is relatively common, it could impact recall (e.g., see Shields et al., 2017). Moreover, certain policies (depending on the agency) may dictate that officers involved in real-life use-offorce events not report anything for a specified period of time (e.g., 24-48 hours and/or after a sleep cycle in an attempt to enhance memory consolidation) and/or after some investigative procedures have occurred (e.g., Grady, Butler, \& Loftus, 2016; Seattle Police Department, 2019; 
Siegel, 2010). The lack of a more realistic time delay in the current study may thus affect the generalizability of the study. Therefore, future research exploring officer recall after various postponements is encouraged.

As noted, another limitation is that the organization that the officers were recruited from are not issued BWCs for operational use. As such, they were arguably accustomed to reporting without the aid of seeing their footage. Although the primed group of participants were explicitly forewarned that they would see their footage while being equipped with a BWC, such information may have been dismissed and/or forgotten (particularly once they were focused on the scenario). It is possible that officers who are used to having footage to look back on would be more apt to offload. An effect might thus appear in future research, when BWCs are more commonplace (especially in Canada, where BWC use remains limited; e.g., Bud, 2016). Similar research to that presented here, especially with a larger sample of officers who are more familiar with BWCs or have experience using them, is encouraged.

Lastly, it is important to note that all officers, regardless of condition, wore an eyetracker and were recorded by several cameras mounted around the scenario room. The footage from these cameras was used for coding purposes (i.e., to establish ground truth). Therefore, even officers without BWCs were aware (via the consent form) that they were being recorded in other ways. It is possible then, that the lack of a significant difference between the two groups was because officers in the control condition offloaded to the stationary cameras (or eyetracker). However, only officers in the BWC condition were explicitly primed that they would have the opportunity to see their footage before reporting. This priming hopefully mitigated the potential effect that the other cameras may have had on the manipulation. The stationary cameras were also placed inconspicuously around the scenario room as not to draw officers' attention to them. 
Moreover, it may be argued that these additional cameras enhanced the ecological validity of the research since bystander's often have camera-phones and surveillance videos often capture police-public interactions. It is thus important to test the effect of offloading while other recording devices (beyond BWCs) are present.

\section{Conclusion}

The current research aimed to investigate the impact of BWCs - a rapidly expanding technology - on human processing under conditions of stress. It is the first known study to examine the phenomena of intention offloading in an applied context, with a sample of police officers under stress. It appears that officers in the current sample do not (yet) use BWCs as tools to offload. BWCs may be unique in some respects, reducing the likelihood that they will be used to house an officers' memory; or perhaps law enforcement training or officers' legal requirements to report their behaviour mitigates tendencies observed in other contexts (e.g., Henkel, 2014; Risko \& Gilbert, 2016; Soares \& Storm, 2018). This lack of offloading may mean that officers are not "freeing up space" for other cognitions that could allow them to engage in better communication, decision-making, problem-solving, and motor skills (Risko \& Gilbert, 2016; Storm \& Stone, 2015). However, this also means that officers, regardless of the camera, are reliant on themselves to encode and retain event details; which is good news if their camera were to fail. Should these findings be replicated, concern among law enforcement agencies that BWC adoption could mean a reduction in accurate recall, may be alleviated. 


\section{References}

Aguinis, H., Cascio, W. F., \& Ramani, R. S. (2017). Science's reproducibility and replicability crisis: International business is not immune. Journal of International Business Studies, $48(6), 653-663$.

Alpert, G. P., \& Smith, M. R. (1999). Police use-of-force data: Where we are and where we should be going. Police Quarterly, 2(1), 57-78.

Andersen, J. P., \& Gustafsberg, H. (2016). A training method to improve police use of force decision making: A randomized controlled trial. Sage Open, 6(2), 1-13.

Andersen, J. P., Pitel, M., Weerasinghe, A., \& Papazoglou, K. (2016). Highly realistic scenariobased training simulates the psychophysiology of real-world use of force encounters: Implications for improved police officer performance. Journal of Law Enforcement, 5(4), $1-13$.

Anderson, G. S., Litzenberger, R., \& Plecas, D. (2002). Physical evidence of police officer stress. Policing: An International Journal of Police Strategies \& Management, 25(2), $399-420$.

Arbel, I., Kadar, T., Silbermann, M., \& Levy, A. (1994). The effects of long-term corticosterone administration on hippocampal morphology and cognitive performance of middle-aged rats. Brain Research, 657(1-2), 227-235.

Arble, E. P., Daugherty, A. M., \& Arnetz, B. B. (2019). Differential effects of physiological arousal following acute stress on police officer performance in a simulated critical incident. Frontiers in Psychology, 10(759), 1-11

Armstrong, J., Clare, J., \& Plecas, D. (2014). Monitoring the impact of scenario-based use-offorce simulations on police heart rate: Evaluating the Royal Canadian Mounted Police 
Skills Refresher Program. Western Criminology Review 15(1), 51-59

Artwohl, A. (2002). Perceptual and memory distortion during officer-involved shootings. FBI Law Enforcement Bulletin, 71, 18-24.

Aschermann, E., Mantwill, M., \& Köhnken, G. (1991). An independent replication of the effectiveness of the cognitive interview. Applied Cognitive Psychology, 5(6), 489-495.

Bachevalier, J., \& Meunier, M. (1996). Cerebral ischemia: Are the memory deficits associated with hippocampal cell loss? Hippocampus, 6(5), 553-560.

Baddeley, A. D. (1983). Working memory. Philosophical Transactions of the Royal Society of London. Series B, Biological Sciences, 302(1110), 311-324.

Baldwin, S., Bennell, C., Andersen, J., Semple, T., \& Jenkins, B. (2019). Stress-activity mapping: Physiological responses during general duty police encounters. Frontiers in Psychology, 10, 1-17.

Baldwin, S., Hall, C., Blaskovits, B., Bennell, C., Lawrence, C., \& Semple, T. (2018). Excited delirium syndrome (ExDS): Situational factors and risks to officer safety in non-fatal use of force encounters. International Journal of Law and Psychiatry, 60, 26-34.

Barton, J., Vrij, A., \& Bull, R. (2000). High speed driving: Police use of lethal force during simulated incidents. Legal and Criminological Psychology, 5(1), 107-121.

Bjork, R. A., \& Woodward, A. E. (1973). Directed forgetting of individual words in free recall. Journal of Experimental Psychology, 99(1), 22-27.

Blaskovits, B., McGale, H., \& Bennell, C. (September, 2017). Everything is not as it appears: Examining the quality of officer-involved body worn camera (BWC) footage. Paper presented at the annual meeting of the Society for Police and Criminal Psychology, San Diego, CA. 
Blumenfeld, R. S., \& Ranganath, C. (2007). Prefrontal cortex and long-term memory encoding: An integrative review of findings from neuropsychology and neuroimaging. The Neuroscientist, 13(3), 280-291.

Bobak, C. A., Barr, P. J., \& O’Malley, A. J. (2018). Estimation of an inter-rater intra-class correlation coefficient that overcomes common assumption violations in the assessment of health measurement scales. BMC Medical Research Methodology, 18(93), 1-11.

Boivin, R., Gendron, A., Faubert, C., \& Poulin, B. (2017). The body-worn camera perspective bias. Journal of Experimental Criminology, 13(1), 125-142.

Bremner, J. D. (1999). Does stress damage the brain? Biological Psychiatry, 45(7), 797-805.

Brisinda, D., Fioravanti, F., Sorbo, A. R., Venuti, A., \& Fenici, R. (2015). Psychophysiological assessment of acute stress induced by high-pressure law-enforcement driving: A pilot study. Psychology and Social Behavior Research, 2, 36-50.

Bud, T. K. (2016). The rise and risks of police body-worn cameras in Canada. Surveillance \& Society, 14(1), 117-121.

Burke, R., Waters, J. A., \& Ussery, W. (2007). Police stress: History, contributing factors, symptoms, and interventions. Policing: An international Journal of Police Strategies \& Management.

Butler, C., \& Hall, C. (2008). Public-police interaction and its relation to arrest and use of force by police and resulting injuries to subjects and officers: A description of risk in one major Canadian urban city. Law Enforcement Executive Forum, 8(6), 141-157.

Carr, N. (2008, July/August). Is Google making us stupid? What the internet is doing to our 
brains. The Atlantic. Retrieved from

https://www.theatlantic.com/magazine/archive/2008/07/is-google-making-usstupid/306868/

Conor, P. (2018, March 28). Police resources in Canada, 2017. Statistics Canada. Retrieved from https://www150.statcan.gc.ca/n1/pub/85-002-x/2018001/article/54912-eng.htm

Data USA. (2019). Police officers. Retrieved from https://datausa.io/profile/soc/policeofficers\#growth

Davis, D., \& Loftus, E. F. (2009). Expectancies, emotion, and memory reports for visual events. In J. R. Brockmole (Ed.), The visual world in memory (pp. 178-214). East Sussex, UK: Psychology Press.

Dawes, D. M., Ho, J. D., Vincent, A. S., Nystrom, P. C., Moore, J. C., Steinberg, L. W., ... \& Miner, J. R. (2014). The neurocognitive effects of simulated use-of-force scenarios. Forensic Science, Medicine, and Pathology, 10(1), 9-17.

Dawes, D., Heegaard, W., Brave, M., Paetow, G., Weston, B., \& Ho, J. (2015). Body-worn cameras improve law enforcement officer report writing accuracy. Journal of Law Enforcement, 4(6), 1-21.

Dickerson, S. S., \& Kemeny, M. E. (2004). Acute stressors and cortisol responses: A theoretical integration and synthesis of laboratory research. Psychological Bulletin, 130(3), 355-391.

Driskell, J. E., \& Salas, E. (Eds.). (1996). Series in applied psychology: Stress and human performance. Hillsdale, NJ: Lawrence Erlbaum Associates, Inc.

Dusek, J. A., \& Eichenbaum, H. (1997). The hippocampus and memory for orderly stimulus relations. Proceedings of the National Academy of Sciences, 94(13), 7109-7114.

Easterbrook, J. A. (1959). The effect of emotion on cue utilization and the organization of 
behavior. Psychological Review, 66(3), 183-201.

Elo, S., \& Kyngäs, H. (2008). The qualitative content analysis process. Journal of Advanced Nursing, 62(1), 107-115.

Eysenck, M. W., Derakshan, N., Santos, R., \& Calvo, M. G. (2007). Anxiety and cognitive performance: Attentional control theory. Emotion, 7(2), 336-353.

Federal Law Enforcement Training Center. (2004). Survival scores research project. Homeland Security.

Fenici, R., Brisinda, D., \& Sorbo, A. R. (2011). Methods for real-time assessment of operational stress during realistic police tactical training. In J. Kitaeff (Ed.). Series in applied psychology: Handbook of police psychology (pp. 95-319). New York, NY:

Routledge/Taylor \& Francis Group.

Field, A. (2009). Discovering statistics using SPSS (3rd ed). London, England: Sage Publications, Ltd.

Fisher, R. P., Geiselman, R. E., \& Amador, M. (1989). Field test of the Cognitive Interview: Enhancing the recollection of actual victims and witnesses of crime. Journal of Applied Psychology, 74(5), 722-727.

Fletcher, J. D. (2009). Education and training technology in the military. Science, 323(5910), 7275.

Fortin, N. J., Agster, K. L., \& Eichenbaum, H. B. (2002). Critical role of the hippocampus in memory for sequences of events. Nature Neuroscience, 5(5), 458-462.

French, L., Garry, M., \& Loftus, E. (2009). False memories: A kind of confabulation in non- 
clinical subjects. In W. Hirstein (Ed.), Confabulation: Views from neuroscience, psychiatry, psychology, and philosophy (pp. 33-62). Oxford, UK: Oxford University Press.

Gagnon, S. A., \& Wagner, A. D. (2016). Acute stress and episodic memory retrieval: Neurobiological mechanisms and behavioral consequences. Annals of the New York Academy of Sciences, 1369(1), 55-75.

Garner, J. H., Hickman, M. J., Malega, R. W., \& Maxwell, C. D. (2018). Progress toward national estimates of police use of force. PloS one, 13(2), e0192932.

Gaub, J. E., Choate, D. E., Todak, N., Katz, C. M., \& White, M. D. (2016). Officer perceptions of body-worn cameras before and after deployment: A study of three departments. Police Quarterly, 19(3), 275-302.

Geiselman, R. E. (2010). Rest and eyewitness memory recall. American Journal of Forensic Psychology, 28(2), 65-69.

George, D., \& Mallery, P. (1995). SPSS/PC+ step by step: A simple guide and reference. Belmont, CA: Wadsworth Publishing Company.

Ghosh, D., \& Vogt, A. (2012). Outliers: An evaluation of methodologies. Joint Statistical Meetings, Selection on Survey Research Methods, 3455-3460.

Gilbert, S. J. (2015). Strategic offloading of delayed intentions into the external environment. The Quarterly Journal of Experimental Psychology, 68(5), 971-992.

Giles, D., Draper, N., \& Neil, W. (2016). Validity of the Polar V800 heart rate monitor to measure RR intervals at rest. European Journal of Applied Physiology, 116(3), 563-571.

Golding, J. M., \& Macleod, C. M. (Eds.). (1998). Intentional forgetting: Interdisciplinary approaches. Mahwah, NJ: Erlbaum. 
Grady, R. H., Butler, B. J., \& Loftus, E. F. (2016). What should happen after an officer-involved shooting? Memory concerns in police reporting procedures. Journal of Applied Research in Memory and Cognition, 5(3), 246-251.

Grossman, D., \& Christensen, L. W. (2007). On combat: The psychology and physiology of deadly conflict in war and in peace. Belleville, IL: PPCT Research Publications.

Hall, C., Votova, K., \& Wood, D. (2013). Prospective analysis of police use of force in four Canadian cities: Nature of events and their outcomes. Defence Research and Development Canada. Retrieved from http://cradpdf.drdcrddc.gc.ca/PDFS/unc127/p537864_A1b.pdf

Hallgren, K. A. (2012). Computing inter-rater reliability for observational data: An overview and tutorial. Tutorials in Quantitative Methods for Psychology, 8(1), 23-34.

Heathers, J., \& Goodwin, M. (2017). Dead science in live psychology: A case study from heart rate variability (HRV). doi: 10.31234/osf.io/637ym

Henkel, L. A. (2014). Point-and-shoot memories: The influence of taking photos on memory for a museum tour. Psychological Science, 25(2), 396-402.

Honig, A., \& Lewinski, W. J. (2008). A survey of the research on human factors related to lethal force encounters: Implications for law enforcement training, tactics, and testimony. Law Enforcement Executive Forum, 8(4), 129-152.

Hope, L., Blocksidge, D., Gabbert, F., Sauer, J. D., Lewinski, W., Mirashi, A., \& Atuk, E. (2016). Memory and the operational witness: Police officer recall of firearms encounters as a function of active response role. Law and Human Behavior, 40(1), 23-35.

Hope, L., Lewinski, W., Dixon, J., Blocksidge, D., \& Gabbert, F. (2012). Witnesses in action: 
The effect of physical exertion on recall and recognition. Psychological Science, 23(4), 386-390.

Huff, J., Katz, C. M., \& Webb, V. J. (2018). Understanding police officer resistance to bodyworn cameras. Policing: An International Journal, 41(4), 482-495.

Jennings, W. G., Fridell, L. A., \& Lynch, M. D. (2014). Cops and cameras: Officer perceptions of the use of body-worn cameras in law enforcement. Journal of Criminal Justice, 42(6), $549-556$.

Johnson, B. R. (2008). Crucial elements of police firearms training. Flushing, NY: Looseleaf Law Publications.

Kahn, K. B., McMahon, J. M., \& Stewart, G. (2018). Misinterpreting danger? Stereotype threat, pre-attack indicators, and police-citizen interactions. Journal of Police and Criminal Psychology, 33(1), 45-54.

Kayihan, G., Ersöz, G., Özkan, A., \& Koz, M. (2013). Relationship between efficiency of pistol shooting and selected physical-physiological parameters of police. Policing: An International Journal of Police Strategies \& Management, 36(4), 819-832.

Kline, R. B. (1998). Principles and practice of structural equation modeling. New York, NY: Guilford.

Kline, R. B. (2005). Principles and practice of structural equation modeling (2nd ed.). New York, NY: Guilford.

Koo, T. K., \& Li, M. Y. (2016). A guideline of selecting and reporting intraclass correlation coefficients for reliability research. Journal of Chiropractic Medicine, 15(2), 155-163.

Lacy, J. W., \& Stark, C. E. (2013). The neuroscience of memory: Implications for the courtroom. Nature Reviews Neuroscience, 14(9), 649-658. 
Laming, E. (2019). Police use of body worn cameras. Police Practice and Research, 20(2), 201216.

Laskowski, E. (2018). What's a normal resting heart rate? Mayo Clinic. Retrieved from https://www.mayoclinic.org/healthy-lifestyle/fitness/expert-answers/heart-rate/faq20057979

Levy, B. J., \& Anderson, M. C. (2002). Inhibitory processes and the control of memory retrieval. Trends in Cognitive Sciences, 6(7), 299-305.

Lewinski, B. (2008). The attention study: A study on the presence of selective attention in firearms officers. Law Enforcement Executive Forum, 8(6), 107-139.

Liao, H., Li, Y., \& Brooks, G. (2016). Outlier impact and accommodation methods: Multiple comparisons of Type I error rates. Journal of Modern Applied Statistical Methods, 15(1).

MacDonald, J. M., Kaminski, R. J., \& Smith, M. R. (2009). The effect of less-lethal weapons on injuries in police use-of-force events. American Journal of Public Health, 99(12), 22682274.

Marsh, E. J., \& Rajaram, S. (2019). The digital expansion of the mind: Implications of internet usage for memory and cognition. Journal of Applied Research in Memory and Cognition, $8(1), 1-14$.

Mason, J. W. (1968). A review of psychoendocrine research on the pituitary-adrenal cortical system. Psychosomatic Medicine, 30(5), 576-607.

McCraty, R., \& Atkinson, M. (2012). Resilience training program reduces physiological and psychological stress in police officers. Global Advances in Health and Medicine, 1(5), 44-66.

McGaugh, J. L. (2000). Memory-A century of consolidation. Science, 287(5451), 248-251. 
McGaugh, J. L. (2013). Making lasting memories: Remembering the significant. Proceedings of the National Academy of Sciences, 110(Supplement 2), 10402-10407.

McHugh, M. L. (2012). Interrater reliability: The kappa statistic. Biochemia Medica, 22(3), 276282.

Memon, A., \& Bull, R. (1991). The cognitive interview: Its origins, empirical support, evaluation and practical implications. Journal of Community \& Applied Social Psychology, 1(4), 291-307.

Mezey, N. (2013). The image cannot speak for itself: Film, summary judgment, and visual literacy. Valparaiso University Law Review, 48(1), 1-39.

Mnookin, J. L. (1998). The image of truth: Photographic evidence and the power of analogy. Yale Journal of Law and the Humanities, 10(1), 1-74.

Morgan III, C. A., Doran, A., Steffian, G., Hazlett, G., \& Southwick, S. M. (2006). Stressinduced deficits in working memory and visuo-constructive abilities in special operations soldiers. Biological Psychiatry, 60(7), 722-729.

Nieuwenhuys, A., \& Oudejans, R. R. (2011). Training with anxiety: Short-and long-term effects on police officers' shooting behavior under pressure. Cognitive Processing, 12(3), 277288.

Office of the Privacy Commissioner of Canada. (2015). Guidance for the use of body-worn cameras by law enforcement authorities. Retrieved from https://www.priv.gc.ca/en/privacy-topics/surveillance/police-and-publicsafety/gd_bwc_201502/

Oudejans, R. R. D. (2008). Reality-based practice under pressure improves handgun shooting performance of police officers. Ergonomics, 51(3), 261-273. 
Parak, J., \& Korhonen, I. (2013). Accuracy of Firstbeat Bodyguard 2 beat-to-beat heart rate monitor, Whitepaper, 6-8.

Payne, J.D., Jackson, J.D., Ryan, L., Hoscheidt, S., Jacobs, W.J. \& Nadel, L. (2006). The impact of stress on neutral and emotional aspects of episodic memory. Memory, 14(1), 1-16.

Pelfrey Jr, W. V., \& Keener, S. (2016). Police body worn cameras: A mixed method approach assessing perceptions of efficacy. Policing: An International Journal of Police Strategies \& Management, 39(3), 491-506.

Plowman, S. A., \& Smith, D. L. (2013). Exercise physiology for health, fitness and performance (4th ed). Baltimore, MD: Lippincott Williams \& Wilkins.

Ramey, S. L., Perkhounkova, Y., Hein, M., Chung, S., Franke, W. D., \& Anderson, A. A. (2016). Building resilience in an urban police department. Journal of Occupational and Environmental Medicine, 58(8), 796-804.

Redshaw, J., Vandersee, J., Bulley, A., \& Gilbert, S. J. (2018). Development of children's use of external reminders for hard-to-remember intentions. Child Development, 89(6), 20992108.

Remsberg, C. (2016, December 30). Should cops see body cam video before giving use of force statements? Force Science Institute. Retrieved from https://www.forcescience.org/2016/12/should-cops-see-body-cam-video-before-givinguse-of-force-statements/

Renden, P. G., Savelsbergh, G. J., \& Oudejans, R. R. (2017). Effects of reflex-based self-defence training on police performance in simulated high-pressure arrest situations. Ergonomics, 60(5), 669-679.

Reporters Committee. (2019). Access to police body-worn camera video. Retrieved from 
https://www.rcfp.org/resources/bodycams/

Risko, E. F., \& Dunn, T. L. (2015). Storing information in-the-world: Metacognition and cognitive offloading in a short-term memory task. Consciousness and Cognition, 36, 6174.

Risko, E. F., \& Gilbert, S. J. (2016). Cognitive offloading. Trends in Cognitive Sciences, 20(9), 676-688.

Schacter, D. L., Norman, K. A., \& Koutstaal, W. (1998). The cognitive neuroscience of constructive memory. Annual Review of Psychology, 49(1), 289-318.

Schwabe, L., Wolf, O. T., \& Oitzl, M. S. (2010). Memory formation under stress: Quantity and quality. Neuroscience \& Biobehavioral Reviews, 34(4), 584-591.

Seattle Police Department. (2019). 8.400 - Use of force reporting and investigation. City of Seattle. Retrieved from https://www.seattle.gov/police-manual/title-8---use-offorce/8400---use-of-force-reporting-and-investigation

Setcan Corporation. (2019). StressVest overview. Retrieved from $\mathrm{http}: / /$ stressvest.com/products/system/stressvests/

Shackman, A. J., Sarinopoulos, I., Maxwell, J. S., Pizzagalli, D. A., Lavric, A., \& Davidson, R. J. (2006). Anxiety selectively disrupts visuospatial working memory. Emotion, 6(1), 40.

Shields, G. S., Sazma, M. A., McCullough, A. M., \& Yonelinas, A. P. (2017). The effects of acute stress on episodic memory: a meta-analysis and integrative review. Psychological Bulletin, 143(6), 636-675.

Siddle, B. K. (1995). Sharpening the warrior's edge: The psychology \& science of training. Millstadt, IL: PPCT Research Publications.

Siegel, J. (2010). Officer involved shooting statements: Wait. The Bill Blackwood Law 
Enforcement Management Institute of Texas. Retrieved from https://shsuir.tdl.org/bitstream/handle/20.500.11875/1745/1365.pdf?sequence=1

Soares, J. S., \& Storm, B. C. (2018). Forget in a flash: A further investigation of the phototaking-impairment effect. Journal of Applied Research in Memory and Cognition, 7(1), $154-160$.

Sparrow, B., Liu, J., \& Wegner, D. M. (2011). Google effects on memory: Cognitive consequences of having information at our fingertips. Science, 333(6043), 776-778.

Staller, M. S., \& Zaiser, B. (2015). Developing problem solvers: New perspectives on pedagogical practices in police use of force training. The Journal of Law Enforcement, 4(3), 1-15.

Staller, M. S., Cole, J. C., Zaiser, B., \& Korner, S. (2017). Representative training with less risk: The effects of non-lethal training and conventional ammunition in police use of force training on heart rate variability. Policing, 1-15.

Steblay, N. M. (1992). A meta-analytic review of the weapon focus effect. Law and Human Behavior, 16(4), 413-424.

Storm, B. C., \& Stone, S. M. (2015). Saving-enhanced memory: The benefits of saving on the learning and remembering of new information. Psychological Science, 26(2), 182-188. Strategies \& Management. 39(3), 491-506.

Tankebe, J., \& Ariel, B. (2016). Cynicism towards change: The case of body-worn cameras among police officers. Hebrew University of Jerusalem, 16-42.

Tarvainen, M. P., Niskanen, J. P., Lipponen, J. A., Ranta-Aho, P. O., \& Karjalainen, P. A. (2014). Kubios HRV-heart rate variability analysis software. Computer Methods and Programs in Biomedicine, 113(1), 210-220. 
Taverniers, J., Smeets, T., Van Ruysseveldt, J., Syroit, J., \& von Grumbkow, J. (2011). The risk of being shot at: Stress, cortisol secretion, and their impact on memory and perceived learning during reality-based practice for armed officers. International Journal of Stress Management, 18(2), 113-132.

Taverniers, J., Van Ruysseveldt, J., Smeets, T., \& von Grumbkow, J. (2010). High intensity stress elicits robust cortisol increases and impairs working memory and visuo-spatial declarative memory in Special Forces candidates: A field experiment. Stress, 13(4), 324334.

Thayer, J. F., Åhs, F., Fredrikson, M., Sollers III, J. J., \& Wager, T. D. (2012). A meta-analysis of heart rate variability and neuroimaging studies: Implications for heart rate variability as a marker of stress and health. Neuroscience \& Biobehavioral Reviews, 36(2), 747-756.

Tsigos, C., \& Chrousos, G. P. (2002). Hypothalamic-pituitary-adrenal axis, neuroendocrine factors and stress. Journal of Psychosomatic Research, 53(4), 865-871.

Van der Kolk, B. A., \& Fisler, R. (1995). Dissociation and the fragmentary nature of traumatic memories: Overview and exploratory study. Journal of Traumatic Stress, 8(4), 505-525.

Vickers, J. N. (2007). Perception, cognition, and decision training: The quiet eye in action. Champaign, IL: Human Kinetics.

Vickers, J. N., \& Lewinski, W. (2012). Performing under pressure: Gaze control, decision making and shooting performance of elite and rookie police officers. Human Movement Science, 31(1), 101-117.

Vrijkotte, T. G., Van Doornen, L. J., \& De Geus, E. J. (2000). Effects of work stress on ambulatory blood pressure, heart rate, and heart rate variability. Hypertension, 35(4), $880-886$. 
Wegner, D. M., Erber, R., \& Raymond, P. (1991). Transactive memory in close relationships. Journal of Personality and Social Psychology, 61(6), 923-929.

Wine, J. (1971). Test anxiety and direction of attention. Psychological Bulletin, 76(2), 92-104.

Wollert, T. N., Driskell, J. E., \& Quail, J. (2011), Stress exposure training guidelines: Instructor guide to reality-based training. Retrieved from http://www.virtualtacticalacademy.com/files/stress_exposure_training_manual_926B.pdf

Woody, E. Z., \& Szechtman, H. (2011). Adaptation to potential threat: The evolution, neurobiology, and psychopathology of the security motivation system. Neuroscience \& Biobehavioral Reviews, 35(4), 1019-1033.

Yuille, J. C., Davies, G., Gibling, F., Marxsen, D., \& Porter, S. (1994). Eyewitness memory of police trainees for realistic role plays. Journal of Applied Psychology, 79(6), 931-936. 


\section{CHAPTER 4}

Triggering Memory: Examining How the Viewing of Body Worn Camera Footage Impacts

\section{Police Officer Reports}

Brittany Blaskovits1*, Andrew Brown1, Bryce Jenkins1, Simon Baldwin1,2, \& Craig Bennell1

1Department of Psychology, Carleton University, Ottawa, Ontario, Canada

2Royal Canadian Mounted Police, Ottawa, ON, Canada

* Address for correspondence: Brittany Blaskovits, Department of Psychology, Carleton

University, 1125 Colonel by Drive, Ottawa, Ontario, Canada, K1S 5B6. Email:

brittanyblaskovits@cmail.carleton.ca

Under review by Police Quarterly 


\begin{abstract}
The ever-expanding adoption of body worn cameras (BWCs) by police agencies across the United States has led to concerns about the appropriate timing for when officers should be able to view their footage in relation to report writing or providing a statement. It has been argued that a more complete and accurate account of police-public encounters is produced when officers view their footage before completing a statement about the event. However, the cognitive literature suggests that combining visual evidence with an officer's memory of an event, prior to obtaining a pure statement of the officer's perceptions of what occurred, may contaminate their recall. Therefore, the current study aimed to examine the effect that viewing BWC footage has on officer recall. Fifty-one officers were exposed to a domestic dispute scenario that resulted in the use of lethal force. Half the sample was allowed to view their BWC footage before completing a statement about the event; the other half were asked to complete their report without any aide. The amount, accuracy, and type of details reported by officers were coded and subjected to analysis. The results revealed that officers who saw their footage reported significantly more about the subject, relative to those who did not see their footage. Interestingly, there was no significant difference in overall accuracy between the two conditions, nor were there any differences in regard to the severity of errors made. However, higher levels of stress were associated with an increase in the amount of moderate and major errors made by officers who were barred from seeing their footage. The findings provide a better understanding of the type of discrepancies that may occur in naturalistic settings for officers unable to view their footage (e.g., hold back evidence) prior to providing a statement.
\end{abstract}

Keywords: report writing, memory, police, body worn cameras, use-of-force 


\section{Triggering Memory: Examining How the Viewing of Body Worn Camera Footage Impacts Police Officer Reports}

BWCs are small, audio/video recording devices, that may be attached to one's clothing, eyewear or helmet (Jennings, Fridell, \& Lynch, 2014). They record events from the point-ofview from which they are mounted, providing wearers with a secondary account of what occurred. Police use of BWCs originated in the United Kingdom when the Devon and Cornwall Police began using them to improve evidentiary elements, namely the disclosure of abuse by survivors of domestic violence (Findlay, 2017). Since then, they have been adopted by almost half (47\%) of all general-purpose law enforcement organizations (consisting of 15,328 agencies) in the United States (US; Hyland, 2018). Roll-out in Canada has been limited largely due to their cost (Laming, 2017); although many agencies have piloted their use (e.g., Durham Police Service, Thunder Bay Police Service, Vancouver Police Department; Findlay, 2017; Laming, 2019).

Not surprisingly, given their quick uptake, the implementation of BWCs appear to provide some important benefits. Research has shown that BWCs may improve citizen behaviour, reduce police use-of-force, and result in fewer claims of police misconduct (Farrar \& Ariel, 2013; Freund, 2015; Jennings et al., 2014; although these studies are fraught with methodological complications; e.g., Ariel, 2016; Findlay, 2017). Moreover, their continued use as an evidentiary tool and ability to provide an additional perspective in cases that have been filmed by other sources (e.g., bystanders camera-phones), are crucial (Freund, 2015). However, concerns regarding storage, privacy, and fiscal costs, eclipse some of these benefits (e.g., Findlay, 2017; Freund, 2015; Hyatt, Mitchell, \& Ariel, 2017). The way that footage is dealt with 
in-house has presented some major challenges; one of the most pertinent being the appropriate timing to view the recordings (Dawes et al., 2015; Mezey, 2013; Mnookin, 1998).

Two opposing perspectives have emerged: One that favors having officers review their footage prior to providing a statement about an event (Police Executive Research Forum [PERF], 2014); and another that argues for a pure account of an event, independent of footage that could confound an officer's recall (Independent Investigation Agencies of Canada, 2016; Pezdek, 2015; Stanley \& Bibring, 2015). Notably, PERF (2014) recommends the first option: “The majority of police executives consulted by PERF are in favor of allowing officers to review [BWC] footage prior to making a statement about an incident in which they were involved. They believe that this approach provides the best evidence of what actually took place" (p. 29). This approach is also consistent with the policies of most law enforcement agencies in the US, as most allow their officers direct access to their recordings, and some (e.g., the Los Angeles Police Department) even require that officers review their footage before completing a statement (Hyland, 2018; Yu \& Bogen, 2017). Alternatively, others have argued that, if it is important to get an officer's account of a recorded event, "then it is important to preserve his [or her] memory untainted by viewing the video footage" (Pezdek, 2015, para. 13). Concerns have been raised about the potential for post-event memory distortion, various issues with a camera's perspective (e.g., bias, quality, blind spots), and the pressure officers are under to ensure their report is consistent with the camera's footage (Yu \& Bogen, 2017).

While both views hold credence, there has been surprisingly little empirical research conducted to support either perspective. One of the few studies conducted on this topic examined differences between police officers' reports before and after watching their BWC footage (Dawes et al., 2015). In that study, officers were tasked with completing a use-of-force report 
following their involvement in a series of scenarios in which they were equipped with a BWC. Once the report was complete, officers were allowed to view their footage and told they could revise their original report as necessary. As expected, following observation of BWC footage, their reports became more accurate. However, certain details in the BWC footage that should have cued proper recall remained inaccurate in the revised reports. For example, none of the participants reported seeing certain weapons at the scene, including a gun, even after they viewed the BWC footage.

Further study is needed to extend Dawes et al.'s (2015) research to better understand officer recall after viewing BWC footage (versus not), while also examining the role of stress on memory (given its ability to impact recall; Hope et al., 2016; Yuille, Davies, Gibling, Marxsen, \& Porter, 1994). Such research will provide police agencies additional, albeit preliminary, evidence from which to ground their decisions about how they should use BWC footage. Indeed, viewing BWC footage may mitigate the impact of stress, and improve officer memory of an event, thus informing current policy. Alternatively, the initial viewing of one's footage could lead officers to present originally unobserved, yet important information in their reports to justify their actions in the encounter; in that case, other regulations may be required. As such, the current study examines differences in recall following a stress-inducing scenario, whereby some officers were allowed to view their BWC footage prior to reporting, and others were prevented from see their footage.

\section{Those in Favor of Viewing Body Worn Camera Footage First}

When an officer uses force, most agencies require that they complete a statement articulating their reasons for doing so (British Columbia Provincial Policing Standards, 2020; Laming, 2017; National Institute of Justice, 2016). These reports may be subject to scrutiny from 
various oversight bodies, and depending on the nature or severity of an encounter, could be used as testimonial evidence in court. Considering the type of interactions that are typical of those requiring the use-of-force (i.e., stressful, fast-paced, complex; e.g., Andersen \& Gustafsberg, 2016), it is arguably impossible for one to remember and ultimately report everything about any given event (Sharps, 2010; Shields, Sazma, McCullough, \& Yonelinas, 2017). Yet, these reports should provide an indication of an officer's memory for that interaction, including their perception of what occurred, risk assessment, and decision-making process (e.g., Civilian Review and Complaints Commission for the Royal Canadian Mounted Police [RCMP], 2015). It is argued that BWC footage may act as a potential memory aide; prompting previously dormant memories and ensuring a more complete and accurate report is produced (Hyland, 2018; PERF, 2014; Yu \& Bogen, 2017).

Visual evidence as cues. There is a long tradition of using visual imagery to enhance recollection (e.g., Ally \& Budson, 2006; Aschermann, Dannenberg, \& Schulz, 1998; Jack, Martyn, \& Zajac, 2015). Eyewitnesses are often shown photographs and/or lineups of individuals in an attempt to prompt recognition memory (i.e., is what you are currently seeing the same as a previously witnessed person of interest?; Jack et al., 2015). Props and/or models may be presented in court for identification purposes (e.g., Gordon et al., 1993; Salmon, Bidrose, \& Pipe, 1995), and various retrieval aids (e.g., drawings, context reinstatement, scene walkthroughs [e.g., Smith \& Vela, 1992]) can be used during interviews to elicit recall (e.g., like in the cognitive interview; Geiselman, Fisher, Mackinnon, \& Holland, 1985). Broadly speaking, research supports using visual material of various sorts to enhance memory (Harvey, Langheinrich, \& Ward, 2016). In fact, it is argued that all 'remembering' is cued (Krafka \& Penrod, 1985; 
Tulving \& Watkins, 1975), and that video footage may be a particularly useful cue (Harvey et al., 2016).

Research exploring 'lifelogging technology' provides some insight into the utility of video for enhancing memory. Lifelogging is, in brief, a phenonemna whereby individuals record their daily life using a wearable camera (Kalnikaite, Sellen, Whittaker, \& Kirk, 2010). The device takes thousands of pictures a day, and then combines these photographs into a useable segment, which an individual can later review. Numerous studies exploring the utility of lifelogging suggest that it improves retrospective memory (that is, memory for past occurrences; Harvey et al. 2016) in both healthy (Sellen et al., 2007; Silva, Pinho, Macedo, \& Moulin, 2013) and memory-impaired individuals (Berry et al., 2007; Woodberry et al., 2015). This could be, in large part because, "episodic memory is innately dominated by visual imaginary, and visual cues (e.g., pictures or videos) are known for maximizing the information they contain by representing objects in relation to each other" (Harvey et al., 2016, p. 6).

The brain attempts to use all stimuli available to piece together and isolate specific memories (Gillund \& Shiffrin, 1984; Harvey et al., 2016). Re-presenting the context (e.g., physical environment) that an instance occurred in, for example, appears to enhance retrieval by increasing the number of cues available (Harvey et al., 2016; Tulving, 1983; Tulving \& Watkins, 1975). The 'encoding specificity hypothesis' maintains that memory is improved when the retrieval environment matches the environment in which the encoding took place (Tulving \& Thomson, 1973). Spatio-temporal information included in video footage then, may work to cue memory because it overlaps with one's memory trace. Harvey and colleagues (2016) argue that watching video footage of past events, like that produced by lifelogging technology (and similar to BWC footage), should thereby successfully augment memory for that event. 
Accuracy of report writing after viewing video footage. Consistent with the above research, Hartman, O’Neill, O’Neill, and Lewinski (2017) found that officers who reviewed their BWC footage tended to produce more accurate reports (albeit this finding was not significant and based on a small sample of 11 officers). In their study, officers were exposed to three traffic stop scenarios. They were then asked to complete a free recall essay and answer two direct questions about the final scenario. After completing the essay, all officers had the opportunity to review their footage of one of traffic stops, although only some elected to do so. They were asked to return four or eight weeks later and recall the traffic stop again. Follow-up recall accuracy for those who had reviewed their video footage was higher compared to those who did not review their footage.

Likewise, the findings from Dawes and colleagues' (2015) study indicated that reports completed after officers watched their BWC footage were more accurate, 16 compared to those completed beforehand. Upon reviewing their footage of the scenario that they were involved in, officers amended errors they had made in regard to their use-of-force (e.g., miscounting, missequencing, and/or ommitting certain instances of force), and fixed inaccuracies they had made about the scene. Dawes et al. (2015) quantified the number of errors made between initial reports (pre-BWC observation) and revised reports (post-BWC observation); and also categorized the errors as "minor," "moderate," or "major" based on their operational relevancy. On average, participants corrected 2.63 minor errors, 5.4 moderate errors, and 0.9 major errors after watching their footage. Unfortunately, given the small sample $(N=11)$, testing for significance was not conducted. 
In a similar study, 10 paramedics were equipped with BWCs and tasked with completing a stressful scenario involving a subject in need of naloxone (Ho et al., 2016). After handing off the case to a nurse, the paramedics completed a report of the call. They were then allowed to see their camera footage and revise their report as necessary. In total, 71 revisions were made, the majority of which were classified as "moderate" errors. While the reports were more accurate following review of the footage, errors remained, even when the camera footage could have been used to correct them. Persistent errors were related to the patient's medications, endangered juveniles, and firearms in the residence, among others. Like police officers, paramedics are repeatedly exposed to stressful incidents which they are expected to accurately recall after-thefact. Ho et al. (2016) suggests that BWCs may help protect first responders from liability issues should they make unintentional, but critical errors, in their reports.

Consistent with this thinking, in a recent panel discussion between attorneys, experts argued that reports written with the help of BWC footage are more difficult to pick apart in court (Remsberg, 2016). They noted that when officers review the footage in a controlled environment, at their own time and pace, their recollection is less likely to be affected by possible stressinduced sensory distortions experienced at the time of encoding (Lacy \& Stark, 2013; Remsberg, 2016). Their recall is thereby enhanced, ensuring reports are completed more accurately. Interestingly, the attorney general of Texas recently clarified a regulation legally entitling officers to see all footage from their BWC and that from all other officers on the scene, before giving any official statement (Remsberg, 2018).

The empirical research to date assumes that the revisions officers make following their viewing of BWC footage occurs because the footage cues their memory, and not because it provides new information (not previously encoded by the officer). Similarly, members of the 
expert panel discussed above appear to confound consistency with accuracy. While a statement that is consistent with an officer's footage may be more difficult to impugn, it is not necessarily accurate as it may not actually correspond to what an officer perceived as the event in question was unfolding. In fact, because camera footage can be misinterpreted as a result of its restricted field of view and issues with its quality (e.g., shaking, blurriness, blocked images), specious information from the footage could be unconciously incorporated into an officer's report (Yu \& Bogen, 2017; similar to the misinformation effect; Crozier \& Strange, 2018). Should an officer adapt their report to be consistent with their footage, only to find the footage is distorted, their credibility could be seriously questioned (Remsberg, 2015, 2016).

\section{Those Opposed to Viewing Body Worn Camera Footage First}

Retrieval of a particular memory requires one to discriminate it from other, often similar memories (Surprenant \& Neath, 2013). New information interacts with mental frameworks or "schemas" that have been developed from past experiences; allowing us to quickly make sense of a situation and respond appropriately (Brewer \& Nakamura, 1984; Tse et al., 2007). While schemas are sometimes useful, exposure to repeated circumstances strengthen them, such that dissimilar and/or inconsistent bits of information may sometimes get lost, engulfed by what "tends to happen." Schemas have been used to understand racial profiling (e.g., Miller, 2008; Plant \& Peruche, 2005; Ruby \& Brigham, 1996), as well as errors in eyewitness testimony (e.g., Greenberg, Westcott, \& Bailey, 1998; Kleider, Pezdek, Goldinger, \& Kirk, 2008) and police officer decision-making (Lacy \& Stark, 2013; Bennell, Jones, \& Corey, 2007).

Consider, for example, a police officer who has been repeatedly exposed to an individual who pulls a gun from their waistband (either in training or on-the-job). The officer may develop a pre-existing schema about this type of behaviour and a reaction applicable to it. Should they 
then encounter someone who pulls a cellphone from their waistband, they may interpret the motion as threatening and even later recall that the individual pulled a gun (consistent with their pre-formed schema). Their recall will necessarily be different than what would be objectively true (and perhaps shown on their BWC footage), but the discrepancy would not be intentional and may actually better reflect their perceptions during the incident. If the officer in question were to then view video footage of the event (that differs from their memory of what occurred), their recollection of the event could be distorted, contaminated by what the footage is showing.

It has been argued that a "misinformation-type" effect could occur when officers watch their footage prior to writing their report (Blaskovits \& Bennell, 2019; Yu \& Bogen, 2017). Details from the camera footage may be unintentionally incorporated into an officer's "memory," even though those details were never originally encoded (Loftus, 2005). In other words, officers may misattribute the source of the details as their own, confounding their recall with that which was integrated after watching the footage. Traditionally, the misinformation effect has occurred when inaccurate post-event information interferes with one's memory for an original event (Loftus, 2005). Grady, Butler, and Loftus (2016) argue that BWC footage could work to inadvertently bias an officer's memory in a similar way.

As noted, although BWC footage typically provides accurate information, it may be different than what an officer perceived. Thus, while, “...their report may seem more accurate since it confirms to the objective reality of the situation, it is actually less accurate about the officer's perception of the event, which may be far more relevant when it comes to figuring out what led to the use-of-force" (Grady et al., 2016, p. 247). Importantly, reliance on schemata and vulnerability to the misinformation effect appears more likely when one is stressed and/or when the original memory is weak (i.e., under such conditions one tends to default toward less effortful 
heuristic processes; Johnson, Hashtroudi, \& Lindsay, 1993; Lacy \& Stark, 2013; Loftus, 2005).

It is, of course, critical incidents, wherein officers are under high levels of stress, that need to be remembered and reported on, and therefore we need to be particularly concerned about misinformation effects occurring.

In an effort to avoid contaminating evidence, the independent investigation agencies of Canada (2016; e.g., Alberta Serious Incident Response Team, Ontario Special Investigations Unit, Independent Investigation Office of British Columbia) assert that video will be "presumptively treated as 'hold back' evidence in relation to the critical incident until such times as the investigative team determines otherwise." While acknowledging the frailties of human memory and that inconsistencies and mistakes of fact do not necessarily constitute untruthfulness, the agencies consider a witness' perception of the incident as critical to their investigation. As a result, with the exception of "rare" circumstances, they posit that only once a "pure statement" has been taken, may an officer be able to refresh their memory with video of the incident for a subsequent interview. Their decision is underpinned by the principle of independence and equality, in that every witness, whether civilian or police, should be held to the same standard (i.e., prohibited from viewing video prior to a statement); otherwise, it may be perceived as preferential treatment (Independent Investigation Agencies of Canada, 2016).

The impact of stress on recall. Policing is, undisputedly, a stressful occupation (Anderson, Litzenberger, \& Plecas, 2002; Baldwin et al., 2019). Over and above the chronic stress resultant from shift work and a heavy workload, officers regularly interact with unpredictable and potentially dangerous individuals (Gershon, Barocas, Canton, Li, \& Vlahov, 2009). While research suggests that stress may improve certain aspects of recall (e.g., for the most central aspects of an event; Knight \& Mather, 2009; Mather \& Sutherland, 2011) and can 
have a differential impact depending on when exactly it occurs (e.g., during encoding, postencoding, and/or retrieval; Shields et al., 2017), much of the literature presumes a negative effect of stress on memory (e.g., Christianson, 1992; Hartman et al., 2017; Lacy \& Stark, 2013).

Biologically, fluctuations in stress hormones (e.g., cortisol) affect the hippocampus - a brain region that plays a major role in memory and learning - thereby impacting the encoding and retrieval of autobiographical details (e.g., Bremner, 1999; Dusek \& Eichenbaum, 1997; Fortin, Agster, \& Eichenbaum, 2002). Typically, the binding of cortisol in the hippocampus ensures short-term survival by facilitating the comparison of a current dangerous situation to prior dangerous situations, thus enhancing threat detection (Bremner, 1999); but under certain conditions, long-term (i.e., memory and learning) function may be sacrificed.

Numerous studies support the notion that processing is limited under high emotional arousal and can result in the inefficient encoding and/or retrieval of events (Christianson, 1992). For example, a meta-analysis by Deffenbacher and colleagues (2004), which combined the results of 63 tests examining the effect of stress on eyewitness identification of perpetrators and event recall, found that high stress impeded memory. Likewise, in the few studies that have examined recall in a policing context, a significant reduction in the amount and accuracy of details has been observed for officers under higher arousal (e.g., Dawes et al., 2014; Hope, Lewinski, Dixon, Blocksidge, \& Gabbert, 2012; Hope et al. 2016). These studies typically use physiological indices such as HR as proxy measures for stress and exertion, measuring postevent articulation via questionnaires or written reports (e.g., Hope et al., 2012; Hope et al., 2016; Hulse \& Memon, 2006). In the most extreme cases, perceptual distortions (i.e., altered visual, temporal, and/or spatial states) have been known to occur (e.g., Crane, 2000; Klinger \& Brunson, 
2009). Such perceptions have implications for how an event is ultimately remembered (Artwohl, 2002; Federal Law Enforcement Training Center, 2004).

Should an individual turn to their BWC footage in an attempt to overcome some of the cognitive and perceptual limits described above, they may be met with a less than perfect representation of the event. Remsberg (2016) notes that while BWC footage is often understood to represent reality, modern digital video footage is compressed. Compression reduces the size of a data file but can trick the human eye. Some images may be dropped, and others repeated, whilst still giving the impression of a continuous recording. Moreover, by design, BWCs do not necessarily "see" what an officer does. Striking examples are the poorer visual clarity experienced by officers during low light conditions, compared to that which can be seen on tape (Remsberg, 2014); as well as the tactile cues present to officers but invisible in a recording (e.g., should a subject tense or change posture while in a hold or arrest). Moreover, videos are twodimensional and may not capture depth, distance, or positional orientation (e.g., Berkeley Police Department, 2019; Remsberg, 2014; San Mateo Police Department, 2017). Depending on where the BWC is mounted (e.g., chest, head), the camera could be pointed an entirely different direction relative to where an officer is looking (e.g., if an officer is looking to the right, but their BWC is positioned forward), or may be obscured by an officer's hands/firearm during a lethal force encounter (Remsberg, 2014).

\section{Purpose}

It is possible that allowing officers to review their BWC footage before preparing their report might improve recall and result in more complete and accurate reports. Consistent with research demonstrating the memory enhancing effects of video (Hodges et al., 2011; Kalnikaite et al., 2010), BWC footage may act to cue legitimate forgotten memories. However, allowing 
officers to view their footage before writing their report/statement could also intentionally (or unintentionally) bias their recall for certain elements (e.g., captured on camera). Dawes et al.'s (2015) study is one of the only known studies that has examined the timing of officer report writing in relation to BWC viewing. The current study aims to extend that research by utilizing a between-groups design with a larger sample. It also intends to examine the role of stress on memory, given that stress may negatively impact recall (Hope et al., 2012; Yuille et al., 1994).

\section{Hypotheses}

Hypothesis 1. Consistent with Dawes et al. (2015), it was hypothesized that reports written after viewing BWC footage (deemed the 'viewing' group) would include significantly more details, compared to those written without seeing any footage (the control group), after controlling for stress.

Hypothesis 2. Moreover, it was hypothesized that the viewing group would have a significantly higher amount of accurate details in their report, compared to the control group, after controlling for stress.

Research Question. The current study also sought to determine whether or not viewing camera footage may positively impact the recall of certain details relative to others. Therefore, the type of details (i.e., whether subject, officer, and/or context-related) most affected by viewing camera footage was explored. Given the lack of prior literature and varying findings in Dawes et al.'s (2015) research, no hypotheses were made a priori.

\section{Method}

\section{Participants}

Fifty-three operational police officers were recruited from an in-service training center in Canada. However, as two participants had reports that could not be retrieved, they were excluded 
from the study, resulting in a sample of fifty-one. Most of the sample was male $(82.4 \%, n=42)$, with $17.6 \%(n=9)$ reporting as female, consistent with the distribution of most police organizations in North America (Conor, 2018; Data USA, 2019). On average, participants reported that they were approximately $36.57(S D=7.20)$ years of age and had $9.35(S D=5.13)$ years of overall police service, $8.80(S D=4.46)$ of which were operational. The majority of the sample reported that they were married $(58.8 \%, n=30)$, and the same amount reported that they had children. Approximately $27.5 \%(n=14)$ of participants had a college diploma or certificate and $23.5 \%(n=12)$ had a bachelor's degree. The most commonly reported rank was Constable $(78.4 \%, n=40)$. Most participants were not trained as a use-of-force instructor $(58.8 \%, n=30)$. The majority of participants had never been involved in a lethal force encounter $(90.2 \%, n=46)$, although $7.8 \%(n=4)$ had been witness to one and one participant $(2 \%)$ had been involved as a subject officer (i.e., they had lethally intervened in an incident). Lastly, it is important to note that at the time of the study, BWCs were not issued to frontline officers in the agency that the sample was recruited from. This means that the participants were familiar with completing their reports without being able to view any footage beforehand.

Independent samples $t$-tests, chi-square analyses, and Fisher's Exact tests were conducted to examine differences between male and female participants on all of the demographic variables. Males were significantly more likely to have use-of-force instructor training ( $p=.007$ by Fisher's Exact test, $\varnothing=-.39, \mathrm{p}=.006)$ and more years of operational policing service $(M=9.42, S D=$ 4.40) compared to females $(M=5.94, S D=3.73), t(49)=-2.20, p=.033, d=.85$. Given these differences, analyses were conducted on the full sample, as well as separately for males and females.

\section{Measures}


Demographics. The demographic questionnaire consisted of 16 questions that asked participants about their age, rank, marital status, years of service, lethal force experience, and police training history, among other qualities.

Standard Use-of-Force Report. Following most applications of force, officers must complete a report about the incident (Alpert \& Smith, 1999; Garner et al., 2018; Laming, 2019). The standard use-of-force report from the agency that the officers were recruited from was used in the current study. These reports are entered online and request information pertaining to the subject (e.g., perceived age, height, gender), as well as various situational factors (e.g., the weather conditions at the time of the event, the time of day, subject behavior, any perceived weapons). Thirty-two of the questions that were relevant to the study scenario are in a drop-down format; clicking on them provides additional drop-down options to specify the response. Two questions contain open text boxes where officers are asked to report on the subject's known history and behaviour. There is a final open text box where officers can describe the totality of the circumstances; providing an account of their observations and risk assessment.

Heart Rate. Common measures of stress reactivity capture sympathetic nervous system (SNS) and hypothalamic-pituitary-adrenal (HPA) axis activation, which result in a surge of catecholamines, stress hormones, and glucose through the bloodstream. These changes stimulate increased respiration, heart rate (HR), and blood pressure (Tsigos \& Chrousos, 2002). While there are several methods of measuring stress (e.g., heart rate variability [HRV], HPA activity, blood markers), situational and environmental constraints can restrict the choice of measure, as they can be highly sensitive to movement or difficult to collect without confounds. Heart rate, however, has been used as an objective, robust, and easily obtainable proxy measure for stress 
among police and highly active participants (Anderson, Litzenberger, \& Plecas, 2002; Baldwin et al., 2019; Vrijkotte et al., 2000), and was used in the present study.

All HR data was entered into Kubios HRV Premium Version. 3.3.1. and cleaned using the automatic artefact correction algorithm with a 5\% artifact correction threshold (Lipponen \& Tarvainen, 2019; Lipponen, Tarvainen, Niskanen, \& Ranta-aho, 2019). Two measures of cardiovascular reactivity were ultimately used: (1) resting HR (HRrest), obtained by calculating the average of each participant's lowest beats per minute (bpm) across one minute (while they completed pre-scenario paperwork), and (2) maximum HR (HRpeak), obtained from each participant's maximum HR (recorded during a critical phase of the scenario [e.g., when a knife was drawn, when a knife was discarded, when shots were fired, when they moved to go hands on with a subject]). To provide a standardized measure for between-subject analysis, the difference (HRpeak above resting) between the officers' HRpeak and their HRrest was calculated (Anderson et al., 2002; Andersen et al., 2016; Andersen \& Gustafsberg, 2016).17

While various factors can affect one's HR, the current study is not considered clinical in nature and thus participants were not medically examined prior to participating. However, in order to participate, all participants needed to be deemed "fit for duty" by their police agency and presently on active duty. Moreover, participants were asked to report if they had cardiovascular disease and whether or not they were taking any medications that could affect their HR. None of the participants reported that they had cardiovascular disease and only 5.9\% $(n=3)$ indicated that they took medication affecting their HR. An independent-samples $t$-test indicated that these participants' HR peak above resting did not differ significantly from the other participants,' $t(49)=$ $1.04, p=.302$

17 This metric ensures that if multiple officers display the same maximum HR, those with a lower resting rate show a larger relative increase (Anderson, Litzenberger, \& Plecas, 2002). 


\section{Equipment}

Heart Rate. To measure HR, participants were equipped with a Polar H7 Chest Strap Heart Rate Monitor ${ }^{\circledR}$ and two Polar V800 Heart Rate Monitor Watches ${ }^{\circledR}$. Utilizing CBluetooth technology, these devices can obtain live, accurate readings of HR (Giles, Draper, \& Neil, 2016). Previous research has validated the use of this technology for obtaining measures of HR during periods of activity (e.g., Barton, Vrij, \& Bull, 2000; Hope et al., 2016; Kayihan, Ersöz, Özkan, \& Koz, 2013). For instance, it appears to be a useful alternative to an electrocardiogram (ECG) for capturing HR when officers participate in high fidelity training exercises (Giles, Draper, \& Neil, 2016; Hope et al., 2016). Participants were also equipped with FirstBeat Bodyguard 2 Heart Rate Monitors $₫$ so that there was a secondary source collecting HR data, and verifying the accuracy of the data that were collected (Parak \& Korhonen, 2013; Ramey et al., 2016).

StressVestтm. The StressVestтм is a non-projectile based firearms training system. It is comprised of two components: (1) the actual vests and StressXTM PRO Belt that are worn by individuals, and (2) the infrared, light emitting weapons (e.g., inert pistols) that can be used to "shoot" those wearing the vests (Setcan Corporation, 2019). The vest registers when an individual is "hit" by a light emitting weapon; the wearer receives a localized electric shock to the abdomen. The shock (and/or potential for a shock) is argued to induce the sort of stress officers experience in the field during critical incidents (Staller, Cole, Zaiser, \& Korner, 2017).

Body Worn Cameras. All participants were equipped with an Axon Body 2 BWC. The camera was attached by a clip to the middle of the officers' vest as per the manufacturer's instruction and turned on prior to the start of the scenario. Participants also wore (CApplied Science Laboratories (ASL) Mobile Eye-5 Glasses (i.e., an eyetracker). These cameras recorded each participant's scenario and ensured that ground truth was captured. 
Surrounding Cameras. Three CGoPRO HERO4 Silver cameras were mounted in central locations around the facility where the scenario took place.

\section{Procedure}

Participants were recruited from a large Canadian police organization. They were informed of the study via email, flyers, and in-person; they could sign-up for an open timeslot if they were interested in participating. Upon arrival, each participant was presented with a consent form and cleansed of their live intervention options. They were equipped with the HR equipment, and then completed the demographic questionnaire and several other surveys not relevant to the current study. Next, participants were equipped with the StressVestrm system, a BWC, and the eyetracker.18

Once participants were equipped with inert intervention options, they were dispatched to a disturbance call at an upstairs apartment. The call involved a subject drinking heavily, in breach of his probation conditions, who was refusing to leave the residence. When the participant arrived at the scene, the scenario progressed into a mental health event, with the subject pulling a knife and threatening suicide. When the participant attempted to de-escalate the situation, then the subject would drop the knife and get into an altercation with another tenant. Eventually, the subject would pull out a firearm and begin shooting, forcing participants to return fire. The scenario concluded when the subject was shot, and participants made an arrest, applied first aid, and/or were waiting for back-up to arrive.

The scenario was standardized (i.e., the same actors followed the same script with every participant) but was developed to ensure it could accommodate a variety of possible responses. 
For example, if a participant decided to use a Conducted Energy Weapon, the subject would imitate swiping the probes away, rendering the deployment ineffective, and continue with scenario. The scenario was designed to be as realistic as possible and was piloted with a sample of 12 officers prior to its finalization. Alcohol bottles were placed around the residence, a radio blared loud music, and a scent training system (AirAware $\left.{ }^{\circledR}\right)$ released the smell of marijuana. Various objects (e.g., couch, candle sticks, magazines) and weapons (e.g., knives, bat, hammer) were placed around the room to add to the complexity of the event (see Figure 1). The scenario aimed to include stressors known to overload arousal such as time pressure, task load, threat, ambiguity, novelty, noise, and performance pressure (Driskell \& Salas, 1996; Wollert, Driskell, \& Quail, 2011).

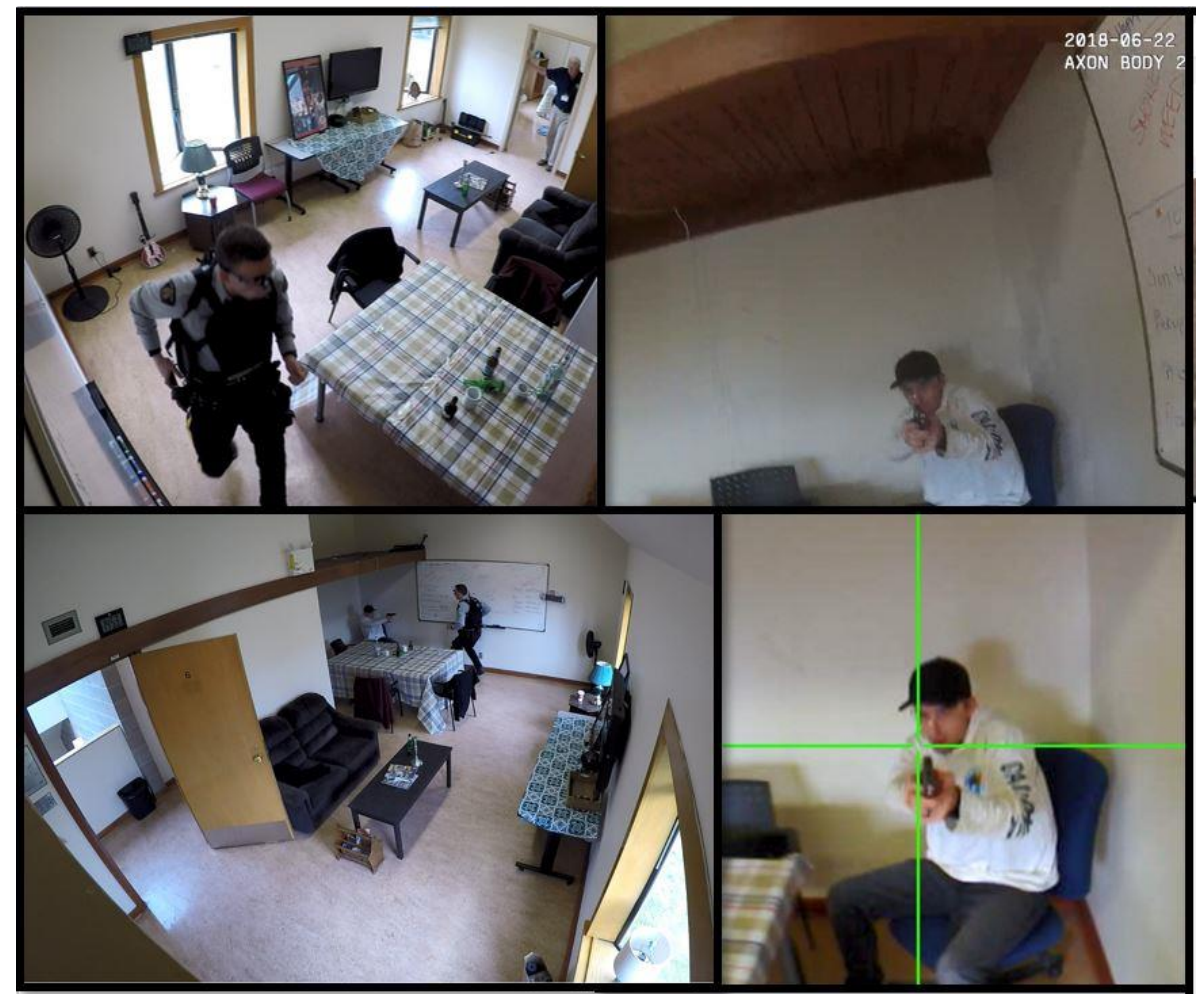

Figure 1. Photographs taken from various mounted cameras that recorded the scenario.

After the scenario, participants were provided another set of questionnaires, which, while not relevant to the current study, provided a time interval between the scenario and the 
completion of their report.19 Participants were then de-equipped. Half of the participants were shown their BWC footage (once through) and asked to complete a use-of-force report. The remaining half were told to complete their use-of-force report without having seen any footage beforehand.20 Once complete, participants were debriefed by the researchers as well as a use-offorce instructor and given the opportunity to withdraw their data. None of the participants chose to withdraw. The study was approved by the XXXX University Ethics Committee for Psychological Research (XXXX Clearance \# 108733) as well as the Research Review Board (2018-04) from the agency in which the officers were recruited.

\section{Analytical Strategy}

In order to assess the extent to which the initial viewing of BWC footage affected the quantity and accuracy of officers' recall, each participant's use-of-force report was coded and subject to analyses.

Qualitative coding. First, the use-of-force reports were divided into individual details. If, for instance, an officer wrote "When I knocked, there was a blonde male," the sentence was broken down to acquire three details pertaining to: (1) a behaviour enacted by the officer (i.e., them knocking), (2) the hair colour of one of the tenants (i.e., blonde), and (3) the sex of one of the tenants (i.e., male). The total number of individual details were then counted to obtain an indication of the quantity of information reported by those who saw their BWC footage compared to those who did not see any footage. A trained research assistant independently coded

19 This interval is comparable to "filler tasks" completed by participants in related research (e.g., Hartman et al., 2017; Hope, Lewinski, Dixon, Blocksidge, \& Gabbert, 2012). It also enhanced the ecological validity of the study as reporting can be delayed after a critical incident (Grady, Butler, \& Loftus, 2016).

20 Note that while every effort was made to ensure the random assignment of participants to either the viewing or control condition, the groups were counterbalanced to ensure each had a relatively equal number of participants in them. Some participants were also assigned to a certain condition as the result of limited time, equipment, and/or availability. Therefore, while the study cannot be said to have true random assignment, the few demographic differences between the groups suggest that it is unlikely any pre-existing differences contributed to the results. 
a random subset $(25 \%)$ of the reports. The intraclass correlation (ICC) for the total number of details reported was .84, which is considered an 'excellent' degree of agreement (Cicchetti, 1994; Hallgren, 2012).

Since the current study is primarily an extension of Dawes et al.'s (2015) work, the coding for accuracy attempted to emulate theirs in various ways. As in Dawes et al.'s study, each detail in a participant's report was compared to "the gold standard" (i.e., what is known to be true about the scenario and how the participant responded to it). This was determined by watching a combination of BWC, (CGoPRO, and eyetracker footage. If a participant reported that the subject was wearing a black shirt, for instance, when in fact he was wearing a white shirt, this was marked as inaccurate. The ICC for the determination of accuracy was .81, again indicating 'excellent' reliability across raters (Cicchetti, 1994; Hallgren, 2012).

Every error in each report was then categorized according to Dawes et al.'s (2015) “grading guidelines" (see Figure 2). The errors were divided into "minor," "moderate," and "major" based on their relative importance to the scenario: "The importance was related to such things as safety (i.e., LEO [law enforcement officer] and involved parties), recognizing criminal activity, or to the policy and constitutional [legal] justification for use-of-force" (p. 7). If, for example, a participant provided an inaccurate description of the subject in their report, then they received a " 1 " for this inaccuracy within the "minor errors" category. Whereas if they miscounted the number of times they used force ( $\pm 0-2)$, then they received a " 1 " in the row related to this criterion within the "moderate errors" category. Each category was summed to obtain a total for the number of errors within each category. The ICC for "minor errors" was .94 and .86 for "moderate errors," both suggestive of 'excellent' reliability. The lack of variability 
for "major errors" was problematic for calculating IRR. However, as nearly all participants did not have a "major error" it can be assumed that the coding between raters was acceptable.

The average number of errors in each category were then compared such that the quantity of "moderate errors" made by those who saw their BWC footage prior to writing their report could be compared to the average made by those who did not see any footage (and similarly for "minor" and "major" errors). For the most part, the grading guidelines provided by Dawes et al. (2015) were broad enough that they could be applied to the current scenario. The only way that the coding differed from Dawes et al. was in terms of "missingness." Dawes et al.'s error count included the frequency with which a participant omitted statements, behaviours, and items in their report, when those things were present in the scenario. Given the sheer complexity of the scenario in the current study, it was impossible to count everything a participant could have reported but failed to. For example, one wall in the scenario room had graffiti covering it. Participants could, technically, report what the graffiti said; however, counting a participant's omissions of everything on that wall would have substantially increased their error count. Because officers are not trained to report absolutely everything (simply given time restrictions), including missingness in this way would likely have resulted in an artificial inflation in the amount of errors made by participants. The comparison with Dawes et al. (2015) is thus limited by differences in the coding of omissions.21

${ }_{21}$ Coding for omitted operationally relevant details was also attempted. However, several issues with this method arose. Foremost, the agency's instructions for officers regarding how to complete the use-of-force report asks them to paint a picture of the event, and not limit themselves to what they might deem operationally relevant information. Their reports thus contained both operational and non-operational details. Moreover, simply defining "operationally relevant" is subjective. Depending on an officer's prior experience and training, what might be relevant to one officer could mean less to another. Seemingly unimportant information like the clothing a subject is wearing, may actually have operational meaning if it indicates a gang relation for example. 


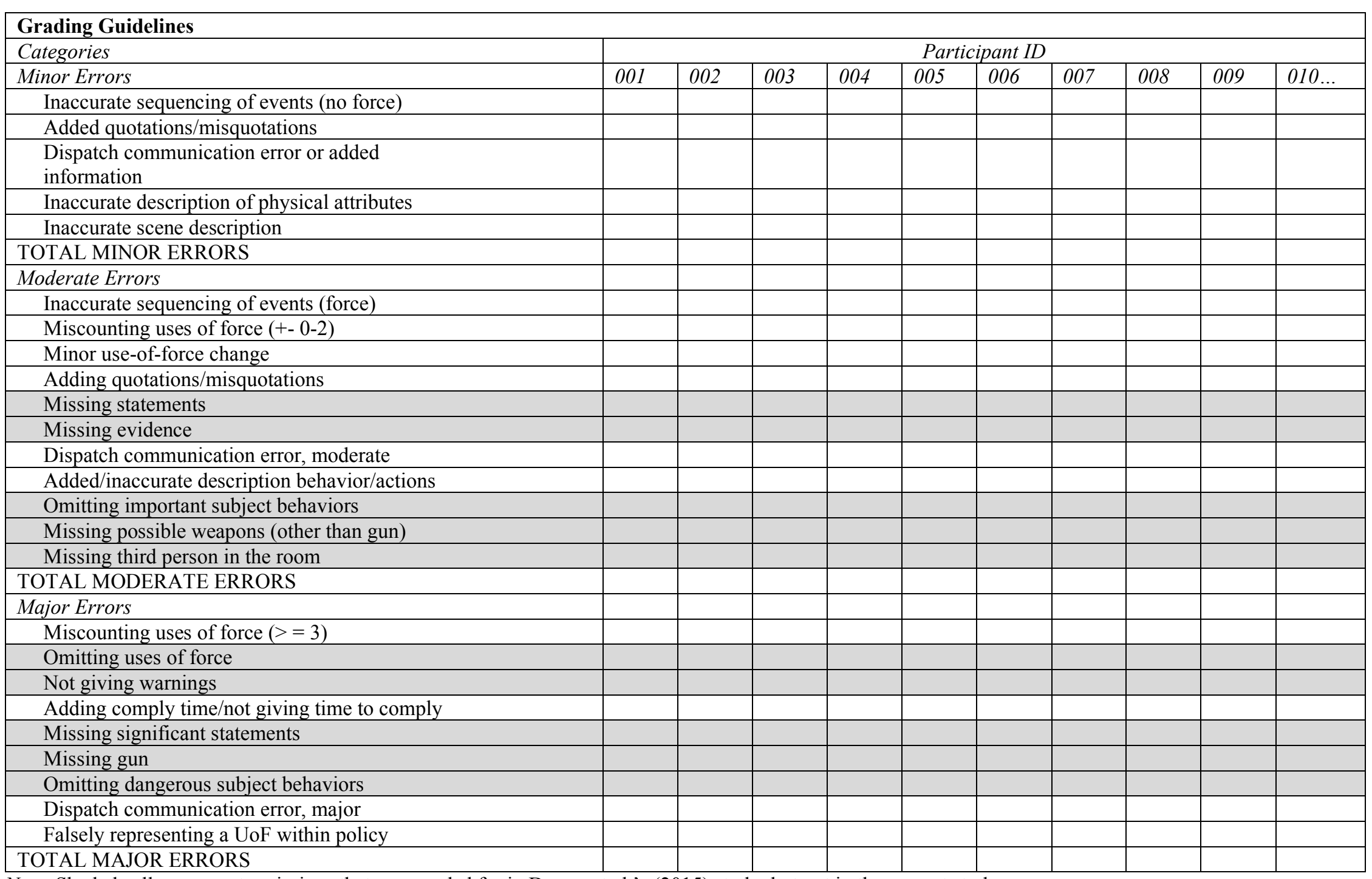

Note. Shaded cells represent omissions that were coded for in Dawes et al.'s (2015) study, but not in the current study.

Figure 2. Grading Guidelines (adapted from Dawes et al. 2015). 
While Dawes and colleagues' (2015) coding guidelines allow us to determine the severity of the inaccuracies made, it does not provide an overall indication of the type of details most likely to be reported. Therefore, the reports were also subjected to deductive content analysis. This approach uses prior knowledge or models to create categories a priori; the data is then coded according to those categories (Elo \& Kyngas, 2008). Officers from the current agency were generally familiar with the standard use-of-force report that we used and had an understanding of what type of information to include. The reports were thus fairly similar (i.e., typically providing a description of the call, subject[s], weapons, the officer's response, and the outcome), and pre-determined categories could be created based on this general model of what a typical report includes.

The categories were: (1) context-related, which included any details made about the environment, including the subject's boyfriend, (2) subject-related, which included any details made about the main perpetrator such as his appearance, behaviour, and statements he made, and (3) officer-related, which included any details made about the behaviour of the participant them self and statements they made. The ICC's for classification into the above categories ranged from .63 to .90, which is considered 'good' to 'excellent' agreement, respectively (Cicchetti, 1994; Hallgren, 2012).

\section{Results}

\section{Heart Rate Analyses}

The mean resting rate (HRrest) for the sample was $76.26 \mathrm{bpm}(S D=10.76)$, which is similar to the baseline reported by Andersen and Gustafsberg (2016) and consistent with the normal resting rate for adults (Laskowski, 2018). Alternatively, participants' mean maximum HR (HReak) during the scenario was $152.64 \mathrm{bpm}(S D=16.01)$, which is slightly higher than that 
reported in other relevant research (e.g., Andersen et al., 2015; Arnetz, Nevedal, Lumley, Backman, \& Lublin, 2009).

A paired samples $t$-test was conducted to examine whether there was a significant difference in participants' average resting rate relative to the maximum rate elicited during the scenario. There was a significant difference between the two phases, $t(50)=33.96, p<.001, d=$ 5.60, indicating that, on average, participants experienced significantly more stress during the scenario than they did at rest. This was the case for both males, $t(41)=-30.77, p<.001, d=5.53$ and females, $t(8)=-19.47, p<.001, d=7.64$. The average HRpeak above resting was $76.38 \mathrm{bpm}(S D$ $=16.06)$, which is in line with others who have assessed stress reactivity in active duty officers on shift and responding to calls for service (Anderson et al., 2002; Andersen et al., 2016; Baldwin et al., 2019). Males, interestingly, had a significantly lower average HReak above resting (M $=73.87, S D=15.56)$ compared to females $(M=88.10, S D=13.58), t(49)=2.54, p=.014, d=$ .97 .

\section{Demographic Differences}

In order to determine whether there were any pre-existing mean differences between the BWC viewing group and the control group, a series of independent sample $t$-tests were conducted. There were no significant differences between the groups on any of the continuous demographic variables including age, years of service, operational years of service, HRrest, HRpeak, or HRpeak above resting. Chi-square analyses or Fisher's Exact tests were conducted to examine differences between the BWC viewing group and control group on the categorical items gender, education level, rank, prior involvement in a lethal force encounter, prior instructor training, presence of dependents, and marital status. A Fisher's Exact test indicated that significantly more females were assigned to the viewing condition $(n=8)$ compared to the 
control condition $(n=1), p=.024, \varnothing=.35, p=.012$, however, given how few female participants there were overall, counts in both cells were very low. No other differences were found for these variables.

\section{Descriptive Statistics of Recall Data}

On average, across both conditions, participants reported approximately 99 details in total. The majority of errors made were classified as "minor" $(M=5.86, S D=3.55)$. Most of the minor errors made were in relation to participants adding quotations or misquotations in their report that were "less important to the case" or did not change the overall meaning of the information (Dawes et al., 2015, p. 21). The majority of details reported were about the context $(M=47.25, S D=18.68)$. Interestingly, the least amount of information reported was in regard to the subject. Descriptive statistics are reported in Table 5.

Table 5

Descriptive Statistics Examining Participants' Overall Recall

\begin{tabular}{lcl}
\hline & $M$ & $S D$ \\
\hline Total Number of Details Reported & 99.18 & 32.86 \\
Minor Errors & 5.86 & 3.55 \\
Moderate Errors & 4.57 & 2.68 \\
Major Errors & .45 & .76 \\
Total Number of Context-Related Details & 47.25 & 18.68 \\
Total Number of Officer-Related Details & 26.73 & 12.01 \\
Total Number of Subject-Related Details & 25.20 & 5.94 \\
\hline
\end{tabular}

\section{Analyses Examining Overall Number of Details Reported}

Spearman's rho correlations and independent samples $t$-tests were conducted in lieu of an Analysis of Covariance (ANCOVA) as the data failed to meet the assumption of linearity between the covariate (i.e., HRpeak above resting) and the total number of details recalled.

The effect of stress on number of details reported. First, Spearman's rho was calculated to examine the relationship between HRpeak above resting and overall recall. The 


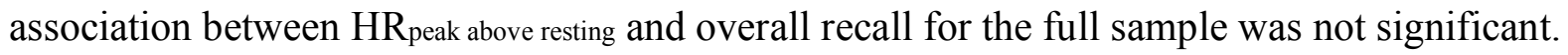

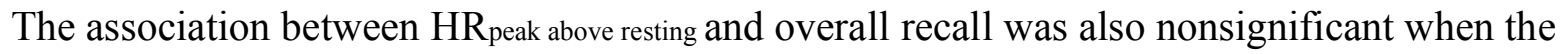
data was split to examine differences between males and females separately.

The effect of condition on number of details reported. An independent samples $t$-test was conducted to examine the extent to which viewing BWC footage resulted in differences in the amount of information reported. Five outliers were noted via visual inspection of a boxplot; however, these values were legitimate and did not impact normality (Shapiro-Wilk's Test was $p$ $>.05$ and skewness and kurtosis were well below the 1.96 cut-off; Field, 2009). The $t$-test indicated that there was no significant difference between those who saw their BWC footage ( $M$ $=104.69, S D=34.29)$ and those who $\operatorname{did} \operatorname{not}(M=93.44, S D=30.95)$ on the amount of information reported, $t(49)=1.23, p=.225, d=.34$. However, as there was a small effect detected, the insignificance is likely a function of the analyses being underpowered. Given that too few females were assigned to the control condition, differences between males and females could not be examined.

\section{Analyses Examining the Accuracy of Information Reported}

Given that all assumptions for an ANCOVA were met with regard to the accuracy data, an ANCOVA was run to determine the effect of viewing BWC footage on the accuracy of the information reported, after controlling for stress. In order to ensure that participants who reported very few details were not artificially inflating the accuracy count, a percentage was calculated. The percentage was derived by dividing the total number of each officers' details by the amount that they reported accurately; this number was then multiplied by 100 . This percentage was then used as the dependent variable in the ANCOVA. The ANCOVA indicated that after adjusting for stress, there was no significant difference in accuracy between those who saw their BWC footage 
$(M=89.43, S D=3.27)$ and those who completed their report without seeing their footage $(M=$ 88.36, $S D=3.87), F(1,48)=1.11, p=.297, \eta_{\mathrm{p} 2}=.023$.

\section{Analyses Examining Severity of Errors Made}

Scatterplots indicated that the data failed to meet the assumption of linearity between HRpeak above resting and Dawes et al.'s (2015) categories of errors (minor, moderate, and major). Therefore, non-parametric tests were conducted in lieu of an ANCOVA.

The effect of stress on error severity. As there was evidence for monotonic

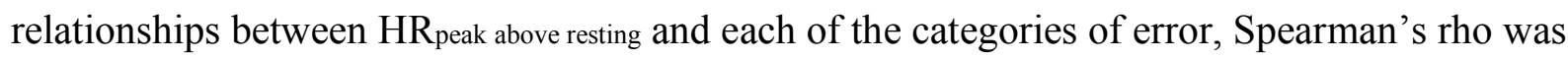
calculated. None of the associations were significant. The dataset was then split by sex to

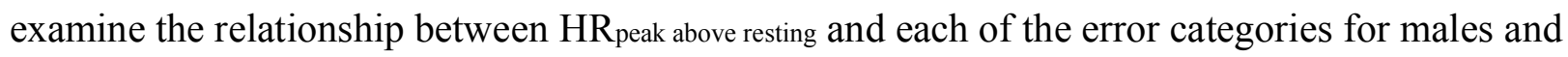
females. There was a significant correlation for females, suggesting that as HR increased, the number of minor errors declined $\left(r_{s}[9]=-.76, p=.008\right)$, as did the number of moderate errors $\left(r_{s}\right.$ $[9]=-.69, p=.020)$. The dataset was also split by condition (control versus viewing) to examine

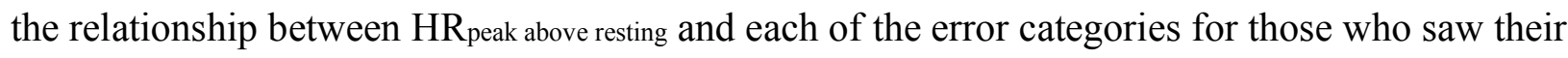
BWC footage before completing their statement compared to those who did not see their footage beforehand. There was a significant relationship observed between HRpeak above resting and moderate errors for those in the control condition $\left(r_{s}[25]=.37, p=.033\right)$, as well as for major errors $\left(r_{s}[25]=.43, p=.016\right)$, suggesting that as HR increased during the scenario, more moderate and major errors were made by those who did not get to see their BWC footage (see Table 6).

Table 6

Correlation Matrix Examining HRpeak above resting and Dawes et al.'s (2015) Categories of Error 


\begin{tabular}{|c|c|c|c|c|c|c|c|c|}
\hline & \multicolumn{2}{|c|}{$\begin{array}{c}\text { Viewing } \\
\text { Conditiona }\end{array}$} & \multicolumn{2}{|c|}{$\begin{array}{c}\text { Control } \\
\text { Conditionb } \\
\end{array}$} & \multicolumn{2}{|c|}{ Malesc } & \multicolumn{2}{|c|}{ Femalesd } \\
\hline & $r_{s}$ & $p$ & $r_{s}$ & $p$ & $r_{s}$ & $p$ & $r_{s}$ & $p$ \\
\hline Minor Errors & .208 & .153 & -.007 & .486 & .098 & .268 & -.763 & $.008 * *$ \\
\hline Moderate Errors & -.245 & .114 & .372 & $.033 *$ & .022 & .444 & -.691 & $.020 *$ \\
\hline Major Errors & -.144 & .242 & .430 & $.016^{*}$ & .177 & .131 & .137 & .363 \\
\hline
\end{tabular}

The effect of condition on error severity. A Mann-Whitney U test was conducted to determine if there were differences in the severity of errors made by those who saw their BWC footage compared to those who did not see their footage. There were no significant differences between the two conditions on the severity of errors made (see Table 7).

Table 7

Mann-Whitney U Test Examining Differences in the Severity of Reporting Errors Made by Those who Saw Their Body Worn Camera Footage Compared to Those who did not see Their Footage

\begin{tabular}{lccccc}
\hline \multicolumn{1}{c}{ Categories } & Viewing Conditionsa & Control Conditionb & & & \\
\hline & $M d n$ & $M d n$ & $U$ & $z$ & $p$ \\
\cline { 2 - 6 } Minor Errors & 5.5 & 5 & 305.5 & -.371 & .711 \\
Moderate Errors & 5 & 4 & 313 & -.229 & .819 \\
Major Errors & 0 & 0 & 308 & -.392 & .695 \\
\hline
\end{tabular}

a $n=26$

$\mathrm{b} n=25$.

\section{Analyses Examining Type of Information Reported}

The linear relationships between the covariate (i.e., HRpeak above resting), and dependent variables examining the type of information (context, officer, and subject) reported for each condition were weak. Therefore, non-parametric tests were conducted in lieu of ANCOVA.

The effect of stress on type of information reported. None of the correlations between stress (as represented by HRpeak above resting) and type of details (context, officer, and subject) for the full sample, were significant. Likewise, when the data was split to examine male and female participants separately, no significant associations were observed; nor were there any significant 
associations observed when the data was split by condition to examine the relationship between HRpeak above resting and type of information reported (see Table 8). 
Table 8

Correlation Matrix Examining HRpeak above resting and Type of Information Required

\begin{tabular}{|c|c|c|c|c|c|c|c|c|c|c|}
\hline \multirow[t]{3}{*}{ Categories } & \multicolumn{10}{|c|}{ HRpeak above resting } \\
\hline & \multicolumn{2}{|c|}{ Full Sample } & \multicolumn{2}{|c|}{ Male } & \multicolumn{2}{|c|}{ Female } & \multicolumn{2}{|c|}{ Viewing Condition } & \multicolumn{2}{|c|}{ Control Condition } \\
\hline & $r_{s}$ & $p$ & $r_{s}$ & $p$ & $r_{s}$ & $p$ & $r_{s}$ & $p$ & $r_{s}$ & $p$ \\
\hline $\begin{array}{l}\text { Total Number of } \\
\text { Context-Related } \\
\text { Details }\end{array}$ & .091 & .263 & .089 & .287 & -.333 & .190 & -.006 & .977 & .169 & .418 \\
\hline $\begin{array}{l}\text { Total Number of } \\
\text { Officer-Related } \\
\text { Details }\end{array}$ & .029 & .420 & .101 & .262 & -.533 & .070 & -.072 & .725 & .154 & .461 \\
\hline $\begin{array}{l}\text { Total Number of } \\
\text { Subject-Related } \\
\text { Details }\end{array}$ & -.082 & .283 & -.108 & .249 & -.357 & .173 & -.100 & .626 & -.089 & .673 \\
\hline
\end{tabular}


The effect of condition on type of information reported. An independent samples $t$-test was conducted to examine if there was a difference between the conditions on the number of context-related details reported. In examining the total number of context-related details that participants reported, a boxplot identified three outliers. These outliers were legitimate and did not impact normality, as assessed by the Shapiro-Wilk test $(p>.05)$. Winsorizing these outliers did not change the outcome of the results, so they were retained as is. The $t$-test indicated that there was no significant difference between those who saw their BWC footage and those who did not see their footage with regard to the number of context-related details they reported. Given that the test was underpowered, Cohens $d$ was calculated despite the insignificant result. A small effect was observed, $d=.24$.

A second independent samples $t$-test was conducted to determine if there was a difference in the number of subject-related details reported for those who saw their BWC footage prior to writing their report, relative to those who did not get to see any footage. Participants who saw their footage before writing their report recalled significantly more subject-related details $(M=$ $27, S D=6.41)$ compared to those who did not see their footage $(M=23.32, S D=4.85), t(49)=$ $2.31, p=.025, d=.65$.

A final independent sample $t$-test was conducted to explore whether there was a difference in the number of officer-related details reported for those who saw their BWC footage prior to writing their report, relative to those who did not get to see any footage. There were two outliers noted, as assessed via a boxplot. However, the values appeared to be legitimate and winsorizing them did not change the outcome of the findings; they were thus retained. Moreover, while the viewing condition was normally distributed, the control condition violated ShapiroWilk's $(p<.05)$. Further examination revealed that skewness and kurtosis values were below a 
problematic threshold (Field, 2009), and the sample sizes in each condition were relatively equal ( $n=26$ versus $n=25$ ). Because the test is robust to violations of normality, we proceeded. The independent samples $t$-test revealed that there was no significant difference between the two conditions on the number of officer-related details reported; a small effect was observed $(d=$ .26). Table 9 and 10 outline the findings for the effect of condition on the type of information participants reported.

Table 9

Independent Samples T-Tests Exploring Differences Between Conditions on the Type of Information Reported

\begin{tabular}{lccccc}
\hline Categories & $t$ & $d f$ & $p$ & $95 \%$ CI & $d$ \\
\hline $\begin{array}{l}\text { Total Number of Context-Related } \\
\begin{array}{l}\text { Details } \\
\text { Total Number of Officer-Related }\end{array}\end{array}$ & .843 & 49 & .403 & $-6.12,14.97$ & .24 \\
$\begin{array}{l}\text { Details } \\
\text { Total Number of Subject-Related }\end{array}$ & 2.305 & 49 & .354 & $-3.62,9.92$ & .26 \\
\begin{tabular}{l} 
Details \\
\hline
\end{tabular} & & & $.025^{*}$ & $.47,6.89$ & .65 \\
\hline
\end{tabular}

Note. Significant at $* p<.05$.

Table 10

Descriptive Statistics Between Conditions on Type of Information Reported

\begin{tabular}{lcccc}
\hline Categories & \multicolumn{2}{c}{ Viewing Condition } & \multicolumn{2}{c}{ Control Condition } \\
\cline { 2 - 5 } & $M$ & $S D$ & $M$ & \multicolumn{1}{c}{$S D$} \\
\hline $\begin{array}{l}\text { Total Number of Context- } \\
\text { Related Details } \\
\text { Total Number of Officer- }\end{array}$ & 49.42 & 19.48 & 45 & 11.48 \\
$\begin{array}{l}\text { Related Details } \\
\text { Total Number of Subject- }\end{array}$ & 28.27 & 12.52 & 25.12 & 4.85 \\
Related Details & 27 & 6.41 & 23.32 & \\
\hline
\end{tabular}

\section{Discussion}

The current study exposed a sample of law enforcement officers to a realistic high stress scenario, and then examined differences in recall for those who were allowed to watch their BWC footage before completing a use-of-force report, relative to others tasked with completing 
their report without any aide. It was hypothesized that officers who watched their footage prereporting would provide more details and their report would be more accurate, compared to those who did not see their footage. It was further hypothesized that stress would act as a covariate in that higher levels of stress would be associated with fewer, less accurate details across both conditions.

Interestingly, contrary to what was expected, there was no significant difference in the overall amount of information (i.e., number of details) reported between officers who were allowed to view their footage and those barred from seeing their footage. It is important to note however, that while the finding was insignificant, the test was underpowered. There appeared to be a small effect, and thus with more participants, a significant difference may be observed. When the details were categorized according to whether they pertained to the context, subject, or officer, analyses revealed that those in the viewing condition reported significantly more subjectrelated details relative to those who did not see their footage.

There was no significant difference in overall accuracy between the two conditions, nor were there any differences in regard to the severity of errors made by officers (coded according to Dawes and colleagues' [2015] minor, moderate, and major error categories). However, there were significant associations between stress and moderate errors, as well as between stress and major errors for those in the control condition, suggesting that those unable to see their BWC footage, who experienced higher levels of stress during the scenario, made more moderate and major errors in their report. The detrimental effect of stress on recall, particularly for those in the control condition, is consistent with what was expected. However, for female participants alone, increased levels of stress appeared to be significantly associated with making fewer minor and 
moderate errors in their reports. The opposing effects of stress on report-writing require greater investigation, particularly with females given the small sample utilized in the current study.

\section{Drawing Comparisons Between the Current Study and Dawes et al.'s (2015) Work}

Both our sample of officers and Dawes and colleague's (2015) sample, were exposed to a simulated use-of-force scenario involving a disturbance call (with multiple subjects and the presence of weapons). However, in the current study, officers were required to use lethal force. In Dawes et al.'s study, the subject was simply handcuffed. The use of lethal force in the current study helped elicit the desired level of stress in participants (i.e., commensurate with real-world police stress responses [Anderson et al., 2002; Andersen et al., 2016; Baldwin et al., 2019]) so that its effect on recall could be tested. Relatedly, the officers in Dawes et al.'s study used a training dummy whenever the situation required them to use physical control. To enhance realism and provoke a stress response, the current study used live actors throughout the scenario. Given differences in the intensity of the scenarios, it was possible that less information might have been recalled in the current study and more errors could have been observed compared to Dawes et al.'s study. That being said, the pattern of results (i.e., where less information and more errors were predicted for those without BWC footage) were expected to be similar to Dawes et al.

As previously mentioned, Dawes et al. (2015) used a within-subjects design and tracked revisions in officers' reports following their viewing of BWC footage. A between-subjects design was utilized in the current study, allowing for a direct comparison to be made between officers who wrote their report without having seen their BWC footage relative to those who completed their report having seen their footage. Consistent with Dawes and colleagues' study, this methodology revealed that BWC footage may help officers provide more details about 
certain aspects of an incident and mitigate the impact of stress on recall. Also in line with the results reported by Dawes et al., our study also revealed that, overall, officers make very few major errors (e.g., miscounting three or more uses of force, falsely representing their use of force against policy) in their report. On average, participants made less than one major error in both studies. Alternatively, contrary to Dawes et al.'s study, the current research found that participants made more minor than moderate errors (this was reversed in Dawes et al.'s study). While difficult to directly compare the findings across the two studies given the inclusion of omissions in Dawes et al.'s research, it seems that in both cases, the largest number of errors made were in relation to misquotations.

The methodological differences between the current research and Dawes et al.'s (2015) study also made it difficult to know whether our sample would have made the same amendments to errors in their report, had they been given the chance. Recall that Dawes and colleagues (2015) allowed participants the opportunity to go back and amend errors that they had made in their original report. While it remains unclear if our participants would have corrected their errors in much the same way as Dawes' et al.'s sample, we were, for the first time, able to examine differences in the amount, accuracy, and severity of errors made between BWC-viewing and non-viewing groups. This provided a purer account of potential discrepancies between officers who are permitted to see their footage before writing their reports versus those who are prohibited from accessing their footage beforehand. Additional research that extends the current study, and the study conducted by Dawes et al., is necessary to determine whether the initial viewing of one's BWC footage promotes vulnerability to the misinformation effect (i.e., specious information from the footage being unconsciously incorporated into an officer's report). By establishing whether one can be misled by BWC footage, a greater understanding may be 
gained into the potential detriments of viewing footage before reporting. The eye tracker footage collected in the current study might provide insights that will help determine whether reported items were actually attended to during the scenario (and thus able to be recalled later on), or if officers who see their BWC footage are more apt to report things that were never truly seen during the incident. This analysis is currently underway and will be reported in a subsequent publication.

\section{Visual Evidence as Cues}

As noted in the literature review, a relatively large body of research has found that visual imagery can enhance episodic memory (e.g., Ally \& Budson, 2006; Aschermann et al., 1998; Jack et al., 2015). For instance, other lifelogging technologies that resemble BWCs appear to improve memory (Harvey et al. 2016; Sellen et al., 2007; Silva et al., 2013). Upon re-presenting an incident to an officer via BWC footage, one would thus expect a jog in memory, and more accurate details subsequently reported. It is surprising then that officers who saw their BWC footage in the current study did not recall significantly more details overall compared to those not exposed to the footage, nor did they show superior accuracy in what they recalled. There are a number of possible reasons for the null effect, beyond the possibility that the result may be explainable by a lack of power to detect one.

First, it is possible that the BWC footage simply did not introduce any new information that officers had not already included in their report. This could be an issue of quality; if, for instance, the footage was often obstructed (which can occur when a firearm is drawn in front of a chest mounted BWC), then it would be of little use for cueing dormant memories. Given the various limitations of BWCs (Blaskovits, McGale, \& Bennell, 2017; Remsberg, 2014), it may be that the technology itself does not provide rich enough visual imagery to facilitate additional 
recall. Granted, less realistic imagery (e.g., props, drawings) have been shown to have beneficial effects on memory (Gordon et al., 1993; Salmon et al., 1995; Wammes, Meade, \& Fernandes, 2016) so it is unlikely that even poor quality footage would not contain some memory enhancing cues. However, as there is no known empirical research to date exploring BWC quality, it is possible that the footage is less useful as a memory enhancement aid than previously imagined. Another reason that both groups may have reported a similar amount of information in the current study, could relate to the sample that was used. Officers in the current study (and in Dawes et al.'s [2015] study) were not accustomed to having BWC footage to review prior to writing their reports. Because the agency particpating in our study does not utlize BWCs, its officers must routinely rely on their own memory of what occurred in a given incident when completing their reports. If their reports are already comprehensive, viewing BWC footage might not add anything over and above what is already included. Considering the critical lens officers are under following their involvement in use-of-force events (Brown, 2016), it is likely that serious effort is invested into completing such reports as comprehensively and as accurately as possible. In fact, it is possible that officers who know they have been filmed but cannot see their footage work even harder to remember what occurred and complete their reports in full since any discrepancies between their report and the footage could be (inappropriately) perceived as deceptive.

While there were no significant differences between conditions in regard to the amount of information reported overall (albeit a small effect detected), those who watched their footage beforehand included significantly more subject-related details in their report. This makes sense given that BWCs are positioned such that they face forward and capture what is directly in front of an officer - which is typically the subject (as was the case in the current study). The fact that 
those in the viewing condition reported more subject-related details could thus be explained by the biased perspective of the camera. Additionally, though, officers might have a tendency to focus on the subject while watching the footage as the behaviour of the subject is likely most relevant when they need to articulate why they made the decisions they did (i.e., to justify their use-of-force); the context and their own behaviour may be less important. Nevertheless, as this was the first known study to explore differences in the type of information reported by officers who saw (or did not see) their BWC footage, future research in this area is encouraged.

\section{The Impact of Stress on Recall}

The current study built on Dawes and colleagues' (2015) work by explicitly measuring officers' stress via their HR. The use of participants' HRpeak above resting was consistent with other relevant research (e.g., Andersen et al., 2016; Andersen \& Gustafsberg, 2016), and the scenario appeared to elicit an appreciable amount of stress in participants in that it was commensurate with real-world police stress responses (Anderson et al., 2002; Andersen et al., 2016; Baldwin et al., 2019). As expected, stress impacted the severity of errors that officers made. Consistent with research suggesting that high and/or maladaptive levels of stress can result in reduced memory for an event (Lacy \& Stark, 2013), the findings indicated that for those unable to view their footage post-event, higher levels of stress related to the production of more moderate and major errors.

Maladaptive stress arousal can result in various deficits (Driskell \& Salas, 1996; Vickers \& Lewinski, 2007), making it difficult for individuals to properly recall certain aspects of an event (Eysenck, Derakshan, Santos, \& Calvo, 2007; Honig \& Lewinski, 2008; Nieuwenhuys \& Oudejans, 2011). These deficits can lead to gaps in one's memory trace, which may perpetuate the use of schemas (Lacy \& Stark, 2013; Bennell et al., 2007). Recall that while schemata are 
often endowed from past, similar occurrences that one has been repeatedly exposed to, they can be incorrect (i.e., they may not represent what occurred this time). The use of inaccurate schemas may have occurred in the current study, resulting in individuals "filling in" details. For example, participants may have reported their "typical" pattern of actions for handcuffing, when this may not have been how it actually happened in the scenario.

Interestingly, the relationship between stress and error production was only significant for those who did not have the opportunity to review their BWC footage. Recall prior research which suggested that when officers review their footage under less stressful circumstances, their recollection is less likely to be affected by possible sensory distortions. This enhanced clarity could be responsible for their improved memory for the event (Lacy \& Stark, 2013; Remsberg, 2016), though additional research is needed to unravel these differences. Nonetheless, agencies or oversight bodies with policies barring officers from viewing their footage prior to providing a statement or interview may want to consider the potentially adverse impacts this could have on the quality and accuracy of an officer's statement.

Because female officers had a significantly higher HRpeak above resting, they were analyzed as part of the full sample, as well as separately. This difference is consistent with other physiological research finding that females tend to have higher resting HRs compared to males (Pham, 2003). The independent analysis revealed that as female officers' HR increased during the scenario, less minor and moderate errors were made. This finding is contrary to what was expected for the full sample. However, females appear to have more complex HR dynamics than males (Ryan, Goldberger, Pincus, Mietus, \& Lipsitz, 1994). Perhaps other indices of stress are thus needed to truly understand its impact in females. Alternatively, it is possible that females who experienced higher levels of stress simply put in additional effort when completing their 
report to overcome any potential detriments. Females' reaction (and resultant behaviour) to their subjective level of stress may be different than males. Finally, it is also possible that some type of attentional narrowing may have occurred with this group. Researchers argue that attentional narrowing can enhance recall for central or important stimuli (on the grounds that such items capture attention; Easterbrook, 1959; Hope et al., 2016; Safer, Christianson, Autry, \& Osterlund, 1998). Female officers, under their elevated levels of stress, may have focused in on certain details, resulting in the production of less errors (minor and moderate) in their subsequent report. Nevertheless, until more research is conducted examining sex differences in memory performance for officers, it is unclear if there is something unique about female officers that changes their susceptibility to stress-related memory impairments.

\section{Limitations}

Recall that the sample of officers used in the current study are not issued BWCs for operational use and were, therefore, familiar with reporting without seeing their footage. While this characteristic of the sample is similar to the sample tested by Dawes and colleagues (2015), it potentially limits the generalizability of the research. As noted above, the recall of officers who do not use BWCs may be different from those who are accustomed to using BWCs since they are always tasked with remembering incidents without the benefit of a memory aid. This could enhance memory-relevant areas of the brain (e.g., like the hippocampus) in ways that are similar to what happens with other people who are forced to routinely rely on their memory to complete work-related tasks (e.g., taxi drivers; Maguire, Woollett, \& Spiers, 2006). Future research could examine this possibility more directly.

There are also two important issues of note in regard to the measures used. Consistent with other police research (Andersen \& Gustafsberg, 2016; Andersen et al., 2016; Arble et al., 
2019), HR was used as a proxy measure for stress. While HR is known to be a robust, ecologically valid measure of stress reactivity (Vrijkotte et al., 2000), it is not a complete measure of one's stress; other biomarkers, such as cortisol, are necessary to obtain a full account of one's level of stress (Arble et al., 2019; Brisinda, Fioravanti, Sorbo, Venuti, \& Fenici, 2015). Nonetheless, the equipment used allowed us to collect data continuously throughout the scenario, which would have been difficult had other, potentially more accurate methods been employed (e.g., cortisol). Research that explores the effect of stress on recall using differing physiological measures of stress is important to ensure the current results are replicable.

In addition, the use-of-force report that officers completed in the current study was adopted from the agency from which the officers were recruited. It was, therefore, representative of what they complete following genuine incidents with the public, increasing the external validity of the study. However, given the complexity of the scenario, it was difficult, if not impossible, to code the reports for omissions. This made it difficult to directly compare the current research to Dawes and colleagues' (2015) study. Nevertheless, despite differences in coding, error severity was similar across the two studies, suggesting that officers tend to make more minor and moderate errors, and very few major errors. The development of a more universal coding template, which requires a greater understanding of what constitutes "operationally-relevant details," is an important step forward.

Lastly, as noted, several of the analyses were underpowered. Effect sizes suggested that small, but potentially valid differences might be observed with the inclusion of more participants. Like other specialized populations, the recruitment of police officers for research purposes is challenging. Yet, the continued pursuit to better understand the cognitions, 
perceptions, and behaviours of those who work within the conditions required by the policing occupation, is pertinent.

\section{Conclusion}

One of the goals of this research was to determine whether memory for a use-of-force incident is improved when officers are permitted to watch their BWC footage before completing their post-event report, or whether such viewing actually makes memory worse. Arguably, our findings may support both positions. The study showed, albeit with a small sample of officers, that regardless of whether individuals watched their footage beforehand, the total amount of information and overall accuracy of that information, is similar. In other words, there was no major advantage gained from watching the footage. Stress, however, appeared to impair (or potentially promote) recall in various respects.

Those in favor of allowing officers access to their footage before report writing might argue that the results suggest that the impact of stress highlights the importance of giving officers the means to ensure their report is completed as comprehensively as possible. On the other hand, it may be argued that given the detrimental impact of stress, officers who see their footage initially may be more apt to report what happened in the footage rather than what they actually remember happening; in that case, one could simply rely on the footage alone. More research is needed to determine if, and how, BWC footage might alter an officer's account of an incident. Until then, greater public awareness of the effect of stress on memory is necessary. Officers cannot be expected to recall an incident like a camera records an event; this is even less true for a particularly critical, high stress occurrence. 


\section{References}

Ally, B. A., \& Budson, A. E. (2006). The worth of pictures: Using high density event-related potentials to understand the memorial power of pictures and the dynamics of recognition memory. NeuroImage, 35, 378-395.

Alpert, G. P., \& Smith, M. R. (1999). Police use-of-force data: Where we are and where we should be going. Police Quarterly, 2(1), 57-78.

Andersen, J. P., Papazoglou, K., Koskelainen, M., Nyman, M., Gustafsberg, H., \& Arnetz, B. B. (2015). Applying resilience promotion training among special forces police officers. Sage Open, 5(2), 2158244015590446.

Andersen, J. P., Pitel, M., Weerasinghe, A., \& Papazoglou, K. (2016). Highly realistic scenariobased training simulates the psychophysiology of real-world use of force encounters: Implications for improved police officer performance. Journal of Law Enforcement, 5(4), $1-13$.

Andersen, J. P., \& Gustafsberg, H. (2016). A training method to improve police use of force decision making: A randomized controlled trial. SAGE Open, 6(2), 2158244016638708.

Anderson, G. S., Litzenberger, R., \& Plecas, D. (2002). Physical evidence of police officer stress. Policing: An International Journal of Police Strategies \& Management, 25(2), $399-420$.

Arnetz, B. B., Nevedal, D. C., Lumley, M. A., Backman, L., \& Lublin, A. (2009). Trauma resilience training for police: Psychophysiological and performance effects. Journal of Police and Criminal Psychology, 24(1), 1-9.

Arble, E. P., Daugherty, A. M., \& Arnetz, B. B. (2019). Differential effects of physiological 
arousal following acute stress on police officer performance in a simulated critical incident. Frontiers in Psychology, 10(759), 1-11.

Artwohl, A. (2002). Perceptual and memory distortion during officer-involved shootings. Federal Bureau of Investigation Law Enforcement Bulletin, 71(10), 18-24.

Aschermann, E., Dannenberg, U., \& Schulz, A. P. (1998). Photographs as retrieval cues for children. Applied Cognitive Psychology, 12(1), 55-66.

Baldwin, S., Bennell, C., Andersen, J., Semple, T., \& Jenkins, B. (2019). Stress-activity mapping: Physiological responses during general duty police encounters. Frontiers in Psychology, 10, 1-17.

Barton, J., Vrij, A., \& Bull, R. (2000). High speed driving: Police use of lethal force during simulated incidents. Legal and Criminological Psychology, 5(1), 107-121.

Bennell, C., Jones, N. J., \& Corey, S. (2007). Does use-of-force simulation training in Canadian police agencies incorporate principles of effective training? Psychology, Public Policy, and Law, 13(1), 35-58.

Berkeley Police Department. (2019). Body worn cameras, policy 425. Retrieved from https://www.cityofberkeley.info/uploadedFiles/Police/Level_3__General/Body_Worn_Cameras.pdf

Berry, E., Kapur, N., Williams, L., Hodges, S., Watson, P., Smyth, G., ...\& Wood, K. (2007). The use of a wearable camera, SenseCam, as a pictorial diary to improve autobiographical memory in a patient with limbic encephalitis: A preliminary report. Neuropsychological Rehabilitation, 17(4-5), 582-601. 
Blaskovits, B., \& Bennell, C. (2019). Exploring the potential impact of body worn cameras on memory in officer-involved critical incidents: A literature review. Journal of Police and Criminal Psychology, 1-12.

Blaskovits, B., McGale, H., \& Bennell, C. (September, 2017). Everything is not as it appears: Examining the quality of officer-involved body worn camera (BWC) footage. Paper presented at the annual meeting of the Society for Police and Criminal Psychology, San Diego, CA.

Bremner, J. D. (1999). Does stress damage the brain? Biological Psychiatry, 45(7), 797-805.

Brewer, W. F., \& Nakamura, G. V. (1984). The nature and functions of schemas. Center for the Study of Reading, 325, 3-87.

Brisinda, D., Fioravanti, F., Sorbo, A. R., Venuti, A., \& Fenici, R. (2015). Psychophysiological assessment of acute stress induced by high-pressure law-enforcement driving: A pilot study. Psychology and Social Behavior Research, 2, 36-50.

British Columbia Provincial Policing Standards. (2020). Use offorce. Retrieved from https://www2.gov.bc.ca/assets/gov/law-crime-and-justice/criminaljustice/police/standards/1-7-1-reporting-and-investigation-use-of-weapons.pdf

Brown, G. R. (2016). The blue line on thin ice: Police use of force modifications in the era of camera-phones and YouTube. The British Journal of Criminology, 56(2), 293-312.

Christianson, S. Å. (1992). Emotional stress and eyewitness memory: A critical review. Psychological Bulletin, 112(2), 284-309.

Cicchetti, D. V. (1994). Guidelines, criteria, and rules of thumb for evaluating normed and standardized assessment instruments in psychology. Psychological Assessment, 6(4), 284-290. 
Civilian Review and Complaints Commission for the Royal Canadian Mounted Police. (2015). Chairperson-initiated complaint and public interest investigation regarding policing in northern British Columbia. Retrieved from https://www.crccccetp.gc.ca/pdf/northernBC-inR-eng.pdf

Conor, P. (March 28, 2018). Police resources in Canada, 2017. Statistics Canada. Retrieved from https://www150.statcan.gc.ca/n1/pub/85-002-x/2018001/article/54912-eng.htm

Crane, S. (2000). The red badge of courage. New York, NY: Random House

Data USA. (2019). Police officers. Retrieved from https://datausa.io/profile/soc/police-officers

Dawes, D.M., Heegaard, W., Brave, M., Paetow, G., Weston, B., \& Ho, J. (2015). Body-worn cameras improve law enforcement officer report writing accuracy. Journal of Law Enforcement, 4(6), 1-21.

Dawes, D. M., Ho, J. D., Vincent, A. S., Nystrom, P. C., Moore, J. C., Steinberg, L. W., ... \& Miner, J. R. (2014). The neurocognitive effects of simulated use-of-force scenarios. Forensic Science, Medicine, and Pathology, 10(1), 9-17.

Deffenbacher, K. A., Bornstein, B. H., Penrod, S. D., \& McGorty, E. K. (2004). A meta-analytic review of the effects of high stress on eyewitness memory. Law and Human Behavior, $28(6), 687-706$.

Driskell, J. E., \& Salas, E. (Eds.). (1996). Series in applied psychology: Stress and human performance. Hillsdale, NJ: Lawrence Erlbaum Associates, Inc.

Dusek, J. A., \& Eichenbaum, H. (1997). The hippocampus and memory for orderly stimulus relations. Proceedings of the National Academy of Sciences, 94(13), 7109-7114.

Easterbrook, J. A. (1959). The effect of emotion on cue utilization and the organization of behavior. Psychological Review, 66(3), 183-201. 
Elo, S., \& Kyngäs, H. (2008). The qualitative content analysis process. Journal of Advanced Nursing, 62(1), 107-115.

Eysenck, M. W., Derakshan, N., Santos, R., \& Calvo, M. G. (2007). Anxiety and cognitive performance: Attentional control theory. Emotion, 7(2), 336-353.

Farrar, W., \& Ariel, B. (2013). Self-awareness to being watched and socially desirable behavior: A field experiment on the effect of body-worn cameras on police use-of force. Washington, DC: Police Foundation.

Federal Law Enforcement Training Center. (2004). Survival Scores Research Project. United States Department of Homeland Security.

Field, A. (2009). Discovering statistics using SPSS (3rd ed). London, England: Sage Publications, Findlay, V. (2017). Body-worn cameras: Not seeing the forest for the technology? Retrieved from https://www.researchgate.net/publication/312234531_Body Worn_Cameras_Not_Seeing_the_Forest_for_the_Technology Ltd.

Fortin, N. J., Agster, K. L., \& Eichenbaum, H. B. (2002). Critical role of the hippocampus in memory for sequences of events. Nature Neuroscience, 5(5), 458-462.

Freund, K. (2015). When cameras are rolling: Privacy implications of body-mounted cameras on police. Columbia Journal of Law and Social Problems, 49, 91-133.

Garner, J. H., Hickman, M. J., Malega, R. W., \& Maxwell, C. D. (2018). Progress toward national estimates of police use of force. PloS one, 13(2), e0192932.

Geiselman, R. E., Fisher, R. P., MacKinnon, D. P., \& Holland, H. L. (1985). Eyewitness memory enhancement in the police interview: Cognitive retrieval mnemonics versus hypnosis. Journal of Applied Psychology, 70(2), 401-412. 
Gershon, R. R., Barocas, B., Canton, A. N., Li, X., \& Vlahov, D. (2009). Mental, physical, and behavioral outcomes associated with perceived work stress in police officers. Criminal Justice and Behavior, 36(3), 275-289.

Giles, D., Draper, N., \& Neil, W. (2016). Validity of the Polar V800 heart rate monitor to measure RR intervals at rest. European Journal of Applied Physiology, 116(3), 563-571.

Gillund, G., \& Shiffrin, R. M. (1984). A retrieval model for both recognition and recall. Psychological Review, 91(1), 1-67.

Gordon, B. N., Ornstein, P. A., Nida, R. E., Follmer, A., Crenshaw, M. C., \& Albert, G. (1993). Does the use of dolls facilitate children's memory of visits to the doctor? Applied Cognitive Psychology, 7(6), 459-474.

Grady, R. H., Butler, B. J., \& Loftus, E. F. (2016). What should happen after an officer-involved shooting? Memory concerns in police reporting procedures. Journal of Applied Research in Memory and Cognition, 5(3), 246-251.

Greenberg, M. S., Westcott, D. R., \& Bailey, S. E. (1998). When believing is seeing: The effect of scripts on eyewitness memory. Law and Human Behavior, 22(6), 685-694.

Hallgren, K. A. (2012). Computing inter-rater reliability for observational data: An overview and tutorial. Tutorials in Quantitative Methods for Psychology, 8(1), 23-34.

Hartman, M., Neill, D., O’Neill, J., \& Lewinski, W. (2017). Law enforcement memory of stressful events: Recall accuracy as a function of detail type. Law Enforcement Executive Forum, 17(3), 22-42.

Harvey, M., Langheinrich, M., \& Ward, G. (2016). Remembering through lifelogging: A survey of human memory augmentation. Pervasive and Mobile Computing, 27, 14-26. 
Ho, J. D., Dawes, D. M., McKay, E. M., Taliercio, J. J., White, S. D., Woodbury, B. J., ... \& Miner, J. R. (2017). Effect of body-worn cameras on EMS documentation accuracy: A pilot study. Prehospital Emergency Care, 21(2), 263-271.

Hodges, S., Berry, E., \& Wood, K. (2011). SenseCam: A wearable camera that stimulates and rehabilitates autobiographical memory. Memory, 19(7), 685-696.

Hope, L., Blocksidge, D., Gabbert, F., Sauer, J. D., Lewinski, W., Mirashi, A., \& Atuk, E. (2016). Memory and the operational witness: Police officer recall of firearms encounters as a function of active response role. Law and Human Behavior, 40(1), 23-35.

Honig, A., \& Lewinski, W. J. (2008). A survey of the research on human factors related to lethal force encounters: implications for law enforcement training, tactics, and testimony. Law Enforcement Executive Forum, 8(4), 129-152.

Hope, L., Lewinski, W., Dixon, J., Blocksidge, D., \& Gabbert, F. (2012). Witnesses in action: The effect of physical exertion on recall and recognition. Psychological Science, 23(4), 386-390.

Hulse, L. M., \& Memon, A. (2006). Fatal impact? The effects of emotional arousal and weapon presence on police officers' memories for a simulated crime. Legal and Criminological Psychology, 11(2), 313-325.

Hyatt, J. M., Mitchell, R. J., \& Ariel, B. (2017). The effects of a mandatory body-worn camera, policy on officer perceptions of accountability, oversight, and departmental culture. Villanova University Charles Widger School of Law, 62, 1005-1035.

Hyland, S. S. (2018). Body-worn cameras in law enforcement agencies, 2016. U.S. Department of Justice, Office of Justice Programs, Bureau of Justice Statistics. Retrieved from https://www.bjs.gov/content/pub/pdf/bwclea16.pdf 
Independent Investigation Agencies of Canada. (2016). Model Independent Investigation Agency Policy - Handling of Incident Video. Canada.

Jack, F., Martyn, E., \& Zajac, R. (2015). Getting the picture: Effects of sketch plans and photographs on children's, adolescents' and adults' eyewitness recall. Applied Cognitive Psychology, 29(5), 723-734.

Jennings, W. G., Fridell, L. A., \& Lynch, M. D. (2014). Cops and cameras: Officer perceptions of the use of body-worn cameras in law enforcement. Journal of Criminal Justice, 42(6), $549-556$.

Johnson, M. K., Hashtroudi, S., \& Lindsay, D. S. (1993). Source monitoring. Psychological Bulletin, 114(1), 3-28.

Jones, K. A., Crozier, W. E., \& Strange, D. (2018). Objectivity is a myth for you but not for me or police: A bias blind spot for viewing and remembering criminal events. Psychology, Public Policy, and Law, 24(2), 259-270.

Kalnikaite, V., Sellen, A., Whittaker, S., \& Kirk, D. (2010). Now let me see where I was: Understanding how lifelogs mediate memory. In Proceedings of the Special Interest Group on Computer Human Interaction Conference, 2045-2054.

Kayihan, G., Ersöz, G., Özkan, A., \& Koz, M. (2013). Relationship between efficiency of pistol shooting and selected physical-physiological parameters of police. Policing: An International Journal of Police Strategies \& Management, 36(4), 819-832.

Kleider, H. M., Pezdek, K., Goldinger, S. D., \& Kirk, A. (2008). Schema-driven source misattribution errors: remembering the expected from a witnessed event. Applied Cognitive Psychology, 22(1), 1-20. 
Klinger, D. A., \& Brunson, R. K. (2009). Police officers' perceptual distortions during lethal force situations: Informing the reasonableness standard. Criminology \& Public Policy, 8(1), 117-140.

Knight, M., \& Mather, M. (2009). Reconciling findings of emotion-induced memory enhancement and impairment of preceding items. Emotion, 9(6), 763-781.

Krafka, C., \& Penrod, S. (1985). Reinstatement of context in a field experiment on eyewitness identification. Journal of Personality and Social Psychology, 49(1), 58-69.

Lacy, J. W., \& Stark, C. E. (2013). The neuroscience of memory: Implications for the courtroom. Nature Reviews Neuroscience, 14(9), 649-658.

Laming, E. (2017, July 18). Canada needs a national database to track deadly force by police. HuffPost. Retrieved from https://www.huffingtonpost.ca/erick-laming/deadly-force-bypolice_a_23034831/

Laming, E. (2019). Police use of body worn cameras. Police Practice and Research, 20(2), 201216.

Laskowski, E. (2018). What's a normal resting heart rate? Mayo Clinic. Retrieved from https://www.mayoclinic.org/healthy-lifestyle/fitness/expert-answers/heart-rate/faq20057979

Loftus, E. F. (2005). Planting misinformation in the human mind: A 30-year investigation of the malleability of memory. Learning \& Memory, 12(4), 361-366.

Maguire, E. A., Woollett, K., \& Spiers, H. J. (2006). London taxi drivers and bus drivers: A structural MRI and neuropsychological analysis. Hippocampus, 16(12), 1091-1101.

Mather, M., \& Sutherland, M. R. (2011). Arousal-biased competition in perception and memory. Perspectives on Psychological Science, 6(2), 114-133. 
Mezey, N. (2013). The image cannot speak for itself: Film, summary judgment, and visual literacy. Valparaiso University Law Review, 48(1), 1-39.

Miller, K. (2008). Police stops, pretext, and racial profiling: Explaining warning and ticket stops using citizen self-reports. Journal of Ethnicity in Criminal Justice, 6(2), 123-149.

Mnookin, J. L. (1998). The image of truth: Photographic evidence and the power of analogy. Yale Journal of Law and the Humanities, 10(1), 1-74.

National Institute of Justice. (2016). Police use of force. Retrieved from https://www.nij.gov/topics/law-enforcement/officer-safety/use-offorce/pages/welcome.aspx

Nieuwenhuys, A., \& Oudejans, R. R. (2011). Training with anxiety: Short-and long-term effects on police officers' shooting behavior under pressure. Cognitive Processing, 12(3), 277288.

Parak, J., \& Korhonen, I. (2013). Accuracy of Firstbeat Bodyguard 2 beat-to-beat heart rate Monitor. White Paper Firstbeat Technology, 6-8.

Pezdek, K. (August 13, 2015). Should cops get to review the video before they report? The Marshall Project. Retrieved from https://www.themarshallproject.org/2015/08/13/should-cops-get-to-review-the-videobefore-they-report

Pham, T. V. (2003). Gender differences in cardiac development: Are hormones at the heart of the matter? Cardiovascular Research, 57, 591-593.

Plant, E. A., \& Peruche, B. M. (2005). The consequences of race for police officers' responses to criminal suspects. Psychological Science, 16(3), 180-183. 
Police Executive Research Forum. (2014). Implementing a body-worn camera program:

Recommendations and lessons learned. Office of Community Oriented Policing Services. Retrieved from https://www.policeforum.org/assets/docs/Free_Online_Documents/Technology/impleme nting $\% 20 \mathrm{a} \% 20$ body-worn $\% 20$ camera $\% 20$ program.pdf

Ramey, S. L., Perkhounkova, Y., Hein, M., Chung, S., Franke, W. D., \& Anderson, A. A. (2016). Building resilience in an urban police department. Journal of occupational and environmental medicine, 58(8), 796-804.

Remsberg, C. (October 1, 2014). 10 limitations of body cams you need to know for your protection. Force Science Institute. Retrieved from https://www.forcescience.org/2014/10/10-limitations-of-body-cams-you-need-to-knowfor-your-protection/

Remsberg, C. (August 28, 2015). First study: Does viewing body cam footage help report writing? Force Science Institute. Retrieved from https://www.forcescience.org/2015/08/first-study-does-viewing-body-cam-footage-helpreport-writing/

Remsberg, C. (December 30, 2016). Should cops see body cam video before giving use of force statements? Force Science Institute. Retrieved from https://www.forcescience.org/2016/12/should-cops-see-body-cam-video-before-givinguse-of-force-statements/

Remsberg, C. (April 10, 2018). Broad pre-statement review of body cam footage supported. Force Science Institute. Retrieved from https://www.forcescience.org/2018/04/broad-prestatement-review-of-body-cam-footage-supported/ 
Ruby, C. L., \& Brigham, J. C. (1996). A criminal schema: The role of chronicity, race, and socioeconomic status in law enforcement officials' perceptions of others. Journal of Applied Social Psychology, 26(2), 95-112.

Ryan, S. M., Goldberger, A. L., Pincus, S. M., Mietus, J., \& Lipsitz, L. A. (1994). Gender-and age-related differences in heart rate dynamics: are women more complex than men? Journal of the American College of Cardiology, 24(7), 1700-1707.

Safer, M. A., Christianson, S. Å., Autry, M. W., \& Österlund, K. (1998). Tunnel memory for traumatic events. Applied Cognitive Psychology, 12(2), 99-117.

Salmon, K., Bidrose, S., \& Pipe, M. E. (1995). Providing props to facilitate children's event reports: A comparison of toys and real items. Journal of Experimental Child Psychology, 60(1), 174-194.

Sharps, M. J. (2010). Processing under pressure: Stress, memory, and decision-making in law enforcement. Flushing, NY: Looseleaf Law Publications.

Shields, G. S., Sazma, M. A., McCullough, A. M., \& Yonelineas, A. P. (2017). The effects of acute stress on episodic memory: A meta-analysis and integrative review. Psychological Bulletin, 143(6), 636-675.

Sellen, A. J., Fogg, A., Aitken, M., Hodges, S., Rother, C., \& Wood, K. (2007). Do life-logging technologies support memory for the past? An experimental study using SenseCam. In Proceedings of the Special Interest Group on Computer Human Interaction Conference, 81-90.

Setcan Corporation. (2019). Stress Vest overview. Retrieved from http://stressvest.com/products/system/stressvests/ 
Silva, A. R., Pinho, S., Macedo, L., and Moulin, C. J. (2013). Does SenseCam improve general cognitive performance? American Journal of Preventative Medicine, 44(3), 302-307.

Smith, S. M., \& Vela, E. (1992). Environmental context-dependent eyewitness recognition. Applied Cognitive Psychology, 6(2), 125-139.

Stanley, J., \& Bibring, P. (January 13, 2015). Should Officers Be Permitted to View Body Camera Footage Before Writing Their Reports? American Civil Liberties Union. Retrieved from https://www.aclu.org/blog/free-future/should-officers-be-permittedviewbody-camera-footage-writing-their-reports

Staller, M. S., Cole, J. C., Zaiser, B., \& Korner, S. (2017). Representative training with less risk: The effects of non-lethal training and conventional ammunition in police use of force training on heart rate variability. Policing, 1-15.

Surprenant, A. M., \& Neath, I. (2013). Principles of memory. New York, NY: Psychology Press.

Tarvainen, M. P., Lipponen, J., Niskanen, J. P., \& Ranta-aho, P. O. (2019). Kubios HRV User's guide. Finland: Kubios.

Tsigos, C., \& Chrousos, G. P. (2002). Hypothalamic-pituitary-adrenal axis, neuroendocrine factors and stress. Journal of Psychosomatic Research, 53(4), 865-871.

Tse, D., Langston, R. F., Kakeyama, M., Bethus, I., Spooner, P. A., Wood, E. R., ... \& Morris, R. G. (2007). Schemas and memory consolidation. Science, 316(5821), 76-82.

Tulving, E. (1983). Elements of episodic memory. New York, NY: Oxford University Press.

Tulving, E., \& Thomson, D. M. (1973). Encoding specificity and retrieval processes in episodic memory. Psychological Review, 80(5), 352-373.

Tulving, E., \& Watkins, M. J. (1975). Structure of memory traces. Psychological Review, 82(4), 261-275. 
Vickers, J. N., \& Lewinski, W. (2012). Performing under pressure: Gaze control, decision making and shooting performance of elite and rookie police officers. Human Movement Science, 31(1), 101-117.

Vrijkotte, T. G., Van Doornen, L. J., \& De Geus, E. J. (2000). Effects of work stress on ambulatory blood pressure, heart rate, and heart rate variability. Hypertension, 35(4), 880-886.

Wammes, J. D., Meade, M. E., \& Fernandes, M. A. (2016). The drawing effect: Evidence for reliable and robust memory benefits in free recall. The Quarterly Journal of Experimental Psychology, 69(9), 1752-1776.

Wollert, T. N., Driskell, J. E., \& Quail, J. (2011). Stress exposure training guidelines: Instructor guide to reality-based training. Retrieved from http://www.virtualtacticalacademy.com/files/stress_exposure_training_manual_926B.pdf

Woodberry, E., Browne, G., Hodges, S., Watson, P., Kapur, N., \& Woodberry, K. (2015). The use of a wearable camera improves autobiographical memory in patients with Alzheimer's disease. Memory, 23(3), 340-349.

Yu, H., \& Bogen, M. (2017). The illusion of accuracy: How body-worn camera footage can distort evidence. Upturn. Retrieved from https://www.upturn.org/static/reports/2017/theillusion-of-accuracy/files/Upturn\%20and\%20LCCHR\%20\%20The\%20Illusion\%20of\%20Accuracy\%20v.1.0.pdf

Yuille, J. C., Davies, G., Gibling, F., Marxsen, D., \& Porter, S. (1994). Eyewitness memory of police trainees for realistic role plays. Journal of Applied Psychology, 79(6), 931-936. 


\title{
CHAPTER 5
}

\section{Evaluating the Utility of the Cognitive Interview for Enhancing the Memory of Police Officers Involved in Use-of-Force Events}

\author{
Brittany Blaskovits, ${ }^{*}$ Craig Bennell, Heather McGale, and Simon Baldwin \\ Department of Psychology, Carleton University, Ottawa, Ontario, Canada
}

* Address for correspondence: Brittany Blaskovits, Department of Psychology, Carleton University, 1125 Colonel by Drive, Ottawa, Ontario, Canada, K1S 5B6. Email:

brittanyblaskovits@cmail.carleton.ca

To be submitted to the Journal of Applied Cognitive Psychology 


\begin{abstract}
Typically, when police officers use force they are required to complete a report describing the encounter and explaining their actions. However, physiological effects that occur while under stress, such as during an officer-involved shooting, can make recall difficult (resulting in the provision of less accurate information). Therefore, it is important to examine techniques that could facilitate officer recall of use-of-force encounters. Research indicates that the efficacy of the cognitive interview (CI) generalizes across cultures, samples, time intervals, and event types. As such, it is possible that the CI could be a valuable tool for police officers when recounting stressful events. To date, there is no known research that has examined the efficacy of the CI for officer-involved shootings. To address this gap in the literature, the current study recruited 123 operational police officers, and exposed them to a realistic domestic dispute scenario that inevitably resulted in the use of lethal force. As a proxy measure for stress, all officers were equipped with a heart rate monitor to capture cardiovascular reactivity during the scenario. Stress reactivity appeared commensurate with real world police encounters. Approximately one third of the sample completed a CI, while the remaining officers were assigned to complete their agency's standard online use-of-force report. As expected, the results suggested that those exposed to a CI recalled significantly more details, and confabulated significantly less information, compared to those who completed the standard report. Scenario-based stress, however, did not have a significant effect on subsequent recall. The findings suggest that recall for use-of-force incidents may be improved with the use of a CI as opposed to a standard use-offorce report. The potential implications of this research on investigations into officer-involved critical incidents are discussed.
\end{abstract}

Keywords: cognitive interview, police, memory, use-of-force, incident reporting, stress 


\section{Evaluating the Utility of the Cognitive Interview for Enhancing the Memory of Police Officers Involved in Use-of-Force Events}

Following an incident involving the use-of-force, most police officers are required to complete a written report describing what occurred (Grady, Butler, \& Loftus, 2016). If the officer has deployed a firearm against a member of the public, a series of necessary procedures occur, and oversight mechanisms are enacted. The primary officer involved in the shooting is typically removed from the scene, provided access to counsel, interviewed, and asked to provide a written statement of the event (Emberlin, 2017; Grady et al., 2016; Long Beach Police Department, n.d.). As the investigation proceeds, the initial statements provided by the officer may be reviewed by senior commanders, district/crown attorneys, and should the case proceed to trial, the courts as well (Police Firearms Officers Association, 2017). Therefore, the integrity of the statements provided are vital, and particular care must be taken to ensure an officer articulates their memory for the event as fully and as accurately as possible (Grady et al., 2016; Hope et al., 2016).

However, physiological effects that occur under stress (such as during a lethal force event), can make recall of the event challenging (Lacy \& Stark, 2013). Research has shown that while moderate physiological arousal can improve memory for an event, high levels of stress can impair recall (Meyer \& Quenzer, 2013; Preston, 2016). Deficits may occur due to attentional narrowing at the time of encoding, exposure to misinformation post-event, or issues resulting from high cognitive load (Hope et al., 2016; Lacy \& Stark, 2013). Unfortunately, memory gaps and/or discrepancies in an officer's statement can be perceived as attempts to deceive (Grady et al., 2016; Hope et al., 2016), which could undermine an officer's credibility in court: 
“...skepticism over the accounts provided by officers in the aftermath of fatal shootings is well documented both in the [United Kingdom] and internationally...”(Hope et al., 2016, p. 23).

Considering the influence that such statements can have on the outcome of an officerinvolved shooting, it is important to test techniques that could potentially mitigate officer stress, and ultimately facilitate their recall of the event. One of the only studies that attempted to improve officer recall following involvement in a use-of-force event utilizing a differential reporting procedure was conducted by Pettalia, Korva, Bennell, Baldwin, and Karimullah (2016). In this unpublished study, 66 officers participated in a simulated use-of-force scenario. They were then randomly assigned to complete a report of the event using either the agency's standard online reporting tool, or an alternate electronic version of the tool that had been adapted using techniques from the Self-Administered Interview (SAI) - a paper and pencil version of the oral cognitive interview (CI; Geiselman et al., 1985; Hope, Gabbert, \& Fisher, 2011; Memon \& Bull, 1991). The findings indicated that more information was obtained via the adapted version relative to the standard tool and that no significant differences existed in the accuracy of the details between the two. These findings are encouraging as they suggest that relatively minor tweaks to a reporting form can increase the amount of evidentiary information obtained.

However, while the SAI is advantageous in that it provides a quick, easy, and costeffective method to enhance recall for stressful events, it may not be as effective as a true CI. The CI is arguably one of the most well-known interview techniques, and it consistently yields more information than other interview techniques when victims and witnesses are asked to recall previous events, without adversely impacting the accuracy of that information (Holliday, Brainerd, Reyna, \& Humphries, 2009; Kohnken, Milne, Memon, \& Bull, 1999; Memon, Meissner, \& Fraser, 2010). As such, use of the CI with law enforcement officials could be 
instrumental in obtaining complete and accurate reports, particularly for those officers involved in potentially traumatic use-of-force events.

\section{The Effect of Stress on Memory}

Police officers are legally authorized to use force if their actions are just and reasonable (Criminal Code, 1985; International Association of Chiefs of Police, 2001); nonetheless, officer involved use-of-force events are a rare occurrence. Available statistics suggest that "police use or threaten to use force in $1.7 \%$ of all contacts and in $20 \%$ of all arrests in the US" (Hickman et al., 2008, p. 563). Likewise, in Canada, force is used infrequently, with estimates suggesting officers use force in $.08 \%$ of police-public interactions (Baldwin et al., 2018). In terms of lethal force, data suggests that upwards of 1,100 civilians are killed each year by police in the US (Peeples, 2019; also see Shane et al., 2017); in Canada, there is approximately 19 police shooting deaths per year (Hopper, 2018). In either case, one's involvement in a lethal force event, or even a nonfatal altercation, undoubtedly contributes to stress in officers (Federal Law Enforcement Training Center [FLETC], 2004).

Indeed, it is widely recognized that police officers experience not only chronic stress, typically associated with ineffective workplace communication, heavy workload, rigid organizational structure, shift work, and overtime (Gershon et al., 2009; Karasek \& Theorell, 1990; Violanti \& Aron, 1995), but also acute stress. Saunders, Driskell, Johnston, and Salas (1996) describe acute stress as a decision-maker's response to a situation that is sudden, novel, intense, short-lived, and disruptive (all of which are characteristic of use-of-force events and officer-involved altercations more generally). The unpredictable nature of officer-citizen interactions, and the potential for threat of harm or death, results in a level of stress that is arguably unique to law enforcement 
One of the areas of the brain most affected by stress is the hippocampus, which resides midbrain near the amygdala (Bremner, 1999). The hippocampus plays a major role in memory and learning. The encoding and retrieval of autobiographical details, for example, relies on the hippocampus (Dusek \& Eichenbaum, 1997; Fortin, Agster, \& Eichenbaum, 2002). Research suggests that as spatial information is processed through the hippocampus, mental images are constructed (e.g., Bird \& Burgess, 2008; Jarrard, 1993); these images are then stored, and ultimately shape one's memory. When an individual is stressed, and there is a rise in cortisol (the principle hormone associated with stress; Kim et al., 2001), more hippocampal receptors become occupied. Exposure to extreme, prolonged, and/or maladaptive levels of stress can overwhelm the hippocampus, and even damage it (Bachevalier \& Meunier, 1996; Fortin et al., 2002). Indeed, research often finds an inverted U-shaped dose-response relationship between stress hormones and memory performance (Lacy \& Stark, 2013), whereby moderate levels of stress can be beneficial, but relatively low or high levels of stress can be detrimental, interrupting explicit memory formation (Meyer \& Quenzer, 2013; Preston, 2016). However, the amount, timing, and type of stress that one experiences can determine whether or not it has a positive or negative effect on their memory (Shields et al., 2017).

\section{Issues Affecting Memory Retrieval}

Research has consistently shown that despite long-standing beliefs in the reliability of memory, it is actually extremely malleable and prone to errors and distortion, particularly at the time of retrieval (Lacy \& Stark, 2013; Loftus, 1975; Loftus \& Palmer, 1974). The classic experiment by Loftus and Palmer (1974) revealed that small changes in questioning (e.g., using the word "smashed" as opposed to "collided," "bumped," "contacted," or "hit," when asking about an automobile accident) can produce differential memory reconstruction for that event. 
Specifically, the verb changes elicited various estimates of speed and the confabulation (i.e., fabrication) of broken glass at the scene in their participants.

Unfortunately, misleading questions about an experience can result in permanent memory loss for the original event (Ayers \& Reder, 1998). Depending on the nature of the questioning, new, false information can replace the original memory, resulting in what is widely known as the “misinformation effect” (Loftus \& Palmer, 1974). Perhaps even more concerning is a related phenomenon, the "false-event suggestion effect," where through suggestion, an individual comes to "remember" entire events that never actually occurred (Bernstein, Scoboria, Desjarlais, \& Soucie, 2018). Researchers have induced participants into believing they were involved in an accident (Hyman, Husband, \& Billings, 1995), attacked by a vicious animal (Porter, Yuille, \& Lehman, 1999), and even that they had tea with Prince Charles (Strange, Sutherland, \& Garry, 2006).

Exposure to various sources (e.g., news reports, discussing an event with others, suggestive interview practices) can impede and alter an original memory (Ayers \& Reder, 1998; Lacy \& Stark, 2013). Given how easily false information can be (unintentionally) incorporated into one's "memory" of an event, measures have been put in place in an attempt to reduce these “system variables” (i.e., controllable elements; Greenberg, Westcott, \& Bailey, 1998) and preserve eyewitness accounts. Eyewitnesses may be asked to provide a statement as soon as possible after an incident (Gabbert, Hope, \& Fisher, 2009), for example, and to avoid the media and/or discussions with others to prevent contamination (Department of Justice, 2015). However, another way to enhance the reliability of eyewitness accounts, and by extension, those involved in stressful encounters (e.g., police officers), is through informed reporting procedures.

\section{Improving Officer Memory of Critical Incidents}


As memory retrieval methods can have a major effect on what is recalled, the legal community has begun to recognize the importance of using sound interview techniques to avoid inaccuracies in recollections (Pezdek, Sperry, \& Owens, 2007). For example, the Canadian Commissions of Inquiry recommends that investigators be fully trained on techniques that enhance the reliability of witness statements and are aware of those that detract from same (Department of Justice, 2015). However, the process for police officers to retrieve memories for events they have been involved in is less clear. As noted, officers are typically required to complete some sort of report that allows them to articulate their reasoning for using force. This report effectively outlines what occurred, the officer's risk assessment, and their decisionmaking process (Laming, 2017; National Institute of Justice, 2016). The goal of these reports is to provide a record of an incident that describes the totality of the circumstances, which can be used for training purposes, policy development, audits, and as liability protection should an incident be investigated or brought to trial (e.g., Royal Canadian Mounted Police, 2014). Depending on the seriousness of the event, officers may also be interviewed, and their statements used as evidence in subsequent inquiries. Yet, reporting and interviewing practices are unstandardized, often varying from service to service, and very little research has been conducted to improve these processes (Kiedrowski, Melchers, Petrunik, \& Maxwell, 2015).

Like eyewitnesses, police officers involved in use-of-force events may be questioned on their statements and the credibility of their testimony. Moreover, with the introduction of body worn cameras, officers are under increasing pressure to ensure their reports coincide with what is shown in the footage (Dawes et al., 2015; Yu \& Bogen, 2017). Given the various issues that can occur at the time of encoding and retrieval (e.g., perceptual distortions, the misinformation effect; Lacy \& Stark, 2013), it is imperative that officer reports reflect their actual perception of 
an event, regardless of how different it may be from what was captured on a camera. As such, it is prudent to explore and employ techniques that may preserve officer memory, similar to those utilized for eyewitness accounts.

The Cognitive Interview. An individual's ability to recall a memory depends on the way that an event was encoded, and how the memory of that event interacts with the retrieval environment (Tulving \& Thomson, 1973). The CI attempts to improve retrieval by accessing the encoded event in various ways (Geiselman, Fisher, MacKinnon, \& Holland, 1986). This process draws on two major theoretical principles of memory: (1) the notion that the efficacy of a retrieval cue is related to its resemblance with the originally encoded event (Flexser \& Tulving, 1978; Geiselman et al., 1986), and (2) that the encoded event may be retrieved via several different pathways (i.e., information not accessible through one cue, may be accessed through a different one; Geiselman et al., 1986; Tulving, 1974). The original CI involves four key techniques (Memon, et al., 2010), two that aim to increase overlap between encoding and retrieval contexts and two that encourage using various retrieval paths (Geiselman et al., 1986).

The first technique is a version of free recall, whereby an interviewee is provided the opportunity to report everything about an event without interruption from the interviewer, regardless of the order it is recalled in, its perceived importance, or its completeness (Fisher \& Geiselman, 2010). Asking individuals to report everything ensures that they do not mistakenly exclude a particular element believing that it is irrelevant to the investigation. The second technique, mental reinstatement of context, aims to "....recreate the context of the original event at the time of recall" (Geiselman \& Fisher, 2014, p. 5). Individuals are often told to reflect on the temperature at the time of the event, what they heard, smelled, and/or the orientation of their surroundings (Memon \& Bull, 1991). Combined, reporting everything and context reinstatement 
aim to reduce the gap between the original event and current cues at the time of memory retrieval (Geiselman et al., 1986).

Next, interviewees may be instructed to recount the event in various orders or from several perspectives (Geiselman et al., 1986). These techniques are employed to aid retrieval and acquire additional information (that was perhaps forgotten or discounted during the individual's free narrative) by accessing the event through different pathways. Asking individuals to recall the event backwards-to-forward or onwards from a notable moment, for example, is based on the notion that gaps in memory tend to be "filled" with schemas or mental "short-cuts" of how a similar event would likely unfold, regardless of accuracy (e.g., Dawes et al., 2015).22 Recounting the event in a different order disrupts these schemas as one is forced to focus on each subsequent detail.

Additional techniques exist that are related to these main four, which can also be used to enhance recall. For instance, the sketch pad technique requires that an individual draw the layout of where an event occurred and/or talk their way through the incident as they draw (Eastwood et al., 2018). Like mental reinstatement of context, sketching can help one return to where an incident occurred (in their mind), thereby eliciting new details. The enhanced version of the CI, introduced in 1992 by Fisher and Geiselman, includes even more techniques that may enhance memory (Nori, Bensi, Gambetti, \& Giusberti, 2014). For the most part, these enhanced techniques relate to communication style and social dynamics (Fisher \& Geiselman, 2010; Nori et al., 2014).

22 Schemas are a way for the brain to compensate for an overloaded working memory. By recognizing patterns of interacting elements or "bits" of information that co-occur frequently, they become neurologically linked as a "set" or "schema" (Bennell, Jones, \& Corey, 2007; Paas, Renkl, \& Sweller, 2003). Schemas allow the brain to rapidly make sense of ambiguous situations (Tse, Lam, Loh, \& Lam, 2007). 
In brief, interviewers using the enhanced CI are trained to: (1) transfer control of the interview to the interviewee (providing interviewees a sense of power over the process; Fisher \& Geiselman, 2010), (2) use open-ended questions (promoting greater discussion and reducing biases; Fisher \& Geiselman, 2010; Reja, Manfreda, Hlebec, \& Vehovar, 2003), (3) develop rapport with the interviewee (which aims to reduce the anxiety associated with revealing often intimate information; Fisher et al., 1987), and (4) introduce guided imagery (during which, the interviewee may be asked to focus on specific features of an object, logo, setting, or moment). The use of images to guide recall can be accomplished in a variety of ways. For example, consistent with investigative research from Reiser (1980), individuals may be asked to slow down a particular phase in their memory and/or zoom in on a certain object (Whitehouse et al., 2005), so that an investigator can acquire more details about specific topics (e.g., the perpetrator, the weapon type).

The CI has mostly been used to enhance eyewitness memory and is often conducted by trained police officers or investigators (e.g., Memon \& Higham, 1999). In the majority of studies $(100+)$ conducted to date, findings indicate that the CI increases the quantity of accurate responses (i.e., more is remembered without affecting the proportion of correct to incorrect responses) relative to other standard interview types (e.g., Kebbell, Milne, \& Wagstaff, 1999; Köhnken, Milne, Memon, \& Bull, 1999; Memon et al., 2010). The CI also appears to improve the quality of information recalled (i.e., the depth of what is elicited). Its efficacy appears to generalize across cultures (e.g., US, Germany, Australia), samples (e.g., students, the cognitively impaired, the elderly, children, victims of crime), time intervals (e.g., minutes versus years), and types of events (e.g., crimes, accidents, daily activities; Fisher \& Geiselman, 2010).

\section{Purpose}


The physiological changes that occur while under stress (such as during an officerinvolved shooting), can make event recall challenging (Lacy \& Stark, 2013). Unfortunately, the public may perceive stress-induced memory gaps and/or discrepancies by officers as attempts to deceive. This could be problematic should the officer be required to testify in court. As research has suggested that the CI is effective at improving memory for past events (Kebbell et al., 1999; Köhnken et al., 1999; Memon et al., 2010), it is possible that the procedure could also have value for police officers who are asked to recount stressful events they have been involved in. To date, there is no known research that has examined the efficacy of the CI for police officers involved in use-of-force events. As such, the current study examined the recall of a sample of officers following a realistic lethal force scenario in which some officers were asked to complete a standard agency report, and the others completed a CI. The comparison allows for a greater understanding of what, if any, improvements to memory are achieved by utilizing the CI within a policing context, and whether this varies as a function of stress reactivity.

\section{Hypothesis 1A}

It is hypothesized that more information will be obtained from participants who provide their report of a simulated use-of-force incident via a CI (deemed the CI cohort), compared to participants who provide the incident in a standard use-of-force report (deemed the report cohort).

\section{Hypothesis 1B}

In addition, because high stress events can result in cognitive deficits (including memory impairment; e.g., Dawes et al., 2014; Dawes et al., 2015; Morgan et al., 2006), it is further hypothesized that stress will act as a covariate. More specifically, officers who recount the event 
via the standard use-of-force report or through a CI are expected to provide a significantly lower number of event-related details if they experience high levels of stress during the scenario.

\section{Hypothesis 2A}

It is hypothesized that individuals who complete a CI will report more accurate information compared to those who deliver their account of the incident via a use-of-force report.

\section{Hypothesis 2B}

It is further hypothesized that stress will act as a covariate. Specifically, officers who deliver their statement via a use-of-force report or through a CI are expected to provide significantly less accurate event-related details, if they experience high levels of stress.

\section{Method}

\section{Participants}

A total of 123 operational police officers participated in the current study. However, two CI's failed to record, and two use-of-force reports did not save to the network and could not be retrieved. Analyses are thus conducted on a sample of 119 officers. The majority of participants were male $(81.5 \%, n=97)$ and $18.5 \%(n=22)$ were female, which is consistent with the distribution of most police organizations in North America (Conor, 2018; Data USA, 2019). Participants ranged in age from 22 to 65 years old, with an average age of 38 years old $(S D=$ 8.26). Approximately 59.7\% $(n=71)$ of participants were married, and a lesser amount were common law $(16.8 \%, n=20)$ or single $(16 \%, n=19)$. Most participants indicated that they have children $(62.2 \%, n=74)$, and completed some sort of post-secondary education (Bachelor's Degree [31.1\%, $n=37]$; College Diploma or College Certificate [21.8\%, $n=26])$. The majority of participants were constables $(68.1 \%, n=81)$ or corporals $(20.2 \%, n=24)$, and had, on average, $11.22(S D=6.68)$ years of police service, $10.59(S D=6.44)$ of which were operational. 
Approximately $31.4 \%(n=37)$ of participants had experience as a use-of-force instructor. Lastly, most participants had never been involved in a lethal force encounter $(89.9 \%, n=107)$; however, $6.7 \%(n=8)$ of participants had witnessed one, and 3.4\%, $(n=4)$ had been involved as a primary officer in such an encounter.

Independent samples $t$-tests, chi-square tests, and Fisher's exact test were conducted to ascertain whether there were any differences between males and females on the various demographic variables. A chi-square test indicated that there was a significant association between sex and marital status, $X_{2}(4)=13.06, p=.011$, Cramer's $\mathrm{V}=.331$, whereby more males $(66 \%, n=64)$ reported being married, compared to females $(31.8 \%, n=7)$. There was also a significant association between sex and the presence of dependents as assessed by Fisher's Exact test, whereby more males $(67 \%, n=65)$ had children, compared to females $(40.9 \%, n=9), p=$ $.029, \varnothing=-.21$. Lastly, Fisher's Exact test indicated a significant association between sex and use-of-force instructor training experience, $p=.002, \varnothing=-.28$. More females $(95.5 \%, n=21)$ reported that they did not use-of-force instructor experience, compared to males $(62.5 \%, n=60)$. Analyses were thus conducted on the full sample, and independently for males and females.

\section{Equipment}

Heart rate. Heart rate was measured using two Polar V800 Heart Rate Monitor Watches ${ }^{\circledR}$ and a Polar H7 Chest Strap Heart Rate Monitor $®$. Together, these devices deliver a live, accurate reading of HR and corresponding R-R intervals23 (Giles, Draper, \& Neil, 2015). These devices have been used in prior research, and appear effective at capturing HR during periods of activity, such as when officers are on-shift or participating in high fidelity training

23 R-R intervals can be understood as the distance between the peaks of two waves that comprise a heart rhythm (Tarvainen, Niskanen, Lipponen, Ranta-aho, Karjalainen, 2014; Thayer, Ahs, Fredrikson, Sollers, \& Wager, 2012). When under stress, one's HR increases, resulting in shorter intervals between the two peaks. As the body returns to homeostasis, HR slows and the intervals become longer. 
exercises (Baldwin et al., 2019; Barton, Vrij, \& Bull, 2000; Kayihan, Ersoz, Ozkan, \& Koz, 2013). They have been validated against hospital-grade electrocardiograms, with recordings between the two appearing highly comparable (Giles et al., 2016). Participants were also equipped with (CFirstBeat Bodyguard 2 Heart Rate Monitors. These monitors have two disposable electrodes which are placed on each side of one's body, attached by a cable. They begin recording automatically and data is downloaded to FirstBeat software (Parak \& Korhonen, 2013). The multiple monitors provided additional sources to ensure the accuracy of the data collected and reduce the likelihood of lost or corrupted HR files (Parak \& Korhonen, 2013; Ramey et al., 2016).

StressVestтм. The StressVestтм is a training system that provides a pain penalty when an officer is "hit" by a mock bullet. Participants wear a vest and a StressXTM PRO BeltTM, and are provided with adapted pistols that can be used to "shoot" others wearing the vests (Setcan Corporation, 2019). Utilizing wireless infrared technology, the vest registers when an individual is "shot," and provides a shock to the abdomen. The system has been argued to induce the sort of stress officers experience in the field during critical incidents (Staller, Cole, Zaiser, \& Korner, 2017). It also provides the added benefits of safety (i.e., non-projectile weapons are used) and other forms of fidelity (e.g., the vest can be hidden under regular clothing resulting in a more realistic scenario, participants can communicate with each other more freely given that they are not required to wear bulky safety gear, such as face masks).

Cameras. In order to verify statements made by participants, each scenario was video recorded by several CGoPro HERO4 Silver cameras affixed in central locations around the facility. All participants also wore (CApplied Science Laboratories (ASL) Mobile Eye-5 Glasses (i.e., an eye-tracker) and certain participants wore Axon Body2® body worn cameras (for 
purposes unrelated to the current study). Combined, these video sources were able to provide a sound indication of ground truth (i.e., an objective account of what occurred).

Audio recorder. CI's were recorded using a CPhilips VoiceTracer Audio Recorder.

\section{Measures}

Demographic Questionnaire. The questionnaire consisted of 16 items that asked participants to report their age, rank, and years of service, among other qualities necessary for describing the sample.

Heart rate. When an individual is exposed to a real or perceived threat, the sympathetic nervous system reacts, resulting in an associated increase in HR (Thayer et al., 2012). Changes in HR are thus argued to indicate the extent to which an individual is experiencing stress. It is also feasible to continuously monitor HR during periods of activity at any time during the day, unlike some other proxies of stress (e.g., HR variability, cortisol; Dickerson \& Kemeny, 2004; Heathers \& Goodwin, 2017). Given the dynamic nature of the simulated scenario that participants were exposed to in the current study, HR was used as a proxy measure for stress.

Three measures of cardiovascular reactivity were calculated: (1) resting HR (HRrest), (2) maximum HR (HRpeak), and (3) peak above-resting (HRpeak above resting). To obtain participants' HRrest, the average of their lowest beats per minute (bpm) across one minute (while they completed pre-scenario paperwork) was calculated.24 Alternatively, participant's mean HRpeak was obtained during a critical phase in the scenario (e.g., when a knife was drawn, when a shooting occurred, when the officer went hands on with a subject). Lastly, participants' average HRpeak above resting was obtained by calculating the difference between the officers'

24 This approach aimed to avoid using potential artifacts (i.e., excessive and/or irregular low beats) as the resting rate. While a more accurate measure of resting HR might be acquired from officers immediately upon waking (Plowman \& Smith, 2013), similar approaches to those utilized in the current study have been used in prior research (e.g., Anderson et al., 2002; Andersen \& Gustafsberg, 2016; Baldwin et al., 2019). 
HRpeak and their HRrest (Anderson et al., 2002; Andersen \& Gustafsberg, 2016; Andersen, Pitel, Weerasinghe, \& Papazoglou, 2016). This metric was calculated to better account for individual differences in HR variability (i.e., such that those with lower resting rates would show larger relative increases compared to those with higher resting rates; Anderson et al., 2002).

Although the study was not clinical in nature, participants were asked whether they had cardiovascular disease and if they took any medication that could affect their cardiovascular system. Three participants (2.5\%) noted that they had cardiovascular disease and $10(8.4 \%)$ indicated that they took medications that could affect their HR. Independent samples t-tests indicated that there was no significant difference in average HRpeak above resting for those with cardiovascular disease, nor did there appear to be any significant difference for those who took medication that could affect their HR. As such, all participants were retained.

Use-of-force report. Following an application of force, the agency from which the officers were recruited require the completion of an online use-of-force report (as is common; Laming, 2017; National Institute of Justice, 2016). This report contains 32 drop-down questions that are relevant to the study, as well as two open-text boxes that request information related to the subject's behaviour, the officer's response, and various situational factors (e.g., weather conditions, time of day, presence of back-up). There is also a large open-text box at the end of the report where officers can elaborate on the event, allowing them to provide a full account of the incident, including their assessment of risk. The report ensures an officer's actions have been articulated should they ever be questioned. Participants assigned to the reporting condition completed this document.

The report captures the time that an officer "last modifies" or "saves" their use-of-force report online. Unfortunately, however, the time that an officer initializes their report is not 
recorded. In order to determine how long it took participants to complete their report, an approximate start time was estimated.25 The end time was then subtracted from the estimated start time to arrive at the average time it took participants to complete their report. The mean participant report completion time was 52 minutes $(S D=38$ minutes $)$.

Cognitive Interview. The remaining participants completed a CI with one of two trained interviewers.26 Interviews ranged in length from 16.25 - 58.11 minutes, averaging 30.89 minutes $(S D=9.75)$. Typically, interviews conducted with eyewitnesses take longer and/or require multiple interview sessions. However, in this study, the simulated scenario that participants were discussing had just occurred, which some research suggests makes recall quicker (e.g., Flin, Boon, Knox, \& Bull, 1992; Larsson et al., 2003). Moreover, the scenario itself was relatively short (i.e., there is only so many details to be remembered from a scenario that was, on average $8: 14$ minutes $[S D=2: 15]$ in duration). Importantly, the interview was also restricted in several ways. As described below, the interviewers used two or more techniques with all participants and stuck to a pre-determined set of close-ended questioning as the interview wrapped up. These decisions were made in order to respect participants' time and to ensure that there was some level of standardization between the two interviewers (and interviews themselves).

In all cases, the interviewers worked to develop rapport, participants were transferred control of the interview process, and provided the instruction to report everything. In fact, both interviewers followed a rehearsed script to ensure all participants received exactly the same initial instructions. The interviewers then asked participants to close their eyes, if they felt

25 Using a combination of HR and GPS data (acquired from a movement pod attached to each participant's foot), it was estimated that participants generally started their report approximately 15 minutes after the scenario (i.e., after they had been de-equipped and completed a short post-scenario questionnaire). Accordingly, a buffer time of 15 minutes was added to each participant's scenario end-time to estimate their report start time.

26 The first and third authors are trained in advanced cognitive interviewing (tier III). 
comfortable, and the mental reinstatement of context technique was utilized, where they were asked to freely recall everything they could about the event after re-imagining themselves back in the context where it occurred. All interviewees then sketched the layout of the building where the event occurred and described the event again while referring to their drawing. Depending on the information a participant disclosed and their receptivity to the process, the interviewers used two or more additional techniques with each participant (e.g., change perspectives, guided imagery).

Open-ended questioning was used throughout the interviews, and prompts were included to elicit more information. Consistent with the CI framework, the interview eventually funneled down into close-ended probing/questioning (Memon, Wark, Bull, \& Koehnken, 1997). The same series of close-ended questions were asked of all participants; these questions ensured certain elements, (i.e., those particularly important for a use-of-force investigation; e.g., number of shots fired, the provision of aftercare), were covered.27, 28

\section{Procedure}

Participants were recruited from a large Canadian police agency using email, flyers, and in-person discussions. If interested in participating, a timeslot was arranged. Upon arrival, participants reviewed an informed consent form. Those officers who consented to participate were cleansed of all live intervention options. They then completed a demographic form and several questionnaires not relevant to the current study. Next, they were outfitted with relevant

27 While the same list of questions was utilized for each participant, only those that pertained to a participant's individual scenario were asked (e.g., questions about shots fired were not asked to those who revealed that they never fired their gun).

28 Both interviewers refrained from observing the scenarios. This aimed to avoid any potential biases that could arise if an interviewer had knowledge about the event before conducting the interview. 
equipment, including the Stress VestTm system, the HR equipment, an eye-tracker, a BWC (if required for other aspects of the research), and inert intervention options.

All participants were dispatched to a simulated domestic disturbance call that was video recorded from several camera angles. Participants were told to respond to the call as they would in real-life. The scenario occurred in a building that had been designed to appear as an apartment complex. There was a living/dining room (with a couch, coffee table, magazines, candles, pictures, television, dining table, dining chairs, and other miscellaneous items) and a separate bedroom (complete with a bed, wardrobe, and clothes). Alcohol bottles were present, a radio blared loud music, and a scent training system (AirAware $\left.{ }^{\circledR}\right)$ released the smell of marijuana. From the outset, all participants experienced the same scenario, which involved a male actor (the witness) yelling, asking the participant to remove a second male (the perpetrator) from the residence, who was concealing a knife. However, depending on how the participant chose to respond, the scenario changed accordingly. For instance, if a participant chose to deploy their firearm immediately upon observing the knife, the perpetrator would say they had been hit and fall to the ground. Alternatively, if the participant tried to de-escalate the perpetrator holding the knife, then the scenario would devolve into a suicide attempt by the perpetrator.

Eventually, if the participant had not yet intervened lethally, the perpetrator and witness would get into a physical altercation. The perpetrator would then produce a firearm as soon as the participant attempted to disrupt the fight, thereby forcing the participant to respond with lethal force. Participants were free to use any of their intervention options and take as much time 
as necessary. The scenario ended once the participant had handcuffed the actor(s), were

providing medical attention to them, and/or were waiting for paramedics to arrive. 29

After the scenario, participants were de-equipped and completed a series of questionnaires unrelated to the current experiment.30 Then, approximately one third $(n=44)$ of participants completed a CI, and the remaining cohort $(n=75)$ completed the agency's standard use-of-force report.31 Participants were then debriefed by the researchers and a use-of-force instructor. All participants were provided the opportunity to withdraw their data, but none chose to withdraw. Participants were compensated with a $\$ 50.00$ gift card.

The study was approved by the XXXX University Ethics Committee for Psychological Research (CUREB-B Clearance \# 108733) as well as the Human Resources Research Review Board (2018-04) of the agency from which the officers were recruited.

\section{Results}

\section{Qualitative Coding}

In order to ensure consistency in coding (allowing for fair comparisons to be made between the two conditions), the use-of-force reports and CI's were coded similarly. In both cases, each sentence was divided such that every detail was captured. For example, if a

\footnotetext{
29 The scenario aimed to increase participant stress by including a threat, ambiguity, novelty, noise, and performance pressure (Driskell \& Salas, 1996; Saunders et al., 1996; Wollert, Driskell, \& Quail, 2011). It was developed in collaboration with several use-of-force subject matter experts and firearms training instructors. It was originally piloted with 12 officers and then amended to ensure that it remained standardized despite there being multiple ways a participant could initially react. The same two actors were present in every scenario. They followed a script that was flexible enough to ensure they could adapt to whatever decisions a participant made. The scenario room was readjusted after every participant so that it appeared the same for each new participant.

30 The questionnaires that participants were asked to complete resulted in a time lapse between the scenario and the time when they were required to recall the event. This enhanced the ecological validity of the study, since officers must often complete various other duties (e.g., wait for back-up, ensure public safety, return to their agency) before completing a report about an event.

31 Note that while every effort was made to ensure the random assignment of participants to either the reporting or CI condition, the groups were counterbalanced for an unrelated study. Some participants were also assigned to a certain condition as the result of limited time, equipment, and/or interviewer availability. Therefore, while the study cannot be said to have true random assignment, the lack of demographic differences between the groups suggest that it is unlikely any pre-existing differences contributed to the results.
} 
participant said, "There was a radio playing rap music and a blond guy there," then it would be broken down into four details: (1) the presence of a radio, (2) the type of music playing (i.e., rap), (3) the hair color of an actor (i.e., blond, and (4) the sex of an actor (i.e., male). The details were counted to obtain the total number of details recalled by each participant. One researcher coded all the CI's, and another independently coded a random subset $(25 \%)$ of them. The intraclass correlation (ICC) for the total number of details reported in the CI's was .65, which is considered 'moderate' agreement (Bobak, Barr, \& O’Malley, 2018; Koo \& Li, 2016). A separate researcher coded all of the use-of-force reports, and another coded a random subset $(25 \%)$ of them. The ICC for the total number of details reported for the use-of-force reports was .82, indicating a 'good' degree of agreement (e.g., Hallgren, 2012; Koo \& Li, 2016; McHugh, 2012).32

To determine the extent to which the details provided were accurate, inaccurate, or confabulated, each item was compared to the ground truth (i.e., if a participant reported that the music was rap, was the music playing at the time in fact rap?).33 As it was possible that individuals who had reported very few details could artificially inflate the counts, the total number of details a participant provided was divided by the number they reported accurately (or inaccurately or confabulated), and then multiplied by 100 . Tests were conducted with the percentage of details recalled as the primary dependent variable.

32 While the ICC for the CI's was notably lower in comparison to the ICC for the use-of-force reports, this is likely the result of the increased difficulty coding oral speech as opposed to written text. Participants in the CI condition were free to recall the event in whatever order they liked, and often talked about certain instances repeatedly, either adding or revising prior statements they made as they worked through their memory log. Alternatively, participants in the use-of-force reporting condition were more apt to write about the event as one cohesive story from start to finish. The researchers who coded the CI's were therefore challenged with updating their prior coding as more information came to light throughout each participant's interview.

33 Ground truth was established by watching a combination of the BWC, CGoPRO footage, and/or eye-tracker recordings. 
Details were considered accurate if ground truth proved them to be objectively correct (e.g., the participant said there was a bedroom, and there truly was a bedroom in the scenario). The ICC for the percentage of details recalled accurately for the CI's was .90 , and .81 for the use-of-force reports. Details were considered inaccurate if they were objectively false (e.g., if a participant noted that the perpetrator was wearing a black shirt when it was actually white). The ICC for the percentage of details recalled inaccurately for the CI's was .81 , and .84 for the useof-force reports. Lastly, details were considered confabulated if they were fabricated (e.g., the participant said the perpetrator was holding scissors when he never actually had scissors; consistent with French, Garry, and Loftus [2009] and Schacter, Norman, \& Koutstaal [1998]). The ICC for the percentage of confabulated details for the CI's was .73, and .74 for the use-offorce reports.

\section{Heart Rate Analyses}

The mean resting rate (HRrest) for the sample (obtained prior to the scenario) was 75.28 bpm $(S D=11.08)$, which is consistent with the baseline reported by Andersen and Gustafsberg (2016) and in line with the normal resting rate for adults (Laskowski, 2018). Whereas participant's mean maximum HR (HRpeak; obtained during the scenario) was $150.02(S D=$ 17.89). This rate is similar to that reported in other relevant research (e.g., Andersen et al., 2015; Arnetz, Nevedal, Lumley, Backman, \& Lublin, 2009), and indicates that participants experienced a notable stress response. Indeed, a paired samples $t$-test found a significant difference between the two phases, $t(118)=49.69, p<.001, d=5.02$, suggesting that on average, participants experienced significantly more stress during the scenario than they did at rest. This was the case for both males, $t(96)=46.31, p<.001, d=5.18$ and females, $t(21)=19.28, p<.001, d=4.47$. 
As noted, average peak above-resting (HRpeak above resting) was also calculated to account for individual differences in HR variability. Participants' average HRpeak above resting was $74.74 \mathrm{bpm}(S D=16.41)$, which is in line with previous research assessing stress reactivity in officers (e.g., Andersen et al., 2016; Andersen \& Gustafsberg, 2016). This metric was used in all subsequent analyses. There was no significant difference between males and females on HRpeak above resting.

\section{Descriptive Statistics}

Overall, across both conditions, the average number of details recalled was $116.74(S D=$ $45.02)$, and the majority of details were accurate $(M=96.89, S D=39.38)$. The mean number of inaccurate details was $8.38(S D=4.70)$, and the mean number of confabulated details was 4.43 $(S D=3.04)$. Relative to their total number of details recalled, on average, participants recalled $88.82 \%(S D=3.71)$ of details accurately, $7.19 \%(S D=2.96)$ inaccurately, and $3.99 \%(S D=$ 2.71) of the details were confabulated.

While it was beyond the scope of the current study to examine the type of errors that participants made, broadly speaking, the majority of inaccuracies and confabulations that were reported related to verbal dialogue that occurred (or not) between the participant and the actors. For example, several participants reported that they said "it's the police" upon arrival, when they never in fact, explicitly identified themselves. Participants also tended to report that they provided more specific details to the actors than they did in reality. For instance, participants often reported that they directed the actors to move in certain ways (e.g., "move to the right," "lift your left hand"); when in actuality, these directives were more ambiguous (e.g., "get out of the way," "come over here"). 
Other inaccuracies were related to the dispatch (e.g., the time until back-up arrived), the number of rounds fired by the participants and by the actors, descriptions of weapons (e.g., length of the knife), descriptions of the surroundings (e.g., the colour of the tablecloth), and descriptions of the actors (e.g., height, weight, colour of their shirts). Other confabulations were related to movements that participants made (e.g., re-holstering their pistol, when their gun actually remained out), movements that the actors reportedly made (e.g., standing up, when they never actually stood), and the presence of alcohol (e.g., noting the presence of liquid in the alcohol bottles, when they were, in fact, empty).

In order to examine the extent to which those assigned to the CI condition were demographically similar to those who completed a use-of-force report, a series of independent samples $t$-tests, chi-square tests, and Fisher's Exact tests were conducted. There were no significant differences observed between the groups on any of the demographic items.

\section{Hypothesis Testing of the Full Sample}

Because the covariate (HRpeak above resting) was not linearly related to the dependent variable (total number of details recalled), ANCOVA was deemed an inappropriate method of analysis. The data also failed to meet the assumption of normality for an independent-samples $t$ test and Pearson correlation. Thus, non-parametric tests were conducted.

Total number of details recalled. The first analysis involved examining the extent to which those who received a CI provided more information relative to those who recalled the incident via a standard use-of-force report. The non-parametric Mann-Whitney U test was conducted to determine if there was a difference in recall between the two groups. Distributions of the total number of details recalled for those in the CI cohort and reporting cohort were similar, as assessed by visual inspection of a population pyramid. The test indicated that the total 
number of details recalled was significantly higher for those who completed a CI $(M d n=139.5)$ than those who completed a use-of-force report $(M d n=89), U=2842.5, z=6.57, p<.001, r=$ .60 .

Next, a Spearman's rank-order correlation was run to assess the relationship between stress (as measured via HRpeak above resting) and the total number of details recalled. A scatterplot indicated the possibility of a monotonic relationship between the variables. However, there was no significant correlation between stress and total recall, $r_{s}=.059, p=.263$.

Percentage of details recalled accurately. To assess potential differences in accuracy between those who received a CI relative to those who completed a use-of-force report, a second Mann-Whitney U test was conducted. There was, however, no significant difference in accuracy between those who completed a CI $(M d n=89.72)$ and those who completed a use-of-force report $(M d n=89.29), U=1768.5, z=.65, p=.514, r=.06$. There was also no significant correlation between stress and accuracy, $r_{s}=.056, p=.274$.

Percentage of details recalled inaccurately. Next, a Mann-Whitney U test was conducted to assess differences in the percentage of details recalled inaccurately between those who received a CI relative to those who completed a report. Again though, there was no significant difference in inaccuracy between those who completed a CI $(M d n=6.88)$ and those who completed a use-of-force report $(M d n=6.42), U=1948, z=1.64, p=.101, r=.15$. Likewise, there was no significant correlation between stress and inaccuracy, $r s=.-.03, p=.388$. Percentage of details confabulated. A final Mann-Whitney U test was conducted to examine if there was a significant difference in the percentage of details confabulated by those who completed a CI compared to those who completed a use-of-force report. The result indicated 
that individuals completing a use-of-force report confabulated significantly more details $(M d n=$ 3.9), compared to those in the CI condition ( $M d n=3.21), U=1226, z=-2.33, p=.020, r=.21$

A final Spearman's rank-order correlation was run to assess the relationship between stress and the percentage of details confabulated. However, there was no significant correlation between stress and the amount of information confabulated, $r_{s}=.004, p=.483$.

\section{Hypothesis Testing of Males versus Females}

As there were some differences between males and females (e.g., use-of-force instructor experience), each sex was examined separately. However, as there were arguably too few females in each group to conduct inferential tests $(n=14$ in the reporting cohort and $n=8$ in the CI cohort), only descriptive statistics were conducted. Non-parametric tests were used with the sample of male participants, although it is important to note that the analyses were slightly underpowered (.79 for a two-tailed test, large effect size $[r=.60]$, alpha of .05 , and $n_{1}=61, n_{2}=$ 36).34

Total number of details recalled. A Mann-Whitney U test was conducted to determine if there was a difference in recall between males who received a CI relative to males who recalled the incident via a use-of-force report. A population pyramid suggested that the distributions of each group were similar and that median differences could thus be interpreted. Like the results utilizing the full sample, the test indicated that the total number of details recalled was significantly higher for males who completed a CI $(M d n=135.5)$ than for males who completed a use-of-force report $(M d n=88), U=1887, z=5.89, p<.001, r=.60$.

34 When the data was filtered to examine male participants alone there appeared to be a weak linear relationship between HRpeak above resting and the dependent variables: (1) total number of details recalled, (2) proportion of details that were accurate. However, the data was severely heteroscedastic and violated the assumption of homogeneity of variances and/or normality. For ease of interpretation non-parametric analyses were used alternative to ANCOVA. 
A Spearman's rank-order correlation was run to assess the relationship between stress (i.e., HRpeak above resting) and the total number of details recalled. A scatterplot indicated the possibility of a monotonic relationship between the variables. However, there was no significant correlation observed, $r_{s}=.14, p=.182$.

Like males, female participants who completed a CI reported more details $(M=150.75$, $S D=32.20)$ than those who completed a use-of-force report $(M=95.93, S D=30.82)$, though the magnitude of the difference between these groups remains unknown. A Spearman's rank-order correlation was run to assess the relationship between stress and the total number of details recalled by females. However, there was no significant correlation observed, $r_{s}=-.21, p=.357$.

Percentage of details recalled accurately. A Mann-Whitney U test was conducted to determine if there were any significant difference in the accuracy of the information reported by males who completed a CI versus males who completed a use-of-force report. No difference in accuracy between those in the CI condition $(M d n=89.77)$ and those in the use-of-force reporting condition $(M d n=89.57)$ was observed, $U=1144, z=.34, p=.731, r=.03$. There was also no significant correlation between stress and accuracy, $r_{s}=.064, p=.536$.

Descriptive statistics suggested that the sample of females' results trended in a similar direction to males. Females who completed a CI recalled more details accurately $(M=89.08, S D$ $=2.75)$ compared to those who completed a use-of-force report $(M=87.26, S D=4.17)$; though more participants are needed to test this difference statistically. Like males, there was no significant association observed between stress and the percentage of details recalled accurately by females, $r_{s}=.19, p=.388$.

Percentage of details recalled inaccurately. Another Mann-Whitney U test was conducted to assess if there was a significant difference between the percentage of details 
recalled inaccurately by males who completed a CI compared to males who completed a use-offorce report. This test suggested that there was no significant difference in inaccuracy between those who completed a CI $(M d n=6.88)$ and those who completed a use-of-force report $(M d n=$ 6.29), $U=1349, z=1.87, p=.061, r=.19$. Similarly, there was no significant relationship between stress and the percentage of details recalled inaccurately by males, $r_{s}=-.03, p=.776$.

Interestingly, the mean percentage of details that females recalled inaccurately in the CI condition was slightly higher $(M=8.30, S D=3.93)$, than that in the reporting condition $(M=$ $7.78, S D=2.59)$, but again, this difference was not tested statistically. There was also no significant association between stress and the percentage of details recalled inaccurately by females, $r_{s}=-.10, p=.665$.

Percentage of details confabulated. A Mann-Whitney U test was conducted to examine differences between males who completed a CI and males who completed a use-of-force report on the percentage of details that were confabulated. There was no significant difference between males who completed a CI $(M d n=3.21)$ and those in the reporting cohort $(M d n=3.9), U=857$, $z=-1.80, p=.072, \mathrm{r}=.18$ There was also no significant association between stress and the percentage of details that were confabulated by males $r_{s}=.02, p=.862$.

For females, a higher percentage of details were confabulated, on average, by those who completed a use-of-force report $(M=4.92, S D=3.10)$ compared to those who completed a CI $(M=2.63, S D=2.28)$; though no significance testing was done. The Spearman's rank-order correlation that was run to assess the relationship between stress and the percentage of details that were confabulated by females, was also non-significant, $r_{s}=-.09, p=.687$. 


\section{Discussion}

Memory of an event can be influenced both during the event at the time of encoding (e.g., via attentional narrowing, due to perceptual distortions; Artwohl, 2002), or after an event during retrieval (e.g., as a result of the misinformation effect; Pezdek et al., 2007). In order to preserve an original memory, factors during the event (e.g., stress) or those occurring after the event (e.g., retrieval cues) can be targeted. The present study investigated the effect of differential post-event reporting procedures for officers involved in a high stress simulated incident which elicited stress reactivity commensurate with real world policing. More specifically, it examined the utility of the CI relative to a standard use-of-force report. Several systematic reviews have found an overall positive effect of the CI on recall (e.g., Fisher \& York, 2009; Holliday et al., 2009), as have more formal meta-analyses (Köhnken et al., 1999; Memon et al., 2010). However, while the CI's utility for victims of crime and eyewitnesses has been recognized, its value for officers who are asked to recall critical incidents has not been established. Considering the gravity of officerinvolved use-of-force events, it is essential that reports provided by officers are completed as fully and accurately as possible.

Overall, the results of the study indicated that the majority of the information participants reported was accurate (i.e., nearly $90 \%$ of the details officers noted were accurate). This suggests that officers were able to recall incidents quite well, despite being under a considerable amount of stress. However, while there was no strong motivation for officers to misreport their actions, all officer reports contained some inaccurate and/or confabulated information. It has been argued that officers may misreport their actions following controversial use-of-force events, particularly if there is an impending criminal trial or they are at risk of losing their job (e.g., Grady et al., 2016; Hope et al., 2016). However, even under optimal conditions for recall (i.e., with no 
incentive or consequence to misreport information), officers had difficulty accurately recalling absolutely everything about a given instance.

The main analyses of the current study examined the quantity and accuracy of information recalled via an agency standard use-of-force report, relative to a CI. The findings indicated that the CI significantly increased the amount of information officers recalled relative to the standard use-of-force report, while significantly reducing the relative number of confabulations made. This finding is encouraging as CI's could mitigate reports that might have otherwise been scant or vague and thus perceived suspiciously by oversight bodies, including the courts (Pettalia et al., 2016). When males and females were examined separately, analyses still suggested that males who completed a CI recalled more details than those who completed the standard use-of-force report. It is important that male officers were receptive to the CI, as they continue to comprise the majority of the law enforcement profession (Conor, 2018; Data USA, 2019). However, future research examining a larger sample of female officers is warranted.

For the most part, it appeared that stress had little effect on recall. However, for male participants alone, higher levels of stress were significantly associated with a greater number of details recalled. This result was contrary to expectation and may be explained by the level of stress experienced by participants. As previous research has suggested, moderate stress levels can be beneficial, and it is only when stress becomes maladaptive that its deleterious effects become noticeable (Davis \& Loftus, 2009; Hope et al., 2016; Shackman et al., 2006). While the change in HR (i.e., increase of 74.74 bpm above resting) during the scenario suggested participants did experience a stress response, it may not have elicited the sort of impairments one would expect to see during a truly life-threatening incident. Moreover, it is not comparable to the 
type of post-incident stress that accompanies investigations into lethal force encounters, of which may also impair recall.

\section{Understanding the Utility of the Cognitive Interview}

Since the beneficial effect of the CI has been replicated across many samples (Fisher \& Geiselman, 2010), it is not necessarily surprising that its efficacy (whereby more information was retrieved without increasing the amount of errors) appears to generalize to police officers involved in stressful events. Unlike standard use-of-force reporting templates, the techniques inherent to the CI align with several major theoretical principles of memory. They aim to increase similarity between encoding and retrieval environments and retrieve the event via different pathways (Flexser \& Tulving, 1978; Geiselman et al., 1986; Tulving, 1974). The mental reinstatement of context and sketch pad techniques that were enacted with all officers in the CI cohort are specifically designed to increase the number of cues available from the encoding environment to aid officers during retrieval. Various other techniques (e.g., guided imagery, change of perspective) were also used depending on the nature of an officer's recall. These attempted to disrupt pre-formed schemas and broaden participant memory for an instance that may otherwise have been limited by stress-related impairments. Providing officers with more cues during retrieval and interrupting their tendency to automatically draw from a schema, appeared to help elicit more information.

Alternatively, the standard use-of-force report that the other participant cohort completed, while utilizing some of these techniques, was obviously constrained. For example, the open text box questions provide officers with the ability to freely recall what had occurred, similar to a CI. Likewise, the questions asked in the report arguably act as their own "cues," ensuring officers speak to various situational factors that might increase overlap between the encoding and 
retrieval environments. However, these cues are also restricted by their question format (i.e., drop-down options), and there is no way for certain memories to be accessed via differential pathways. The findings suggest that these differences in reporting techniques are important in terms of the amount of information that is evoked.

Recall that officers were also more likely to confabulate if they completed a use-of-force report; suggesting there may be something about the report that encourages the fabrication of information. Perhaps the questions presented in the report bias officer memory, resulting in an unintentional misinformation or false-event suggestion effect, where instances that never occurred are "remembered" as though they had occurred. For example, a close-ended question like "Was the subject perceived to be under any influences? If so, were they under the influence of drugs? Alcohol? Inhalants?" could, theoretically prompt an officer who may not have originally believed a subject to be intoxicated to consider if their behaviour might be explainable by substance use. A qualitative analysis was beyond the scope of the current study which would have allowed us to explore the possibility of a misinformation effect. However, in line with this line of thinking, it is interestingly to note that while all of the bottles in the scenario room were empty, several officers who completed the use-of-force report mistakenly "recalled" that there was alcohol in the bottles and even that they remember smelling alcohol.

It is also possible that a higher rate of confabulation occurred in the use-of-force reporting condition because officers felt undue pressure to complete the report in its entirety, and thus filled in each box of the report with something, even if they could not truly recall those details. At the outset of the CI, officers are instructed not to "guess" and that if they are making a guess or are unsure about their answer to inform the interviewer. They are reminded of this again 
prior to the close-ended questioning. These cautions are provided face-to-face and arguably highly salient. The use-of-force report, on the other hand, does not have any such cautions.

On the other hand, it could also be that the confabulations present in the use-of-force report occurred as the result of schemas. As noted, well-formed schemas may be favoured when recalling an incident, especially when an individual is under stress during encoding (Bennell et al., 2007; Paas et al., 2003). These schemas may be automatically elicited and heavily relied upon when completing something as common and/or familiar to an officer as a use-of-force report, regardless of their accuracy. The CI on the other hand, as noted, utilizes techniques like change of perspective which is designed to disrupt schemas by asking individuals to recount "typical" actions (e.g., like handcuffing) from the point of view of someone else in the room. This gets them to break down a sequence of actions that is usually automatic to them, often resulting in more details about said behaviour (e.g., Geiselman et al., 1986).

Importantly, the current findings were consistent with Pettalia and colleagues' (2016) study. Recall that in their study, officers who were provided an electronic reporting template that had been modified using techniques from the SAI (a paper and pencil adaptation of the oral CI), included more information about a critical incident, compared to those who used a standard useof-force report. Pettalia et al.'s findings suggested that incorporating memory enhancing techniques into traditional police reporting tools has the potential to increase the amount of informatin reported by officers, at least for simulated events. 35 Our study extended Pettalia et al.'s work by immersing officers in a notably longer, more complex, lifelike scenario; then exposing some officers to the full CI (comprised of various and individualized memory exposed to a video of a stressful incident, projected onto a life-size screen, that requires them to shoot (using an adapted pistol) at the screen. 
enhancing techniques). Our work indicates that even under these more genuine conditions, a similar effect is observed.

Interestingly, the null findings were also similar to Pettalia et al.'s (2016). Like their study, we did not find a significant difference in the accuracy of the information reported by participants in the standard versus adapted condition. This suggests that while the memory enhancing techniques used elicited more information from participants, it did not affect the accuracy of that information (albeit, our study did find that the CI decreased the number of confabulations made by participants - a subcomponent of accuracy). In Pettalia et al.'s research, there were too few items to explore that relationship statistically. Moreover, Pettalia et al. found no significant relation between recall and stress (as measured via self-report scales). Likewise, in the current study, the main analyses found no significant effect of stress (in this case, measured via HRpeak above resting) on recall either.

\section{Limitations}

As noted, a lethal force event may precipitate an interview with the primary officer and the completion of a use-of-force report (Emberlin, 2017; Grady et al., 2016). Therefore, regardless of which reporting procedure is more beneficial for recall, officers may still be required to complete both. An additional comparison is thus needed comparing the CI to other, current interview practices in use with officers. The present study does, however, provide an indication of which format - CI or standard use-of-force report - should be relied on by the courts, external oversight bodies (e.g., civilian review agencies), police investigators and executives, and the general public. It is unlikely that an officer's account of an incident will ever be $100 \%$ accurate, simply due to the limitations of the human memory system. However, by placing more weight on officer recollections provided through a CI, those scrutinizing officer 
accounts can be confident they are receiving a more holistic and all-encompassing account of an event (with no additional errors). Written statements may be best used as a record, removed from high-profile inquiries.

While great lengths were taken to ensure the scenario had high external validity (e.g., by utilizing the StressVestTm system, the apartment set-up, the role-players), the participants were obviously aware that their performance would have no real life or death consequences, nor any impact on their employment or result in legal consequences. This may have lessened the stress they experienced during the event, as well as the pressure felt to complete a use-of-force report as thoroughly as a genuine incident would have required. Yet, participant HRpeak above resting rates indicated they had experienced a stress response, which was consistent with prior research that has attempted to elicit stress via high fidelity training scenarios (e.g., Andersen \& Gustafsberg, 2016; FLETC, 2004; Hope et al., 2012, 2016). The HR acquired in the current study was, in fact, comparable to those recorded in actual police encounters (Andersen et al., 2016, Anderson et al., 2002, Baldwin et al., 2019).

The way in which HR was used as a proxy measure for stress comes with certain drawbacks as well. HR has been reliably used in prior studies with police officers (e.g., Andersen \& Gustafsberg, 2016; Andersen et al., 2016; Arble et al., 2019), and is arguably an accurate, objective measure of one's stress (Vrijkotte et al., 2000). However, other biomarkers may provide more precise estimates of stress. Heart rate variability, for example, is known to be a robust indicator of stress, providing detailed information about the functional regulatory characteristics of the autonomic nervous system (von Borrell et al., 2007). However, this measure is susceptible to error when collected during periods of movement (such as during a scenario-based training exercise; Dickerson \& Kemeny, 2004; Heathers \& Goodwin, 2017). The 
pros and cons of various physiological measures were thus considered in line with the study's design. Future research that corroborates the findings of this study using other measures of stress reactivity (e.g., salivary cortisol) is necessary.

It is also important to note that the quality of the CI's was likely reduced in our attempt to standardize them. Indeed, in order to respect officers' time and enhance control across participants (and between interviewers), the CI's were restricted in certain ways. For example, while additional probing questions could have been used with some participants, only the predetermined list of questions was referred to in the final stages of the interview. Likewise, while more techniques could have been drawn on with participants who were particularly receptive to the process, interviewers were mindful of the time spent with officers and rarely used more than two additional techniques (over and above mental reinstatement of context and sketching). While these artificial limitations reduce the ecological validity of the study to some extent, it is likely that various restraints would also exist in "real life." Moreover, given the findings, it is probable that the use of more CI techniques and/or more individualized interviews would have simply increased the beneficial effects already found. Nonetheless, additional research is needed to ensure that the value of a CI approach outweighs any cost (e.g., time, training) that would be invested in adopting it.

Relatedly, it is unclear if the additional information provided via the CI would be relevant and/or necessary for an investigation. It was beyond the scope of the current research to examine the nature of the information provided through one medium relative to the other. However, if, for instance, the additional information that is being reported using the CI is simply extraneous and/or meaningless (e.g., the colour of a bystander's shirt, the brand of chips on a kitchen table), then it may not be worthwhile to incorporate CI's into current practice. Therefore, before police 
organizations consider adopting the CI for officer-involved use-of-force events, additional research must examine the quality of the information obtained from these interviews. The present study was a preliminary step focused on examining the efficacy of certain articulation tools available to law enforcement. An ongoing goal to improve recall following officer-involved useof-force events is encouraged.

\section{Conclusion}

Given the level of scrutiny under which police officers function (e.g., Laucius, 2019), it is important that officers involved in high-profile use-of-force cases be provided techniques known to enhance recall. It appears that the CI may help ensure a more complete account of an event is documented, whilst mitigating the potential for confabulations. Many police agencies have adopted the CI for use in investigations (e.g., interviewing survivors and witnesses; FLETC, 2015). The results of this study suggest there may be value in also providing access to a cognitive interviewer for officers involved in critical use-of-force events. Considering that the standard use-of-force report took officers nearly double the amount of time to complete then did a CI, the implementation of a CI may actually save officers time; 36 time being a highly limited resource in policing. In any case, the findings shed light on the efficacy of cognitive interviewing in a novel context. In a practical sense, this is crucial information for police agencies looking to improve their investigations of officer-involved shootings in the future.

36 Albeit, it is important to note that this does not take into account the resources and time required at the front-end by organizations, such as the initial training of interviewers. 


\section{References}

Andersen, J. P., \& Gustafsberg, H. (2016). A training method to improve police use of force decision making: A randomized controlled trial. SAGE Open, 6(2).

Andersen, J. P., Papazoglou, K., Koskelainen, M., Nyman, M., Gustafsberg, H., \& Arnetz, B. B. (2015). Applying resilience promotion training among special forces police officers. Sage Open, 5(2).

Andersen, J. P., Pitel, M., Weerasinghe, A., \& Papazoglou, K. (2016). Highly realistic scenariobased training simulates the psychophysiology of real-world use of force encounters: Implications for improved police officer performance. Journal of Law Enforcement, 5(4), $1-13$

Anderson, G. S., Litzenberger, R., \& Plecas, D. (2002). Physical evidence of police officer stress. Policing: An International Journal of Police Strategies and Management, 25(2), $399-420$.

Arble, E. P., Daugherty, A. M., \& Arnetz, B. B. (2019). Differential effects of physiological arousal following acute stress on police officer performance in a simulated critical incident. Frontiers in Psychology, 10(759), 1-11.

Arnetz, B. B., Nevedal, D. C., Lumley, M. A., Backman, L., \& Lublin, A. (2009). Trauma resilience training for police: Psychophysiological and performance effects. Journal of Police and Criminal Psychology, 24(1), 1-9.

Artwohl, A. (2002). Perceptual and memory distortion during officer-involved shootings. Federal Bureau of Investigation Law Enforcement Bulletin, 71(10), 18-24. 
Ayers, M. S., \& Reder, L. M. (1998). A theoretical review of the misinformation effect: Predictions from an activation-based memory model. Psychonomic Bulletin and Review, $5(1), 1-21$.

Bachevalier, J., \& Meunier, M. (1996). Cerebral ischemia: Are the memory deficits associated with hippocampal cell loss? Hippocampus, 6(5), 553-560.

Baldwin, S., Bennell, C., Andersen, J., Semple, T., \& Jenkins, B. (2019). Stress-activity mapping: Physiological responses during general duty police encounters. Frontiers in Psychology, 10(2216), 1-17.

Baldwin, S., Hall, C., Blaskovits, B., Bennell, C., Lawrence, C., \& Semple, T. (2018). Excited delirium syndrome (ExDS): Situational factors and risks to officer safety in non-fatal use of force encounters. International Journal of Law and Psychiatry, 60, 26-34.

Barton, J., Vrij, A., \& Bull, R. (2000). High speed driving: Police use of lethal force during simulated incidents. Legal and Criminological Psychology, 5(1), 107-121.

Bennell, C., Jones, N. J., \& Corey, S. (2007). Does use-of-force simulation training in Canadian police agencies incorporate principles of effective training? Psychology, Public Policy, and Law, 13(1), 35-58.

Bernstein, D. M., Scoboria, A., Desjarlais, L., \& Soucie, K. (2018). "False memory" is a linguistic convenience. Psychology of Consciousness: Theory, Research, and Practice, $5(2), 161-179$.

Bird, C. M., \& Burgess, N. (2008). The hippocampus and memory: Insights from spatial processing. Nature Reviews Neuroscience, 9(3), 182-194. 
Bobak, C. A., Barr, P. J., \& O’Malley, A. J. (2018). Estimation of an inter-rater intra-class correlation coefficient that overcomes common assumption violations in the assessment of health measurement scales. BMC Medical Research Methodology, 18(93), 1-11.

Bremner, J. D. (1999). Does stress damage the brain? Biological Psychiatry, 45(7), 797-805.

Conor, P. (March 28, 2018). Police resources in Canada, 2017. Statistics Canada. Retrieved from https://www150.statcan.gc.ca/n1/pub/85-002-x/2018001/article/54912-eng.htm

Criminal Code, RSC 1985, c. C - 46. Protection of persons acting under authority, RSC 1985, s. 25. Retrieved from https://laws-lois.justice.gc.ca/eng/acts/c-46/section-25.html Data USA. (2019). Police officers. Retrieved from https://datausa.io/profile/soc/police-officers Davis, D., \& Loftus, E. F. (2009). Expectancies, emotion, and memory reports for visual events. In J. R. Brockmole (Ed.), The visual world in memory (pp. 178-214). Psychology Press.

Dawes, D. M., Ho, J. D., Vincent, A. S., Nystrom, P. C., Moore, J. C., Steinberg, L. W., ... \& Miner, J. R. (2014). The neurocognitive effects of simulated use-of-force scenarios. Forensic Science, Medicine, and Pathology, 10(1), 9-17.

Dawes, D.M., Heegaard, W., Brave, M., Paetow, G., Weston, B., \& Ho, J. (2015). Body-worn cameras improve law enforcement officer report writing accuracy. Journal of Law Enforcement, 4(6), 1-21.

Department of Justice. (2015). FPT Heads of Prosecutions Committee report of the Working Group on the Prevention of Miscarriages of Justice. Retrieved from https://www.justice.gc.ca/eng/rp-pr/cj-jp/ccr-rc/pmj-pej/p5.html

Dickerson, S. S., \& Kemeny, M. E. (2004). Acute stressors and cortisol responses: A theoretical integration and synthesis of laboratory research. Psychological Bulletin, 130(3), 355-391. 
Driskell, J. E., \& Salas, E. (Eds.). (1996). Series in applied psychology: Stress and human performance. Lawrence Erlbaum Associates, Inc.

Dusek, J. A., \& Eichenbaum, H. (1997). The hippocampus and memory for orderly stimulus relations. Proceedings of the National Academy of Sciences, 94(13), 7109-7114.

Eastwood, J., Snook, B., \& Luther, K. (2018). Measuring the effectiveness of the sketch procedure for recalling details of a live interactive event. Applied Cognitive Psychology, 32(6), 747-754.

Emberlin, R. (2017, December 20). What happens after a police officer uses deadly force? Police One. Retrieved from https://www.policeone.com/health-fitness/articles/what-happensafter-a-police-officer-uses-deadly-force-Pko1xmTB2dbHXDOu/

Federal Law Enforcement Training Center. (2004). Survival scores research project. Department of Homeland Security. Retrieved from https://www.fletc.gov/sites/default/files/imported_files/reference/researchpapers/survival_scores_research.pdf

Federal Law Enforcement Training Centers. (2015). Advanced interviewing for law enforcement investigators. Retrieved from https://www.fletc.gov/training-program/advancedinterviewing-law-enforcement-investigators

Fisher, R. P. \& York, R. M. (2009). Enhancing eyewitness memory with the cognitive interview. In M. St-Yves \& M. Tanguay (Eds.), The psychology of criminal investigations: The search for the truth (pp. 41-62). Carswell.

Fisher, R. P., \& Geiselman, R. E. (2010). The cognitive interview method of conducting police interviews: Eliciting extensive information and promoting therapeutic jurisprudence. International Journal of Law and Psychiatry, 33(5-6), 321-328. 
Fisher, R. P., Geiselman, R. E., Raymond, D. S., Jurkevich, L. M., et al. (1987). Enhancing enhanced eyewitness memory: Refining the cognitive interview. Journal of Police Science \& Administration, 15(4), 291-297.

Flexser, A. J., \& Tulving, E. (1978). Retrieval independence in recognition and recall. Psychological Review, 85(3), 153-171.

Flin, R., Boon, J., Knox, A., \& Bull, R. (1992). The effect of a five-month delay on children's and adults' eyewitness memory. British Journal of Psychology, 83(3), 323-336.

Fortin, N. J., Agster, K. L., \& Eichenbaum, H. B. (2002). Critical role of the hippocampus in memory for sequences of events. Nature Neuroscience, 5(5), 458-462.

French, L., Garry, M., \& Loftus, E. (2009). False memories: A kind of confabulation in nonclinical. In W. Hirstein (Ed.), Confabulation: Views from Neuroscience, Psychiatry, Psychology, and Philosophy (pp. 33-35). Oxford University Press.

Gabbert, F., Hope, L., \& Fisher, R. P. (2009). Protecting eyewitness evidence: Examining the efficacy of a self-administered interview tool. Law and Human Behavior, 33(4), 298-307.

Geiselman, R. E., \& Fisher, R. P. (2014). Interviewing witnesses and victims. In M. St. Yves (Ed.), Investigative interviewing: Handbook of best practices (pp. 1-21). Thomson Reuters Publishers.

Geiselman, R. E., Fisher, R. P., MacKinnon, D. P., \& Holland, H. L. (1986). Enhancement of eyewitness memory with the cognitive interview. The American Journal of Psychology, $385-401$.

Geiselman, R. E., Fisher, R. P., MacKinnon, D. P., \& Holland, H. L. (1985). Eyewitness memory enhancement in the police interview: Cognitive retrieval mnemonics versus hypnosis. Journal of Applied Psychology, 70(2), 401-412. 
Gershon, R. R., Barocas, B., Canton, A. N., Li, X., \& Vlahov, D. (2009). Mental, physical, and behavioral outcomes associated with perceived work stress in police officers. Criminal Justice and Behavior, 36(3), 275-289.

Giles, D., Draper, N., \& Neil, W. (2016). Validity of the Polar V800 heart rate monitor to measure RR intervals at rest. European Journal of Applied Physiology, 116(3), 563-571.

Grady, R. H., Butler, B. J., \& Loftus, E. F. (2016). What should happen after an officer-involved shooting? Memory concerns in police reporting procedures. Journal of Applied Research in Memory and Cognition, 5(3), 246-251.

Greenberg, M. S., Westcott, D. R., \& Bailey, S. E. (1998). When believing is seeing: The effect of scripts on eyewitness memory. Law and Human Behavior, 22(6), 685-694.

Hallgren, K. A. (2012). Computing inter-rater reliability for observational data: An overview and tutorial. Tutorials in Quantitative Methods for Psychology, 8(1), 23-34.

Heathers, J., \& Goodwin, M. (2017). Dead science in live psychology: A case study from heart rate variability (HRV). PsyArXiv Preprints, 1-34.

Hickman, M. J., Piquero, A. R., \& Garner, J. H. (2008). Toward a national estimate of police use of nonlethal force. Criminology \& Public Policy, 7(4), 563-604.

Holliday, R. E., Brainerd, C. J., Reyna, V. F., \& Humphries, J. E. (2009). The cognitive interview: Research and practice across the lifespan. In R. Bull, T. Valentine, \& T. Williamson (Eds.), Handbook of the psychology of investigative interviewing: Current developments and future directions (pp. 137-160). John Wiley \& Sons, Ltd.

Hope, L., Blocksidge, D., Gabbert, F., Sauer, J. D., Lewinski, W., Mirashi, A., \& Atuk E. (2016). Memory and the operational witness: Police officer recall of firearms encounters as a function of active response role. Law and Human Behavior, 40(1), 23-35. 
Hope, L., Gabbert, F., \& Fisher, R. P. (2011). From laboratory to the street: Capturing witness memory using the Self-Administered Interview. Legal and Criminological Psychology, 16(2), 211-226.

Hope, L., Lewinski, W., Dixon, J., Blocksidge, D., \& Gabbert, F. (2012). Witnesses in action: The effect of physical exertion on recall and recognition. Psychological Science, 23(4), 386-390.

Hopper, T. (2018, April 24). Why Canadian police are so good at not shooting people. National Post. Retrieved from https://nationalpost.com/news/canada/why-canadian-police-are-sogood-at-not-shooting-people

Hyman Jr, I. E., Husband, T. H., \& Billings, F. J. (1995). False memories of childhood experiences. Applied Cognitive Psychology, 9(3), 181-197.

International Association of Chiefs of Police. (2001). Police use offorce in America. Retrieved from https:/www.theiacp.org/sites/default/files/2018-08/2001useofforce.pdf

Jarrard, L. E. (1993). On the role of the hippocampus in learning and memory in the rat. Behavioral and Neural Biology, 60(1), 9-26.

Karasek, R.A. \& Theorell, T. (1990). Healthy work: Stress, productivity and the reconstruction of working life. Wiley.

Kayihan, G., Ersöz, G., Özkan, A., \& Koz, M. (2013). Relationship between efficiency of pistol shooting and selected physical-physiological parameters of police. Policing: An International Journal of Police Strategies \& Management, 36(4), 819-832.

Kebbell, M. R., Milne, R., \& Wagstaff, G. F. (1999). The cognitive interview: A survey of its forensic effectiveness. Psychology, Crime and Law, 5(1-2), 101-115. 
Kiedrowski, J., Melchers, R., Petrunik, M., \& Maxwell, C. (2015). A discussion of the collection and analysis of data on the use of force in encounters between the police and members of the public. Public Safety Canada. Retrieved from http://publications.gc.ca/collections/collection_2015/sp-ps/PS18-21-2014-eng.pdf

Kim, J. J., Lee, H. J., Han, J., \& Packard, M. G. (2001). Amygdala is critical for stress-induced modulation of hippocampal long-term potentiation and learning. The Journal of Neuroscience, 21(14), 5222-5228.

Köhnken, G., Milne, R., Memon, A., \& Bull, R. (1999). The cognitive interview: A metaanalysis. Psychology, Crime, and Law, 5(1-2), 3-27.

Koo, T. K., \& Li, M. Y. (2016). A guideline of selecting and reporting intraclass correlation coefficients for reliability research. Journal of Chiropractic Medicine, 15(2), 155-163.

Lacy, J. W., \& Stark, C. E. (2013). The neuroscience of memory: Implications for the courtroom. Nature Reviews Neuroscience, 14(9), 649-658.

Laming, E. (2017, July 18). Canada needs a national database to track deadly force by police. HuffPost. Retrieved from https://www.huffingtonpost.ca/erick-laming/deadly-force-bypolice_a_23034831/

Larsson, A. S., Anders Granhag, P., \& Spjut, E. (2003). Children's recall and the cognitive interview: Do the positive effects hold over time? Applied Cognitive Psychology: The Official Journal of the Society for Applied Research in Memory and Cognition, 17(2), 203-214.

Laskowski, E. (2018). What's a normal resting heart rate? Mayo Clinic. Retrieved from https://www.mayoclinic.org/healthy-lifestyle/fitness/expert-answers/heart-rate/faq20057979 
Laucius, J. (2019, June 21). In the spotlight: When everyone has a cell phone, police use of force under scrutiny. Ottawa Citizen. Retrieved from https://ottawacitizen.com/news/localnews/in-the-spotlight-when-everyone-has-a-cell-phone-police-use-of-force-underscrutiny

Loftus, E. F. (1975). Leading questions and the eyewitness report. Cognitive Psychology, 7(4), $560-572$.

Loftus, E. F., \& Palmer, J. C. (1974). Reconstruction of automobile destruction: An example of the interaction between language and memory. Journal of Verbal Learning and Verbal Behavior, 13, 585- 589.

Long Beach Police Department. (n.d.). Officer involved shooting investigation process.

Retrieved from http:/www.longbeach.gov/police/about-the-lbpd/bureaus/investigationsbureau/officer-involved-shooting-investigation-process/

McHugh, M. L. (2012). Interrater reliability: The kappa statistic. Biochemia Medica, 22(3), 276282.

Memon, A., \& Bull, R. (1991). The cognitive interview: Its origins, empirical support, evaluation and practical implications. Journal of Community \& Applied Social Psychology, 1(4), 291-307.

Memon, A., \& Higham, P. A. (1999). A review of the cognitive interview. Psychology, Crime and Law, 5(1-2), 177-196.

Memon, A., Meissner, C. A., \& Fraser, J. (2010). The Cognitive Interview: A meta-analytic review and study space analysis of the past 25 years. Psychology, Public Policy, and Law, 16(4), 340-372. 
Memon, A., Wark, L., Bull., R., \& Kohnken, G. (1997). Isolating the effects of the cognitive interview techniques. British Journal of Psychology, 88, 179-197.

Meyer, S., \& Quenzer, L. (2013). Psychopharmacology: Drugs, the brain, and behavior (2nd ed.). Sinauer Associates Inc.

Morgan III, C. A., Doran, A., Steffian, G., Hazlett, G., \& Southwick, S. M. (2006). Stressinduced deficits in working memory and visuo-constructive abilities in special operations soldiers. Biological Psychiatry, 60(7), 722-729.

National Institute of Justice. (2016). Police use of force. Retrieved from https://www.nij.gov/topics/law-enforcement/officer-safety/use-offorce/pages/welcome.aspx

Nori, R., Bensi, L., Gambetti, E., \& Giusberti, F. (2014). Individual differences in the Enhanced Cognitive Interview: The role of imagery. Psychology, Crime \& Law, 20(9), 833-851.

Paas, F., Renk1, A., \& Sweller, J. (2003). Cognitive load theory and instructional design: Recent developments. Educational Psychologist, 38(1), 1-4.

Parak, J., \& Korhonen, I. (2013). Accuracy of Firstbeat Bodyguard 2 beat-to-beat heart rate monitor. White Paper Firstbeat Technology, 6-8.

Peeples, L. (2019, September 4). What the data say about police shootings. Nature. Retrieved from https:/www.nature.com/articles/d41586-019-02601-9

Pettalia, J., Korva, N., Bennell, C., Baldwin, S., \& Karimullah, M. (2016). Enhancing officer recall of use-of-force scenarios: Tests of a standard vs. modified use-of-force reporting tool. Ottawa, ON: Royal Canadian Mounted Police.

Pezdek, K., Sperry, K., \& Owens, S. M. (2007). Interviewing witnesses: The effect of forced confabulation on event memory. Law and Human Behavior, 31, 463-478. 
Plowman, S. A., \& Smith, D. L. (2013). Exercise physiology for health fitness and performance. Lippincott Williams \& Wilkins.

Police Firearms Officers Association. (2017). Police involved shooting. Retrieved from https://www.pfoa.co.uk/articles/police-involved-shooting

Porter, S., Yuille, J. C., \& Lehman, D. R. (1999). The nature of real, implanted, and fabricated memories for emotional childhood events: Implications for the recovered memory debate. Law and Human Behavior, 23(5), 517-537.

Preston, J. (2016). Understanding the neurobiology of traumatic assault and the implications for prosecutors and investigators. California District Attorneys Association Prosecutors Brief, 38(4), 258-266.

Ramey, S. L., Perkhounkova, Y., Hein, M., Chung, S., Franke, W. D., \& Anderson, A. A. (2016). Building resilience in an urban police department. Journal of Occupational and Environmental Medicine, 58(8), 796-804.

Reiser, M. (1980). Handbook of investigative hypnosis. LEHI Publishing Company.

Reja, U., Manfreda, K. L., Hlebec, V., \& Vehovar, V. (2003). Open-ended vs. close-ended questions in web questionnaires. Developments in Applied Statistics, 19(1), 159-177.

Royal Canadian Mounted Police. (2014). Subject Behaviour/Officer Response Database (SBOR) - Addendum. Retrieved from http://www.rcmp-grc.gc.ca/en/privacy-impact-assessmentaddendum-subject-behaviour-officer-response-database-sbor

Saunders, T., Driskell, J. E., Johnston, J. H., \& Salas, E. (1996). The effect of stress inoculation training on anxiety and performance. Journal of Occupational Health Psychology, 1(2), $170-186$. 
Schacter, D. L., Norman, K. A., \& Koutstaal, W. (1998). The cognitive neuroscience of constructive memory. Annual Review of Psychology, 49(1), 289-318.

Setcan Corporation. (2019). StressVest overview. Retrieved from http://stressvest.com/products/system/stressvests/

Shackman, A. J., Sarinopoulos, I., Maxwell, J. S., Pizzagalli, D. A., Lavric, A., \& Davidson, R. J. (2006). Anxiety selectively disrupts visuospatial working memory. Emotion, 6(1), 4061.

Shane, J. M., Lawton, B., \& Swenson, Z. (2017). The prevalence of fatal police shootings by US police, 2015-2016: Patterns and answers from a new data set. Journal of Criminal Justice, 52, 101-111.

Shields, G. S., Sazma, M. A., McCullough, A. M., \& Yonelinas, A. P. (2017). The effects of acute stress on episodic memory: A meta-analysis and integrative review. Psychological Bulletin, 143(6), 636-675.

Staller, M. S., Cole, J. C., Zaiser, B., \& Korner, S. (2017). Representative training with less risk: The effects of non-lethal training and conventional ammunition in police use of force training on heart rate variability. Policing, 1-15.

Strange, D., Sutherland, R., \& Garry, M. (2006). Event plausibility does not determine children's false memories. Memory, 14(8), 937-951.

Tarvainen, M. P., Niskanen, J. P., Lipponen, J. A., Ranta-Aho, P. O., \& Karjalainen, P. A. (2014). Kubios HRV-heart rate variability analysis software. Computer Methods and Programs in Biomedicine, 113(1), 210-220. 
Thayer, J. F., Åhs, F., Fredrikson, M., Sollers III, J. J., \& Wager, T. D. (2012). A meta-analysis of heart rate variability and neuroimaging studies: Implications for heart rate variability as a marker of stress and health. Neuroscience \& Biobehavioral Reviews, 36(2), 747-756.

Tse, S. K., Lam, J.W., Loh, E.K., \& Lam, R., Y. (2007). The influence of the language that Hong Kong primary school students habitually speak at home on their Chinese reading ability in school. Journal of Multilingual and Multicultural Development, 28(5), 400-417.

Tulving, E. (1974). Cue-dependent forgetting: When we forget something we once knew, it does not necessarily mean that the memory trace has been lost; it may only be inaccessible. American Scientist, 62(1), 74-82.

Tulving, E., \& Thomson, D. M. (1973). Encoding specificity and retrieval processes in episodic memory. Psychological Review, 80(5), 352-373.

Violanti, J. M., \& Aron, F. (1995). Police stressors: Variations in perception among police personnel. Journal of Criminal Justice, 23(3), 287-294.

Von Borell, E., Langbein, J., Després, G., Hansen, S., Leterrier, C., Marchant-Forde, J., ... \& Valance, D. (2007). Heart rate variability as a measure of autonomic regulation of cardiac activity for assessing stress and welfare in farm animals - A review. Physiology \& Behavior, 92(3), 293-316.

Vrijkotte, T. G., Van Doornen, L. J., \& De Geus, E. J. (2000). Effects of work stress on ambulatory blood pressure, heart rate, and heart rate variability. Hypertension, 35(4), $880-886$.

Whitehouse, W. G., Orne, E. C., Dinges, D. F., Bates, B. L., Nadon, R., \& Orne, M. T. (2005). The cognitive interview: Does it successfully avoid the dangers of forensic hypnosis? The American Journal of Psychology, 118(2), 213-234. 
Wollert, T. N., Driskell, J. E., \& Quail, J. (2011). Stress exposure training guidelines: Instructor guide to reality-based training. Retrieved from http://www.virtualtacticalacademy.com/files/stress_exposure_training_manual_926B.pdf

Yu, H., \& Bogen, M. (2017). The illusion of accuracy: How body-worn camera footage can distort evidence. Upturn. Retrieved from https://www.upturn.org/static/reports/2017/theillusion-of-accuracy/files/Upturn\%20and\%20LCCHR\%20\%20The\%20Illusion $\% 20$ of $\% 20$ Accuracy\%20v.1.0.pdf 


\section{CHAPTER 6}

\section{General Discussion}

Technology has the power to improve many facets of human life. Some even argue that it has the power to reduce violence and “...end killing as we know it" (Smith, 2019, p. 13). BWCs rose to popularity quickly as a means to quell public unrest following several controversial officer-involved use-of-force events. Many of these incidents resulted in the loss of young lives (e.g., 18-year old Michael Brown [Salter, 2019], 18-year old Sammy Yatim [Loriggio, 2020]), the dissolution of police officers' careers, and the fracture of communities. When former President Obama awarded more than $\$ 23$ million dollars in funding to support the examination of BWCs, the hope was that they might enhance transparency, accountability, and credibility of the police (United States Department of Justice, 2015). One way they could do this is by acting as an objective source; a means of showing the interactions that occur between officers and citizens. However, an additional, less studied way that they might improve police-public trust is by cuing officers about what actually occurred during these rapid, highly dynamic, and stressful interactions. Officers who confuse what happened during a use-of-force occurrence have been criticized for being dishonest, corrupt, and ultimately culpable (e.g., Hope et al., 2016). This perception perpetuates scepticism in the police, potentially contributing to more volatile interactions in the future.

The present dissertation thus aimed to determine: (1) whether the presence of a BWC during a use-of-force interaction impacted an officer's recall of the event, (2) best practice for the timing of when officers should watch their footage, and (3) the extent to which differential reporting practices impacted recall. Across all three studies, officers were exposed to the same simulated use-of-force scenario in which they were tasked with de-escalating two individuals in 
an apartment complex. Officers were equipped with inert intervention options and wore a Stressvestтм to help induce arousal equivalent to a true lethal force call. However, depending on the condition they were assigned, they experienced a different manipulation that targeted one of the three research questions.

Since each prior chapter presented a study-specific discussion, this final chapter serves to compile the overarching findings of the dissertation research and considers some general limitations. Specifically, recall that Study 1 investigated the psychological phenomena of cognitive offloading, wherein individuals appear to discount information that they believe will be saved in another form for future reference (i.e., they fail to encode it). Not surprisingly, this appears to result in difficulties retrieving said information later on. To explore whether police officers might experience challenges recalling information that they unintentionally delegate to their BWC, two groups of officers were created. One group was equipped with a BWC and told that they could watch their footage before giving a statement about what occurred in the scenario. The other group was not provided a camera and knew they would need to rely solely on their memory to recall what happened. Nevertheless, both groups were asked to provide a statement without seeing any footage. Interestingly, the results indicated that regardless of the presence of a camera, officers recalled a similar amount of information. This contrasts with previous research conducted in non-police settings (e.g., Henkel, 2014; Risko \& Dunn, 2015). Thus, the current findings suggest that there may be something unique about policing that mitigates an effect observed in other contexts. For example, the training officers receive, the legal requirements they have to accurately report events, and/or the BWC user-face (i.e., it requires little-to-no user intervention once attached to an officer's uniform and may thus be forgotten), could allay any potential impact. 
In light of controversy about the appropriate timing for when officers should review their BWC footage (Pezdek, 2015; Yu \& Bogen, 2017), Study 2 examined differences in recall between those allowed to see their footage immediately following a use-of-force event, compared to those barred from accessing their footage. Some scholars argue that video footage, like other visual imagery, can act as a cue, prompting an officer to remember more than they otherwise would (in line with Tulving's [1983] 'encoding specificity principle'; e.g., Harvey, Langheinrich, \& Ward, 2016). Alternatively, others contend that previewing one's footage before recall could contaminate the true memory of an event, similar to the misinformation effect (Grady et al., 2016; Yu \& Bogen, 2017).

The findings indicated that overall, officers recalled a similar amount of information, regardless of whether they were allowed to see their footage or not. The accuracy of the information and the severity of errors made in the reports were also similar between conditions. However, officers who saw their footage before writing their report included significantly more information about the subject, compared to those who completed their statement without any aide. Moreover, for those unable to view their footage, higher levels of stress were related to an increase in the number of moderate and major errors made. These results suggest that officers may benefit from viewing BWC footage pre-report writing in some regards. However, additional research must be conducted to ascertain whether the improvements made to the reports by the pre-viewing cohort occurred because the footage cued officers' memories, and not because it led them to believe (erroneously) that they encoded something that they never actually did.

The final study examined the efficacy of cognitive interviewing officers following a critical incident. After an officer deploys an intervention option, a series of actions occur that are enacted to understand what happened. A comprehensive statement is paramount, especially since 
it could be entered as evidence in court. Currently, most agencies rely on a written report and/or a standard interview with a commanding officer to ensure oversight (e.g., Grady et al., 2016). The findings of Study 3 suggest that this process may be improved by integrating a CI. The cohort of officers who were asked to recall the event via a CI included significantly more details in their recollection, while maintaining a high degree of accuracy. In fact, those who completed a CI confabulated significantly less information, relative to those who completed the standard useof-force report. Should future studies replicate these results, the CI may become a tool recommended to better ensure an officer's memory of an event is captured to the best extent possible.

\section{Limitations}

Inherent to each study were limitations that qualified the conclusions drawn. For example, there were drawbacks to the measures that were used (i.e., HR is not a perfect proxy for stress). There was also a lack of external validity in some respects (e.g., officers were asked to recall the event almost immediately after it was over, and this brief delay is not necessarily representative of the time at which officers would be asked to recall such an incident in "the real world"). Issues like these were discussed in detail in the chapters above. However, there are also several broader limitations that warrant consideration. These occurred as a result of the methodology of the dissertation as a whole, and include: (1) group overlap, (2) potential priming effects, and (3) equipment malfunctions.

The police are a specialized population that are challenging to recruit for research purposes. In light of this, compromise power analyses were conducted, and the goal was to acquire the projected sample sizes. However, certain concessions were also made to the methodology to increase the likelihood that all studies could be completed with a reasonable 
number of officers in each cohort. As such, certain cohorts experienced multiple manipulations, as they were used in more than one study. For example, recall that Study 1 required deceiving approximately half of the sample into believing that they would be allowed to see their BWC footage before writing their report. The other half of the sample did not wear a BWC during the scenario and were aware that they had no footage to rely on. Both of these groups were also used in Study 3 (i.e., they were combined) so that comparisons could be drawn between officers who recalled their scenario via a standard use-of-force report versus those who recalled it through a CI. In light of this constraint, a series of two-way ANOVAs were conducted to determine the extent to which the manipulations from Study 1 and/or 2 impacted the results of Study 3 . These interactions were all non-significant,37 suggesting that any possible within-group differences that might exist by using the same participants from Study 1 (and 2) in Study 3 were largely mitigated. Nevertheless, these differences should be removed in future studies to ensure they do not confound the results.

Another potential limitation to the current research was the potential priming that might have occurred if participants who went through the experiment told newcomers what to expect. In order to run someone through the experiment, a strict set of procedures needed to be in place. For instance, access to the scenario room was required, the same two actors needed to be dressed and ready, a host of equipment (e.g., HR monitors, the Stress VestTm system, cameras) needed to be available, both a Police and Public Safety Instructor and police trainer had to be present, and an agency computer or cognitive interviewer were necessary. Thus, only one participant could ever run through the experiment at any one time. Given this restriction, as well as how highprofile the research was (largely due to the novel equipment that was used and the unique 
scenario), it is highly likely that some participants discussed their experience with others who had yet to complete the experiment.

Prior knowledge about the research could have impacted participant's expectations of what was going to happen. For example, if a participant had heard that there were "technological issues" with some of the BWCs and some of their fellow officers had not been able to see their footage, they may have instinctively failed to offload, believing that the cameras were unreliable. In light of potential priming issues, participants were told not to discuss the research with others. Moreover, the location where the research took place is a transient training facility for most officers. Therefore, most are only there for a brief period of time (i.e., to complete training) and come from various parts of the country. We also invited officers from numerous different agencies to participate. As such, many of the officers did not know each other or have the time/ability to discuss the research with one another. Nevertheless, future research should attempt to minimize demand-like biases as much as possible.

Lastly, it is important to note that there were some malfunctions with the equipment specifically the StressVestTM - that may have affected the conclusions drawn. Recall that the StressVestтм is designed to deliver a shock to a participant's abdomen in the event that they are "shot" from a laser-adapted pistol. All participants were shot by the subject in the scenario in order to increase their level of arousal and better ensure a high degree of external validity (i.e., the experience of a lethal force encounter). However, in a few cases $(n=2)$, the StressVestTm delivered a shock before a participant began the scenario or at an inopportune time during the scenario (e.g., when the officer was delivering first aid to the subject). It is unclear why this occurred, although it may have been due to the dynamic nature of the scenario and/or a reaction to the temperature in the room. The malfunctions may have impacted a participant's stress 
response, as well as their recall. However, all malfunctions were recorded and if a participant recalled that one of the shocks delivered in error was a "hit," this detail was removed and not counted toward their accuracy, inaccuracy, or confabulation count. As it is difficult to predict how equipment that is designed to increase the generalizability of a study might thwart it in some respects, it is important to collect data from actual police-public encounters, thereby ensuring the results truly translate to the real-world.

\section{Future Directions}

Additional research of the type explored in this dissertation is urgently needed. In particular, it is important to determine the extent to which information that officers report after watching their BWC footage is truly elicited from their memory stores, rather than simply reiterations of the footage they have seen. If officers are, unintentionally (or not), completing statements that aim to coincide with their BWC footage, but do not accurately reflect what they perceived, then their statements are arguably futile. One way that future research may explore this issue is through the use of eye-tracker technology that can assess the degree to which officers attend to certain details that they report in their statements. For instance, take an officer who watches their BWC footage and goes on to report that they pulled their pistol upon seeing a knife. If their eye-tracker footage indicates, however, that they never actually attended to the knife, then ideally, one would be able to say that they were misled by watching their BWC footage and their pistol was pulled for a different, unreported reason. These issues are difficult to study given the dynamic nature of lethal force scenarios and the bulkiness of most eye-tracker technology. Nonetheless, they are extremely worthwhile for future policy development and to potentially aid in decisions regarding officer culpability. 
Relatedly, as none of the studies included in the current dissertation explored the quality and/or type of details that officers recalled in any more depth than simply separating them into those that related to the "subject," "officer," "context," as well as "minor, "moderate," and "major" errors, future studies may wish to qualitatively examine the recall of officers. The eyewitness literature, for example, has benefitted from exploring participants' recall for central versus peripheral details (e.g., Brown, 2003). It is possible that this type of study would be useful in understanding what type of information officers tend to remember best, and what they tend to report inaccurately or confabulate. If research suggests that officers have difficulty recalling certain types of information, then questioning them on it in court may not be reasonable and/or training may need to be implemented to help them mitigate these challenges.

Lastly, in all three studies, many of the main analyses were underpowered. Effect sizes were provided when appropriate to provide an indication of the size of the difference between conditions. However, the findings require replication utilizing larger samples of officers. Moreover, as noted previously, the current research attempted to enact control over extraneous variables (e.g., subjects, context, call information, duty belt options) such that examination of the manipulations of interest could be achieved. While, at the same time, the scenario that officers were exposed to was meant to ensure the research was as generalizable as possible. This balance of internal and external validity helped create a solid foundation from which future studies can be built. Nonetheless, additional research is needed on real-world use-of-force events. These studies are necessary for determining how comparable lab-based findings are to those achieved in the field. Practitioner-academic partnerships may allow for more research of this kind to be conducted (see, Baldwin, Bennell, Andersen, Semple, \& Jenkins [2019] for an example), and ultimately move the police psychology field forward. 


\section{Conclusion}

Camera-phones, surveillance videos, and BWCs captured the last minutes of George Floyd's life - an unarmed black man who died at the hands of a white police officer on May 25, 2020 (McLaughlin, 2020; Singh 2020). Since then, protests have erupted around the world with citizens calling for justice and police reform; some figures suggest the movement may be the largest in US history (Buchanan, Bui, \& Patel, 2020). Thereafter, Prime Minister Trudeau requested that police agencies in Canada move toward equipping all officers with BWCs (Tunney, 2020). These recent events underscore how timely the current research is and forces us to re-examine how we study policing issues, for what purpose, and how to utilize technology to better police-citizen relations. The goal to enhance officer memory for critical events will hopefully result in the most comprehensive reports possible, thereby improving public trust and contributing to less volatile interactions in the future. The findings of this research could also help inform police agencies in their design of BWC policies going forward and serve to temper expectations of what BWCs will be able to provide in terms of their ability to act as a memory enhancement tool.

It has been said that human beings' capacity to think back on past happenings gives us an exceptional power to bend time's arrow into a loop: “The rememberer has mentally travelled back into her past and thus violated the law of the irreversibility of the flow of time" (Tulving, 2002, p. 1-2). Technology has, in many ways, transformed this ability. Camera-phones, GoPros, and Smart Watches, all extend our mental faculties in a myriad of ways. They act as additional, prosthetic memory stores. It remains imperative, however, to examine the ways that these advances could also negatively affect us; whether it be through potential offloading or the misinformation effect. The current dissertation was thus not only an examination of how BWCs 
impact police officers' cognitions, but more importantly how we, as humans, remember volatile events in our lives and the allowances that should be made, despite the technological crutches available to us. 


\section{References}

Baldwin, S., Bennell, C., Andersen, J., Semple, T., \& Jenkins, B. (2019). Stress-activity mapping: Physiological responses during general duty police encounters. Frontiers in Psychology, 10, 1-17.

Brown, J. (2003). Eyewitness memory for arousing events: Putting things into context. Applied Cognitive Psychology, 17, 93-106.

Buchanan, L., Bui, Q., \& Patel, J. K. (2020, July 3). Black Lives Matter may be the largest movement in U.S. history. New York Times. https://www.nytimes.com/interactive/2020/07/03/us/george-floyd-protests-crowdsize.html

Grady, R. H., Butler, B. J., \& Loftus, E. F. (2016). What should happen after an officer-involved shooting? Memory concerns in police reporting procedures. Journal of Applied Research in Memory and Cognition, 5(3), 246-251.

Harvey, M., Langheinrich, M., \& Ward, G. (2016). Remembering through lifelogging: A survey of human memory augmentation. Pervasive and Mobile Computing, 27, 14-26.

Henkel, L. A. (2014). Point-and-shoot memories: The influence of taking photos on memory for a museum tour. Psychological Science, 25(2), 396-402.

Hope, L., Blocksidge, D., Gabbert, F., Sauer, J. D., Lewinski, W., Mirashi, A., \& Atuk, E. (2016). Memory and the operational witness: Police officer recall of firearms encounters as a function of active response role. Law and Human Behavior, 40(1), 23-35.

Risko, E. F., \& Dunn, T. L. (2015). Storing information in-the-world: Metacognition and cognitive offloading in a short-term memory task. Consciousness and Cognition, 36, 6174. 
Loriggio, P. (2020, January 21). James Forcillo, officer who fatally shot teen Sammy Yatim on Toronto streetcar, gets full parole. National Post. Retrieved from https://nationalpost.com/news/full-parole-for-toronto-cop-who-shot-teen-sammy-yatimon-empty-streetcar

McLaughlin, E. (2020, June 23). Three videos piece together the final moments of George Floyd's life. CNN. https://www.cnn.com/2020/06/01/us/george-floyd-three-videosminneapolis/index.html

Pezdek, K. (August 13, 2015). Should cops get to review the video before they report? The Marshall Project. Retrieved from https://www.themarshallproject.org/2015/08/13/should-cops-get-to-review-the-videobefore-they-report

Salter, J. (2019, August 8). 5 years after Michael Brown shooting, Ferguson still struggles with racial tension. Global News. Retrieved from https://globalnews.ca/news/5741014/michael-brown-shooting-ferguson-5-years/

Singh, M. (2020, July 9). George Floyd told officers 'I can’t breathe' more than 20 times, transcripts show. The Guardian. https://www.theguardian.com/usnews/2020/jul/08/george-floyd-police-killing-transcript-i-cant-breathe

Smith, R. (2019). The end of killing: How our newest technologies can solve humanity's oldest problem. Page Two.

Tulving, E. (1983). Elements of episodic memory. New York, NY: Oxford University Press. Tulving, E. (2002). Episodic memory: from mind to brain. Annual Review of Psychology, 53(1), $1-25$.

Tunney, C. (2020, June 8). RCMP agrees to outfit some Mounties with body cameras. Canadian 
Broadcasting Corporation. https://www.cbc.ca/news/politics/rcmp-body-camera1.5603030

United States Department of Justice. (2015). Justice Department awards over \$23 million in funding for body worn camera pilot program to support law enforcement agencies in 32 states. Retrieved from https://www.justice.gov/opa/pr/justice-department-awards-over23-million-funding-body-worn-camera-pilot-program-support-law

Yu, H., \& Bogen, M. (2017). The illusion of accuracy: How body-worn camera footage can distort evidence. Upturn. Retrieved from https://www.upturn.org/static/reports/2017/theillusion-of-accuracy/files/Upturn\%20and\%20LCCHR\%20\%20The\%20Illusion $\% 20$ of\%20Accuracy\%20v.1.0.pdf 


\begin{tabular}{|c|c|c|c|}
\hline Co-Author & Statement of Contribution & Signature & Date \\
\hline Bryce Jenkins & $\begin{array}{l}\text { I, Bryce Jenkins, affirm that I have read and agreed to the preface in } \\
\text { Brittany Blaskovits" dissertation, and acknowledge that Brittany took the } \\
\text { lead role in the manuscripts titled "Misplacing memory: Examining the } \\
\text { phenomenon of cognitive offloading during an officer-involved use-of- } \\
\text { force scenario" and "Triggering memory: Examining how the viewing of } \\
\text { body worn camera footage impacts police officer reports" of which I am a } \\
\text { co-author. }\end{array}$ & & $07 / 15 / 2$ \\
\hline Andrew Brown & $\begin{array}{l}\text { I, Andrew Brown, affirm that I have read and agreed to the preface in } \\
\text { Brittany Blaskovits" dissertation, and acknowledge that Brittany took the } \\
\text { lead role in the manuscripts titled "Misplacing memory: Examining the } \\
\text { phenomenon of cognitive offloading during an officer-involved use-of- } \\
\text { force scenario" and "Triggering memory: Examining how the viewing of } \\
\text { body worn camera footage impacts police officer reports" of which I am a } \\
\text { co-author. }\end{array}$ & & $07 / 15 / 20$ \\
\hline Simon Baldwin & $\begin{array}{l}\text { I, Simon Baldwin, affirm that I have read and agreed to the preface in } \\
\text { Brittany Blaskovits' dissertation, and acknowledge that Brittany took the } \\
\text { lead role in the manuscripts titled "Misplacing memory: Examining the } \\
\text { phenomenon of cognitive offloading during an officer-involved use-of- } \\
\text { force scenario," "Triggering memory: Examining how the viewing of } \\
\text { body worn camera footage impacts police officer reports," and } \\
\text { "Evaluating the utility of the cognitive interview for enhancing the } \\
\text { memory of police officers involved in use-of-force events," of which I am } \\
\text { a co-author. }\end{array}$ & & $\begin{array}{l}\text { signed by } \\
\text { 3aldwin } \\
\text { Simon } \\
\text {, o=Carleton } \\
\text { ity, ou, } \\
\text { imonbaldwin } 8 \\
\text { irleton.ca, } c=C / \\
20.07 .14 \\
0-04^{\prime} 00^{\prime}\end{array}$ \\
\hline $\begin{array}{l}\text { Heather } \\
\text { McGale }\end{array}$ & $\begin{array}{l}\text { I, Heather McGale, affirm that I have read and agreed to the preface in } \\
\text { Brittany Blaskovits" dissertation, and acknowledge that Brittany took the } \\
\text { lead role in the manuscript titled "Evaluating the utility of the cognitive } \\
\text { interview for enhancing the memory of police officers involved in use-of- } \\
\text { force events," of which I am a co-author. }\end{array}$ & & $07 / 14 / 20$ \\
\hline Craig Bennell & $\begin{array}{l}\text { I, Dr. Craig Bennell, affirm that I have read and agreed to the preface in } \\
\text { Brittany Blaskovits' dissertation, and acknowledge that Brittany took the } \\
\text { lead role in the manuscripts titled "Exploring the potential impact of body } \\
\text { worn cameras on memory in officer-involved critical incidents: A } \\
\text { literature Review," "Misplacing memory: Examining the phenomenon of } \\
\text { cognitive offloading during an officer-involved use-of-force scenario," } \\
\text { "Triggering memory: Examining how the viewing of body worn camera }\end{array}$ & & $07 / 19 / 20$ \\
\hline
\end{tabular}


footage impacts police officer reports," and "Evaluating the utility of the cognitive interview for enhancing the memory of police officers involved

in use-of-force events," of which I am a co-author. 


\title{
Appendix B: Screenshot of Published Literature Review from Chapter 2
}

Juma of Police and Oinind Pychology

https//doiorg/ 10.100//s1189601909354-1

\section{Exploring the Potential Impact of Body Worn Cameras on Memory in Officr-Involved Oitical Incidents a Literature Review}

\author{
Brittany Blaskovits ${ }^{1} \odot$ \&Craig Bennell ${ }^{1}$
}

\# Siciety for Police and Oinina Pychology2019

Abstract

Thecurrent peper reviews existing literature that rdates to how body worn cameras might infiluencean officer's memory of their interactions with the public, namely those that involve the use of force Notably, most of this research does not come from the policing field but focuses on the impart of camera technology in other settings Much of the available reseerch supports the commonly hdd view that body wom cameras could be used to enhence memory for these interactions, perticularly interactions that are complex or stressul. However, contray to what people might expect, reserch also exists that suggests bady wom cameras may actudly have a detrimented effect on officer memory. Three major potentid detriments cognitive offiloaring, refrievd-induced forgetting and misinformation-type effects arehighlighted. Future studies examining theimpact of body wom cameras on officers memory are necessery. Ways forward are discussed.

Keywords Police - Body worn cameras - Memory - Officaring - Misinformation - Use of force

On June 25th, 2016, two members of the Fresno Pdice Department shot and killed 19-yer-old Dylan Noble (Hamilton and Winton 2016). Noble was suspected of carying a rifle, and did not comply with policeinstructions, unfortunately, it was not until after the police opened fire that it became apperent that Noble was unamed. TheFresno shooting is only one case in a succession of controversid use offorce (UoF) incidents that have occurred in recent years, such as the 2013 fatd shootings of Semmy Yatim in Toronto, Ontario (Loriggio 2016) and that of Michas Brown in Ferguson, Missouri in 2014 (British Broadcasting Corporition 2015). Consequently, there has been growing, widespread public criticism of police decision-making and performance (Hansford 2019; Kleinig 2016), culminating in protests (Hamilton and Winton 2016), allegetions of police brutality (Hamilton and Winton 2017; Smith 2018), and even deady attarks, including thesriper attack in Dallas, Texas, in 2016 (Karimi et a. 2016).

Many police agencies are now using body wom cameras (BWCs) as a way to improve policepublic encounters, and subsequently instill confidence and trust in policing (Jenings

\footnotetext{
- Brittany Blakovits

brittanyblakovits@oma _caletonca

1 Depatrnert of Psychology, Caleton University, 1125 Colond By Dive, Ottava, Ontaio K1S 586 , Canada
}

d d. 2014). Not only might BWCs positively influence how the police and the public at, by potentially encouraging more respectid interafions (Arid \&A. 2015), thistednology might aso allow the police and the public to more fully undestand what traspired during policepublic encounters One meche nism by which BWCs might do this is by farilitzing an officer's aility to recall detils of their encounters, such as what trenspired during the incident, induding aspects of their risk asesement, which speck to why they made the decisions they dd (Daweset d. 2015). If viewing BWC fodege can enhence an officer's menory for a Uof encounter, this may asist the officer in avaiety of contexts (eg. prepering their report about the encounter, when being questioned during intemed investigetions, or when testifying about the incident in court).

The current peper reviews the literzture to dzte, which speeks to how BWCs might influence an officer's memory of their interactions with the public. Notady, most of this research does not come from the policing field but focuses on the impact of camera technology in other settings. Much of the avalatle reserch supports the commonly held view that BWCscould beused to enhencememory for these interactions, particularly interations that are complex or stressful. However, contray to expectetions, resegrch also exists that suggests BWCs may axtudly have a detrimental effect on officer memory. Both types of potential memory effects (i.e positive and negative) will be reviewed in this peper. For the most pert, we will focus our discussions on interactions with the public that involveUoF by the police. While thesearenot 
Appendix C: Examination of Within-Group Differences Across Studies
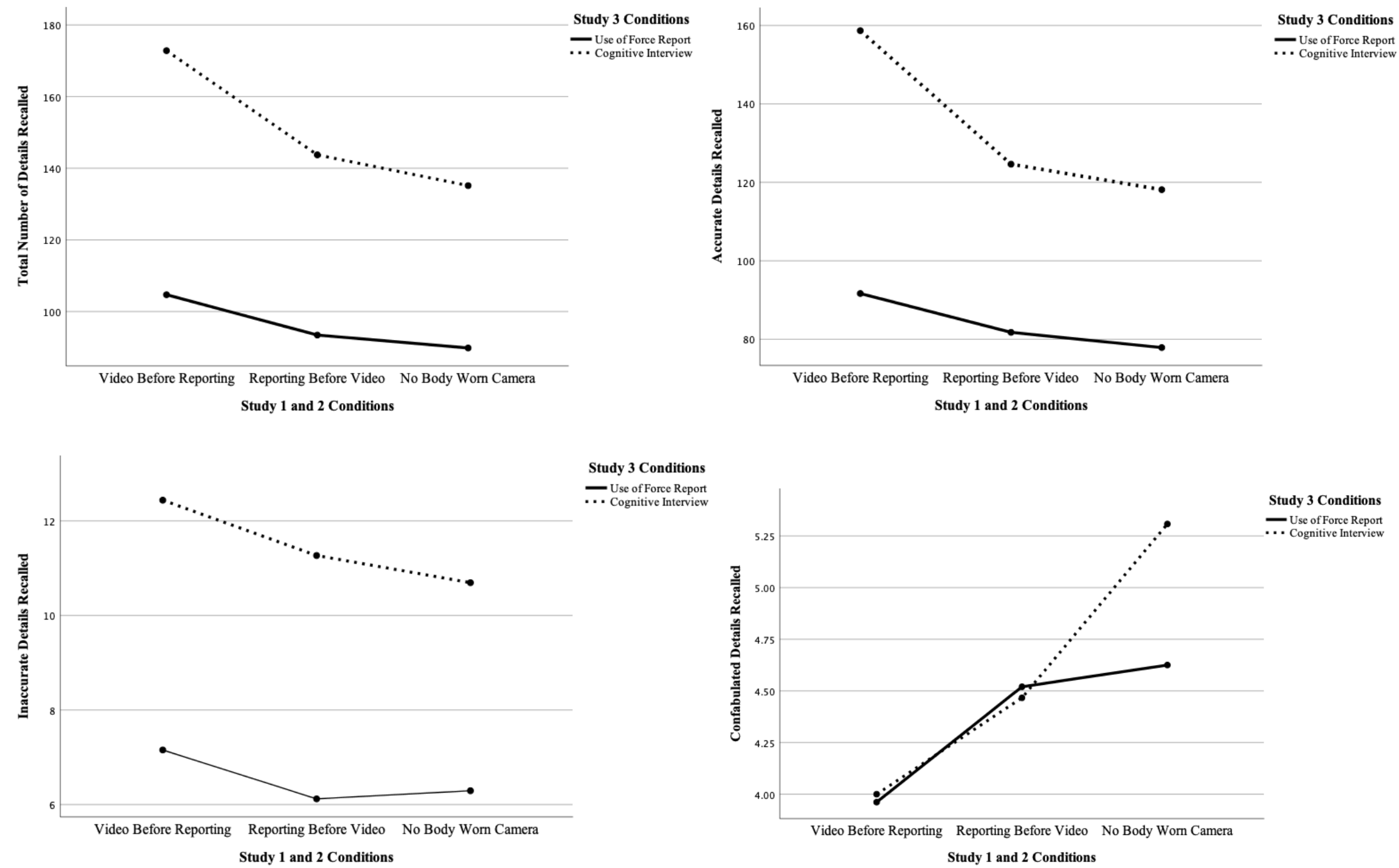